University of Louisville

ThinkIR: The University of Louisville's Institutional Repository

Electronic Theses and Dissertations

$12-2010$

\title{
The four-year experience of first-generation students at a small independent university : engagement, student learning, and satisfaction.
}

David M. Mahan

University of Louisville

Follow this and additional works at: https://ir.library.louisville.edu/etd

\section{Recommended Citation}

Mahan, David M., "The four-year experience of first-generation students at a small independent university : engagement, student learning, and satisfaction." (2010). Electronic Theses and Dissertations. Paper 886. https://doi.org/10.18297/etd/886

This Doctoral Dissertation is brought to you for free and open access by ThinkIR: The University of Louisville's Institutional Repository. It has been accepted for inclusion in Electronic Theses and Dissertations by an authorized administrator of ThinkIR: The University of Louisville's Institutional Repository. This title appears here courtesy of the author, who has retained all other copyrights. For more information, please contact thinkir@louisville.edu. 
THE FOUR-YEAR EXPERIENCE OF FIRST-GENERATION STUDENTS AT A SMALL INDEPENDENT UNIVERSITY: ENGAGEMENT, STUDENT LEARNING, AND SATISFACTION

\title{
By
}

David M. Mahan

B.A., Bellarmine University, 1993

M.A., University of Louisville, 1999

\author{
A Dissertation \\ Submitted to the Faculty of the \\ Graduate School of the University of Louisville \\ in Partial Fulfillment of the Requirements \\ for the Degree of
}

Doctor of Philosophy

Department of Leadership, Foundations, and Human Resource Education

University of Louisville

Louisville, KY

December 2010 
Copyright 2010 by David M. Mahan

All rights reserved 

THE FOUR-YEAR EXPERIENCE OF FIRST-GENERATION STUDENTS AT A SMALL INDEPENDENT UNIVERSITY: ENGAGEMENT, STUDENT LEARNING, AND SATISFACTION

By

David M. Mahan

B.A., Bellarmine University, 1993

M.A., University of Louisville, 1999

A Dissertation Approved on

November 23, 2010

by the following Dissertation Committee:

Dr. Joseph M. Petrosko, Co-Chair

Dr. Kristin B. Wilson, Co-Chair

Dr. Marco A. Munoz

Dr. Helen Grace Ryan 


\section{DEDICATION}

I dedicate this dissertation to my wonderful wife Cheryl. Because of her tireless efforts in caring for our children, I was able to devote the needed time to complete this research. These efforts were made in addition to working as a full-time second grade school teacher. I will forever appreciate her skills as a great mother and her inspiration as a devoted wife. Happiness is not a destination, but is in our day-to-day work together, our struggles in "suburbia" to provide the best possible life for our children. I hope that my work on this project will serve as an example for Peyton and Will that learning is the greatest of all privileges. 


\section{ACKNOWLEDGMENTS}

First and foremost, I would like to extend my sincere appreciation and gratitude to Dr. Joe Petrosko and Dr. Kristin Wilson, who served as co-chairs of the committee. I am humbled by their generosity with time, which created an invaluable learning experience. Both of these individuals never refused a meeting or an additional review of my work, even while managing incredibly busy schedules. I would also like to extend an important thank you to committee members Dr. Marco Munoz and Dr. Helen Grace Ryan, who are very busy as well, but took time to help me greatly with this project.

I have the priviledge of working in a truly supportive environment with wonderful and dynamic people. On top of the list are Dr. Carole Pfeffer and Dr. John Stemmer. Carole is an inspiration to me every day and is a truly brilliant editor. She is among the unique administrators who can balance leadership and the details of data work. John is also a terrific editor and a creative librarian, who gave me endless feedback and strategy. As I told him, "there are good friends, and there is John Stemmer." I want to thank many other members of the community: Claudette Berry for her friendship, laughter and encouragement; Ann Olsen for her example of excellence; Heather Boutell for her example of a great work ethic; Dr. Mike Luthy who taught me the art of planning; Dr. Hannah Clayborne for the gift of empathy and helping me prep for comprehensive exams; Dr. Doris Tegart for her strong but warm leadership; Dr. Fred Rhodes for his words of encouragement; Dan Bays who went over and above the call of duty as a reference librarian; Dr. Nelson Lopez who challenged me to finish; Beth Davis for 
sharing her talents in formatting and editing; Dr. Sara Yount for the warm words; Dr. Page Curry who gave me the recipe for completion; Tim Askew for his excellent data mining skills; and my friends in the Admission Office who offered great fun and laughter during lunch hour (Tim Sturgeon, Sean Ryan, David Kline, Kevin Brinkman, John Blackwell). And last but not least, a special thanks to my close friend Paul Wenz for the countless times watching our children to help me meet a deadline or to give us a much needed break.

The Association of Institutional Research (AIR) sponsored me as a fellow for graduate studies. The program provided tremendous support from the National Center for Education Statistics (NCES), not only financial, but with wonderful learning and networking opportunities. I was honored to attend the 2009 National Summer Data Policy Institute in Washing DC. A special thanks to the Executive Director, Dr. Randy Swing, and his team for this opportunity. 


\section{ABSTRACT \\ THE FOUR-YEAR EXPERIENCE OF FIRST-GENERATION STUDENTS AT A SMALL INDEPENDENT UNIVERSITY: ENGAGEMENT, STUDENT LEARNING, AND SATISFACTION \\ David Mahan}

November 23, 2010

This dissertation explored the four-year college experience of first-generation and continuing-generation students at a small private institution. Using Astin's I-E-O model (1970), the following variables in the student experience were considered: precollege student characteristics (input); engagement in academic experiences, cocurricular activities, campus relationships (environment); and satisfaction, learning (outcome).

The sample consisted of seniors participating in the National Survey of Student Engagement (NSSE) and/or a direct measure of general education learning, the ETS Measure of Academic Proficiency and Progress.

Results of the analysis of learning indicated no difference in first-generation and continuing-generation students' measures $(n=342)$. One exception was found in a subsequent model built which excluded students who did not submit a FAFSA (less financially needy students); first-generation status was a positive predictor of learning ( $\beta$ $=.25$ ). No precollege characteristics (input) or engagement variables (environment) were associated with learning (outcome), other than aptitude ACT composite $(\beta=.66, n=39$ ).

Regarding satisfaction, no significant difference existed in senior measures between first-generation and continuing-generation students after controlling for 
aptitude $(p<.05)$. When considering the environmental variables which influence satisfaction, campus relationships were strong positive predictors of satisfaction $(n=$ 175). These environment variables were calculated from NSSE Pike "scalelets," four of which were significant $(p<.05)$ : quality of campus relationships/interpersonal environment $(\beta=.59)$; varied education experience $(\beta=-.18)$; support for student success $(\beta=.17)$; and higher order thinking skills $(\beta=.14)$. No precollege characteristics significantly influenced satisfaction.

In comparing the overall college experience, the difference in the student groups was limited to only a few variables, none of which influenced learning or satisfaction. First-generation students rated lower the quality of their campus relationships and the support they received for success $(p<.05)$. First-generation students typically worked more hours for pay, commuted to campus, and had greater financial need.

The results of this single institution study did not support previous literature showing first-generation students high-risk, a characteristic which can influence retention, satisfaction, and learning. The most significant finding from this project was the positive influence of campus relationships on seniors' satisfaction, regardless of parents' education level. 
TABLE OF CONTENTS

PAGE

DEDICATION

iii

ACKNOWLEDGMENTS

iv

ABSTRACT

vi

LIST OF TABLES

xii

LIST OF FIGURES

xiv

CHAPTER

I. INTRODUCTION 1

Engagement, Learning, and Satisfaction $\quad 4$

Summary of Research Problem $\quad 8$

$\begin{array}{ll}\text { Introduction of Research Design } & 12\end{array}$

Limitations of the Study $\quad 14$

$\begin{array}{ll}\text { Purpose Statement and Research Questions } & 15\end{array}$

II. REVIEW OF THE LITERATURE 17

The Astin Input-Environment-Outcome (I-E-O) Model 22

First-Generation Student Input Characteristics 23

Demographic Characteristics $\quad 24$

Secondary Preparation 26

Access and the College Choice Process $\quad 30$

Expectations of College $\quad 35$ 
Environmental Experiences of First-Generation Students 38

The First-Year Experience 39

Involvement, Engagement, and Integration $\quad 42$

High School to Postsecondary Education $\quad 45$

Interventions: Educationally Purposeful Activities 48

Declaring Major and Upperclassman Experience $\quad 51$

College Outcomes of the First-Generation Students $\quad 56$

Persistence, Degree Attainment and Learning $\quad 57$

Early Labor and Graduate School Outcomes $\quad 62$

Measuring Success and Satisfaction Outcomes $\quad 63$

Summary of Implications for First-Generation Students $\quad 67$

$\begin{array}{ll}\text { III. METHODS } & 74\end{array}$

$\begin{array}{ll}\text { Research Design } & 77\end{array}$

$\begin{array}{lr}\text { Population and Sample } & 80\end{array}$

$\begin{array}{lr}\text { Sampling Procedures } & 81\end{array}$

Instrumentation and Data Sources $\quad 83$

Student Information System $\quad 84$

National Survey of Student Engagement (NSSE) $\quad 84$

NSSE Validity and Reliability $\quad 85$

ETS MAPP 95

$\begin{array}{lr}\text { Data Collection Procedures } & 98\end{array}$

$\begin{array}{lr}\text { Data Analysis } & 99\end{array}$

$\begin{array}{ll}\text { Research Questions } & 101\end{array}$

$\begin{array}{ll}\text { Limitations } & 106\end{array}$ 
$\begin{array}{ll}\text { IV. RESULTS } & 111\end{array}$

Research Question One $\quad 111$

Research Question Two 116

$\begin{array}{ll}\text { Research Question Three } & 122\end{array}$

$\begin{array}{ll}\text { Research Question Four } & 125\end{array}$

Research Question Five $\quad 135$

$\begin{array}{ll}\text { Research Question Six } & 140\end{array}$

Summary of Research Findings $\quad 146$

$\begin{array}{lll}\text { V. DISCUSSION AND CONCLUSION } & 147\end{array}$

Overview of the Research Problem 147

$\begin{array}{ll}\text { Purpose Statement and Research Questions } & 149\end{array}$

Review of the Methods $\quad 150$

$\begin{array}{ll}\text { Summary of Findings } & 153\end{array}$

$\begin{array}{ll}\text { Findings Related to the Literature } & 157\end{array}$

Astin (1970) Inputs $\quad 157$

Astin (1970) Environment 159

Astin (1970) Outcomes $\quad 163$

Recommendations for Practitioners and Policymakers $\quad 167$

$\begin{array}{ll}\text { Future Research } & 175\end{array}$

$\begin{array}{ll}\text { REFERENCES } & 178\end{array}$

APPENDIX

A. NSSE INSTRUMENT 188

B. NSSE 2009 Measurement Scales, Component Scales, and $\begin{array}{ll}\text { Intercorrelation Tables } & 189\end{array}$ 
C. NSSE Syntax Library 190

D. Creating NSSE Benchmarks 200

E. Categories for Expected Family Contribution (EFC)

and Miles from Home 204

F. Comparison of Learning Measures for Incoming Freshmen 205

G. Pike Scalelets as Significant Predictors of Satisfaction 206

$\begin{array}{ll}\text { CURRICULUM VITAE } & 210\end{array}$ 


\section{LIST OF TABLES}

TABLE PAGE

1. Student Response Rate for NSSE and ETS MAPP 81

2. Internal Consistency of NSSE Benchmarks 88

3. Correlation of Student Engagement and Self-Reported Outcomes 90

4. Internal Consistency of NSSE Pike Scalelets 92

5. Internal Consistency of NSSE Satisfaction Score 92

6. Internal Consistency of NSSE Quality of Campus Relationships 93

7. Internal Consistency of NSSE Combined Relationships and Satisfaction 93

8. Average Student-level Correlations ETS MAPP, CAAP, CLA 98

9. ETS MAPP Reliability Scores 98

10. Summary of Variables Used in Research Questions 109

11. Resulting Means of ETS MAPP Sub-Scores by Student Group 113

12. Resulting Model with NSSE Benchmarks as Predictors of $\begin{array}{ll}\text { ETS MAPP (Students with an EFC) } & 119\end{array}$

13. Resulting Model with NSSE Benchmarks as Predictors of $\begin{array}{ll}\text { ETS MAPP (Excluding EFC) } & 121\end{array}$

14. Resulting Means of NSSE Satisfaction Items by Student Group 125

15. Resulting Model $R^{2}$ for High Impact Practices/University-Specific Activities as Predictors of NSSE Satisfaction 
16. Resulting Model Coefficients High Impact Practices/University-Specific Activities as Predictors of NSSE Satisfaction

17. Resulting Model $R^{2}$ for Pike Scalelets as Predictors of NSSE Satisfaction

18. Resulting Model Coefficients for Pike Scalelets as Predictors of NSSE Satisfaction

19. Resulting Model with Campus Relationships as Predictors of NSSE Satisfaction

20. Resulting Model with Campus Relationships as Predictors of ETS MAPP (Students with an EFC)

21. Resulting Model with Campus Relationships as Predictors of ETS MAPP (Excluding EFC Available) 


\section{LIST OF FIGURES}

FIGURE PAGE

1. CLA Performance by Parental Education 62

2. Model of Influencing Factors of Learning 73

3. Astin I-E-O (1970) Model Used in Study 79

4. Model of Factors Investigated in Study 110

5. Resulting Model of Influencing Factors of Satisfaction 171

6. Resulting Model of Influencing Factors of Learning 174 


\section{CHAPTER I}

\section{INTRODUCTION}

Higher education researchers, practitioners, and administrators well understand the attrition risk of first-generation college students and therefore consider their success an important measure of institutional effectiveness and an overall reflection of access to American higher education. Independent nonprofit four-year institutions typically enroll small numbers of minority and low-income students; however, most of the minority and low-income students they do enroll are first-generation and when considered as a group, first-generation college students represented a sizable $12.8 \%$ of the 2005 U.S. private four-year freshmen (Saenz, Hurtado, Barrera, Wolf, \& Yeung, 2007).

First-generation students retain and graduate at lower rates and thus are considered a high-risk group for attrition at both private and public institutions. Pascarella \& Terenzini (2005) found that even after controlling for institution type, socioeconomic status, and enrollment patterns, first-first-generation status negatively influenced completion of degree. Specifically, "Students whose parents held a bachelor's degree or higher were five times more likely to earn a bachelor's degree than were similar first-generation students" (p. 590). Private four-year institutions typically graduate a higher percentage of first-generation students than public four-year institutions (Ishitani, 2006; Wilcox, 2008); thus recruiting more first-generation students is an opportunity for growth in the number of degrees conferred to minority and low-income 
students by independent institutions. Smaller private institutions typically offer more individual student attention because faculty members can focus more on teaching and student learning without the pressures associated with scholarship at larger research institutions. Small schools attempt to create an environment that encourages and affirms high-risk students, typically leading to better retention and graduation rates. Firstgeneration students therefore are an appropriate target for small independent institutions seeking to improve graduation rates and confer more degrees by promoting success of these diverse and high-risk students.

The number of first-generation traditional freshmen choosing private institutions has increased, narrowing the gap between private and public four-year institutions. In 1971, first-generation students represented $30.4 \%$ of the student population at four-year private institutions, compared to $42.2 \%$ at four-year public institutions, a gap of $11.8 \%$. In 2005 , first-generation students represented $12.8 \%$ of the student population at fouryear private institutions, compared to $17.5 \%$ at four-year public institutions, a gap of 4.7\% (Saenz, et al., 2007).

Although a greater percentage of first-generation students are now choosing private institutions, competition to recruit these students continues to grow. Firstgeneration students now represent a smaller percentage of the overall U.S. student population. In the latter half of the 20th century, more U.S. citizens had access to higher education and successfully completed a college degree. Thus the percentage of the firstgeneration college students has decreased substantially since 1971. With fewer firstgeneration students available for recruitment, private institutions are making targeted efforts to attract more of these diverse students. Organizations such as the Council of 
Independent Colleges (CIC) and the Wal-mart Foundation have used financial aid and strong communication campaigns to encourage more first-generation students to consider a private college or university (Lipka, 2010).

Research in the latter half of the $20^{\text {th }}$ century has focused on student involvement (Astin, 1984), the quality of student effort (Pace, 1980), and student academic and social integration into the university community (Tinto, 1993). Practitioners have begun to better understand the attrition risk of first-generation students and targeted their efforts towards retention. When students participated in educationally purposeful activities in the first year of college, the negative effects of demographics, precollege characteristics and prior academic achievement greatly diminished. The influence of parents' education level, an example of a precollege characteristic, essentially "disappeared" (Kuh, Cruce, Shoup, Kinzie, \& Gonyea, 2008, p. 555). First-generation students persisting in college typically later graduate and gain employment with similar income levels as continuinggeneration students (Chen, 2005; Choy, 2001; Nunez \& Cuccaro-Alamin, 1998; Pascarella, Pierson, Wolniak, \& Terenzini, 2004; Saenz, et al., 2007; Terenzini, Springer, Yaeger, Pascarella, \& Nora, 1996; Warburton, Bugarin, \& Nunez, 2001). Practitioners therefore use interventions to help foster an environment where more at-risk students remain continuously enrolled, which ultimately leads to graduating more students However, emphasis on first-year programs which focus primarily on retention is not sufficient. School leaders need a better understanding of the entire four-year experience of first-generation students in terms of engagement, learning, and satisfaction. The quality of the overall, long-term learning experience both inside and outside of the classroom is an important indicator of institutional effectiveness. Important to note, for 
instance, that graduating more first-generation students from four-year institutions, while a laudable goal, does not necessarily indicate the same quality learning experienced by continuing-generation students. For example, first-generation students who earned baccalaureate degrees typically received lower grades and were less likely than continuing-generation students to enroll in graduate school (Chen, 2005; Choy, 2001; Nunez \& Cuccaro-Alamin, 1998; Pascarella, et al., 2004).

\section{Engagement, Learning, and Satisfaction of First-Generation Students}

Decades of research literature confirms the relationship between what students do in college and successful college outcomes (Astin, 1993; Kuh, Kinzie, Buckley, Bridges, \& Hayek, 2006; Pascarella \& Terenzini, 2005). Student engagement involves a reciprocal relationship between the quality of the student effort (Pace, 1980) and how the institution promotes student learning opportunities both in and outside of the classroom (Kuh, 2001; Wolf-Wendel, Ward, \& Kinzie, 2009). Much of the previous research has focused on retention and graduation rates, urging practitioners to provide more of the engagement opportunities proven to influence the percentage of students successfully retained and graduated (Ishitani, 2006; Kuh, et al., 2008). Surprisingly, however, there is limited research studying the effects of various types of student engagement on direct measures of student learning (Arum \& Roksa, 2010; Pascarella, et al., 2004; Terenzini, et al., 1996) and satisfaction (Kim \& Sax, 2009; Lohfink \& Paulsen, 2005), especially at time of degree completion, over a four-year undergraduate college experience. Researchers have typically only demonstrated the positive effects of engagement on student learning gains and other outcomes through student self-report instruments such as the National Survey of Student Engagement (NSSE) (Gordon, Ludlum, \& Hoey, 2008; Kuh, 2003a; Pike, 
2006a). Student satisfaction is even less frequently researched, however it is also an important predictor of student learning and success (Kuh, et al., 2006).

Engagement has long been viewed as an important part of understanding the college students' experience (Wolf-Wendel, et al., 2009), and as research in this area developed, scholars have discovered that different student subpopulations experienced engagement efforts in distinct ways. In particular, Pascarella, et al. (2004) found firstgeneration students experienced college differently than continuing-generation students because of their unique family characteristics. Practitioners must better understand this difference to optimize learning and satisfaction of first-generation students through targeted institutional efforts.

Researchers have studied these differences in terms of overall student engagement, as well as academic and social integration (Tinto, 1993). Pike and Kuh (2005) concluded that first-generation college students were generally less engaged in their overall education than continuing-generation students; first-generation students in many cases failed to understand both the importance of cocurricular or extracurricular activities and how to become involved in such activities.

For instance, many first-generation students chose a college close to home for a shorter commute and often came from families where English was not the primary language spoken in the home. First-generation students reported key differences in the type of successful engagement in the campus community. Because of more time spent working off-campus and with other family commitments, school clubs and social involvement did not correlate positively with persistence for first-generation students (Lohfink \& Paulsen, 2005). First-generation students thus reported a difference in their 
four-year experience because of not living on-campus, time spent with family obligations and working off-campus (Pascarella, et al., 2004). Pascarella and Terenzini (1991) concluded first-generation students were negatively influenced by hours worked (either volunteer service or to earn money) and were more successful when enrolled continuously and full-time. Furthermore, academic integration, such as the frequency of faculty-student interactions and the quality of the interaction, influenced first-generation student success more than social activities. First-generation students reported a need for validation from faculty members that they were capable of doing college work (Lohfink \& Paulsen, 2005). Because minority and low-income students were disproportionately represented within the first-generation group, attending an institution where the majority of students were racially, ethnically, or religiously different created additional challenges when acclimating to college.

Fortunately, research demonstrates institutional efforts to intervene early with first-generation students (before attrition) proved highly effective in terms of student retention. Programs such as freshman seminars, small classes where faculty members validate a student's ability to do college-level work, proved "compensatory" or more meaningful to first-generation students than continuing-generations (Kuh, et al., 2008, p. 549). Now there is a need for additional research to better understand engagement in the overall four-year experience and how various types of engagement influence satisfaction and learning of first-generation students.

In terms of student learning, differences in the collegiate experience between firstgeneration and continuing-generation students failed to translate into substantial differences in student learning outcomes (Pascarella, et al., 2004; Terenzini, et al., 1996). 
Pascarella et al. (2004) found no significant differences in second-year writing skills or third-year reading comprehension or critical thinking scores, and only a small difference in second-year science reasoning (which reduced to nonsignificant when researchers accounted for various college experiences). Terenzini (1996) reported similar findings in the freshman year using the same student sample. Arum and Roska (2010) found that first-generation students started with lower standardized test scores and gained less over the first two years of college than students with parents holding a graduate or professional degree (after controlling for aptitude with ACT or SAT scores). High school preparation and college experiences however accounted for $40 \%$ of the gap and when removed, firstfirst-generation status no longer was statistically significant. Because there is limited research addressing direct measures of first-generation student learning, additional study is needed in the senior year of college, focused on final learning outcomes at the end of the four-year experience (closer to the time of baccalaureate degree completion); Ideally, this study would explore the college experiences which influence student learning outcomes.

In terms of student satisfaction, Kuh, et al. (2006) summarized satisfaction research over the past two decades. The college environment influenced satisfaction scores more than precollege characteristics (Astin, 1993). The majority of college senior students rated the overall experience at least "good" with less than $5 \%$ rating the experience as "poor" (NSSE, 2005). However, satisfaction scores remain only modestly researched, especially comparing first-generation to continuing-generation students in terms of satisfaction with their overall college experience. 
Most student satisfaction scores improve as the number of quality interactions with peers and faculty members increase (Kuh, et al., 2006). Pascarella and Terenzini (2005) concluded however that effects of college experiences on outcomes are conditional and thus engagement trends vary across student groups. Because the overall college experience of first-generation students varies from continuing-generation students, satisfaction scores may vary as well. First-generation students' satisfaction may be more contingent upon academic integration in terms of frequency and quality of the classroom interactions, rather than the social and cocurricular experiences important for continuing-generation students. An important research question is to determine the college experiences which influence first-generation satisfaction.

\section{Summary of Research Problem}

Pascarella, et al., (2004) found that first-generation students experienced college differently than continuing-generation students because of their unique family characteristics. Much previous research of U.S. first-generation students focused on second-year persistence and degree completion, by following longitudinally a nationally representative sample across multiple institution types. The U.S. Department of Education sponsored much of this research and the results influenced national policy for persistence at both two-year and four-year institutions (Chen, 2005; Choy, 2001; Horn \& Nunez, 2000; Nunez \& Cuccaro-Alamin, 1998; Warburton, et al., 2001). Small private school administrators learned how to better retain and graduate high-risk students for attrition; however administrators and faculty members now need to better understand the four-year experience of first-generation students to develop programming and curriculum to create an experience which may be different than that of the general student 
population, but which would facilitate better learning and satisfaction for these high-risk students. This study will comprehensively examine the four-year experience of firstgeneration students at a small, private university, by comparing their engagement, learning, and satisfaction levels to those of continuing-generation students.

Over the past decade, higher education leaders frequently discussed and debated the communication gap between research and practice. The issues identified were relevance of study problems to the needs of practitioners and the lack of adequate dissemination of research findings through practitioner communication channels. Bensimon, Polkinghorne, Bauman, and Vallejo (2004), however, contended that the problem lies in the traditional research model used because it fails to account for the uniqueness and ever changing makeup of each local institution. Thus research findings cannot be generalized across institution type. The traditional research model also lacks any element of action research because leaders from individual institutions are not involved in the research. The results of national studies, therefore, "rarely provide a picture that reflects the reality of a particular place and particular people" (Bensimon, et al., 2004, p. 107). For example, Arum and Roska (2010) found in a national study that institutional difference varied a significant $29 \%$ across schools in terms of longitudinal gains in student learning (as measured by the Collegiate Learning Assessment before the freshman year and after the sophomore year). In the same study but comparing firstgeneration students as a group to continuing-generation students, the variance in learning gains was no longer significant after controlling for the institution attended; thus the uniqueness and quality of the undergraduate experience at an individual institution significantly related to student learning, especially important for disadvantaged students. 
A single institution study, therefore, is justified to better understand the four-year experience of first-generation students and provide results which could be used immediately by practitioners to improve learning and satisfaction.

Findings from this study of the four-year student experience could provide practical models which not only influence retention efforts of high-risk students, but suggest best practices to influence student learning and satisfaction. Much previous research has focused on attrition risk factors and intervention strategy; however, persisting first-generation students also have obstacles which presumably influence learning and satisfaction. As compared to continuing-generation students, first-generation students work more hours for pay while attending school, spend more time commuting to campus, have family obligations requiring large amounts of time, earn lower grades, and choose a major with immediate financial gain after graduating (Chen, 2005; Pascarella, et al., 2004; Pascarella \& Terenzini, 1991). Furthermore, first-generation students completing a four-year degree attended graduate school at significantly lower rates, citing lower educational aspirations as early as the first year of college (Choy, 2001; Nunez \& Cuccaro-Alamin, 1998; Terenzini, et al., 1996). Lower grades in the second and third year of college also could constitute a contributing factor (Chen, 2005; Pascarella, et al., 2004).

Administrators and faculty members at each institution reflect on whether the mission of the college or university is merely to help students land their first job. The answer is no for many independent, nonprofit four-year institutions, where students are prepared to be good citizens, life-long learners and often candidates for graduate school. However, first-generation students more often chose professional majors rather than 
liberal arts curriculums, leading to short term improvement in finances, but with less preparation for graduate school. Continuing-generation students declared majors more frequently in mathematics, engineering, architecture, humanities, arts, or sciences (Chen, 2005).

In summary, first-generation students experience college differently, which often leads to attrition at four-year institutions. Many practitioners have learned how to intervene during the first-year experience with an educationally purposeful activity (Kuh, et al., 2008), keeping more at-risk students continuously enrolled and graduating a larger percentage of first-generation students. There is evidence, however, that first-generation students learn less and do not have the same quality experience as continuing-generation students. Pike and Kuh (2005) concluded that first-generation students self-report less learning and intellectual development, as well as perceiving the college environment as less supportive. These conclusions were a direct result of not living on-campus and having lower educational aspirations; however, these conclusions were only indirectly related to first-first-generation status. Thus Pike and Kuh summarized that the results were less related to precollege characteristics (first-first-generation status) and more influenced by what the students do during college. The critical factors which influenced student learning were the reported frequency of diverse experiences and the perceptions of the college environment. Because first-generation students were generally less engaged in the overall college experience, the quality of the learning experience may be influenced.

Practitioners and faculty members must better understand how to foster an optimal four- year. learning environment for first-generation students. Small private 
institutions have an opportunity to foster an environment which promotes first-generation student success because of smaller class sizes, a faculty focus on teaching and learning, and a community which strives to deliver a personal experience for each of its students. Curriculum, institutional programs, and faculty-student relationships may influence firstgeneration students more than continuing-generation students. Student success is less related to first-first-generation status than the experience these students have in college.

\section{Introduction of Research Design}

A quantitative, ex post facto research design was used to compare the four-year experience of first-generation students in terms of engagement, learning, and satisfaction to continuing-generation-student students at a single institution. The research was conducted using full-time undergraduate students participating in either one or both of the following two instruments. The NSSE is a short questionnaire which indirectly measures learning through the students' self reported perceptions of their collegiate experience (both in and outside of the classroom). The Educational Testing Service Measure of Academic Proficiency and Progress (ETS MAPP) is a direct measure of general education student learning. Using the NSSE instrument, researchers built several composite scores to help practitioners focus their efforts on the best practices associated with student success. NSSE grouped five factors as national benchmarks common to learning and student success: active and collaborative learning (ACL); student-faculty interaction (SFI); enriching educational experiences (EEE); supportive campus environment (SCE); and level of academic challenge (LAC). Pike (2006a) developed 12 "scalelets," each representing a specific content area with a set of survey questions. To make generalizations about a construct, one survey item will not suffice; thus a group of 
survey questions increases the measure's richness of that element of the student experience. "Scalelets" include the following: course challenge; writing; active learning; higher order thinking skills; collaborative learning; course interaction; out-of-class interaction with faculty; use of information technology; emphasis on diversity; varied educational experiences; support for student success; and interpersonal environment.

The research setting was a small, private, Catholic university located in a large Midwestern city. In fall of 2009, the university enrollment included over 2000 full-time undergraduate students, and nearly 700 graduate students, with over 950 of the undergraduate students living in the residence halls. Enrollment of first-generation students was substantial at the institution, which was somewhat unusual for a private Catholic Master's level institution. In fall 2009, the freshman cohort included $40 \%$ firstgeneration students. The university defined a first-generation student as one with neither parent completing a baccalaureate degree. This definition was appropriate for the institution since it is a four-year institution. The institution's NSSE selected peers (25 small private schools used for benchmarking purposes) reported less than $30 \%$ firstgeneration students (using the same definition to determine first-generation status) (NSSE, 2009).

The conceptual framework used for the study was the Astin input-environmentoutcome (I-E-O) model (1970), which serves as a tool to better understand student development while in college. Inputs represented the student characteristics at the time of entry into an institution. Environment addressed various educational and cocurricular experiences to which a student was exposed as well as the relationships with student peers, faculty and staff members. Outcomes focused on student characteristics after the 
student experienced the collegiate environment (spring of the senior year of college). Because of the complexity of the student experience during college, the model was a tool to assess student growth holistically. The premise of the model involves understanding students at point of entry to determine whether the collegiate experience influences student outcomes. Several statistical methods were used to assess measurements of the students' overall four-year experience. The models specifically were built using multiple regression techniques to identify predictor environmental (engagement) variables which influence student learning and satisfaction. Multivariate analysis of covariance (MANCOVA) methods were also used to compare first-generation and continuinggeneration student groups, after controlling for the key predictive variable, aptitude (ACT composite). Final models from the study may be presented to support practitioner efforts in fostering satisfaction and stronger learning environments for first-generation students.

\section{Limitations of the Study}

A limitation of single institution studies at small private schools is the number of student participants relative to the number of variables considered for analysis. This study's sample, however, was representative of the small population at the university (both first-generation and continuing-generation students). Independence of sample was also a consideration because NSSE participation is typically not proctored. This selfreporting issue already has been studied by the NSSE research team and poses only a limited threat to validity and reliability.

The ETS MAPP assessment has proved to be a reliable and valid direct measure of student learning in general education. Sample size, however, was an important consideration on the abbreviated form because the assessment was only 40 minutes in 
length. Additionally, while the writing sub-score proved valid in measuring a student's ability to determine sentence structures for example, actual writing skills cannot be assessed with multiple choice questions.

The Astin I-E-O model (1970) simplified some of the complexity of the student experience. Astin suggested several considerations while using the model. The basic premise of the Astin model is to determine the input characteristics of students to assess if the college experience has made a difference in student development. While many input student characteristics and control variables were used in this study, there were many more that could not be considered because of sample size and the scope of the study.

The final limitation was in studying the four-year experience only. Students who did not persist for four years may have withdrawn because of academic struggles related to factors such as first-generation status. However, the purpose of this research was to determine if engagement, learning, and satisfaction measures were influenced over the course of the entire collegiate experience due to first-generation status.

\section{Purpose Statement and Research Questions}

The purpose of the study was to better understand the four-year college experience of first-generation students and continuing-generation students at a small private institution by comparing their engagement, learning, and satisfaction. Using Astin's I-E-O model (1970), the following variables in the student experience were considered: precollege student characteristics (input); academic experiences, cocurricular involvement, campus relationships (environment); and satisfaction, learning measures 
(outcome). Results may be used to help practitioners at a small private four-year college to better engage first-generation students on campus. Research questions included:

1. Does a statistically significant difference exist in senior measures of learning between first-generation and continuing-generation students?

2. Do senior NSSE benchmark scores (engagement variables) significantly predict senior measures of learning for first-generation and/or continuing-generation students?

3. Does a statistically significant difference exist in senior satisfaction measures between first-generation and continuing-generation students?

4. Do Pike "scalelets" generate a better predictive model of senior satisfaction than the engagement variables from high impact practices/university-specific activities?

5. Is the quality of relationships (with other students, faculty members, and administrative personnel and offices) a significant predictor of senior satisfaction for first-generation and/or continuing-generation students?

6. Is the quality of relationships (with other students, faculty member, and administrative personnel and offices) a significant predictor of senior measures of learning for first-generation and/or continuing-generation students? 


\section{CHAPTER II}

\section{REVIEW OF THE LITERATURE}

The purpose of the study was to better understand the four-year college experience of first-generation students and continuing-generation students at a small private institution by comparing their engagement, learning, and satisfaction. Using Astin's I-E-O model (1970), the following variables in the student experience were considered: precollege student characteristics (input); academic experiences, cocurricular involvement, campus relationships (environment); and satisfaction, learning measures (outcome). Results may be used to help practitioners at a small private four-year college to better engage first-generation students on campus.

Because of working more hours per week, attending less selective institutions, living off-campus, and unique family circumstances, Pascarella, et al., (2004) found that first-generation students experienced college differently than continuing-generation students. Much research of U.S. first-generation students has focused primarily on persistence and degree completion, using a nationally representative sample across multiple institution types. The U.S. Department of Education sponsored many of longitudinal studies to inform national policy (Chen, 2005; Choy, 2001; Horn \& Nunez, 2000; Nunez \& Cuccaro-Alamin, 1998; Warburton, et al., 2001). As a result of this research, practitioners at both two-year and four-year institutions learned how to better retain and graduate high-risk students with campus-wide interventions typically housed in 
the first year of college. However, research is needed to better understand the four-year experience of first-generation students to determine whether an experience which may be different than the general student population can be intentionally developed to facilitate the learning and satisfaction needs of these high-risk students.

Higher education leaders frequently have discussed and debated the communication gap between research and practice over the past decade. Some of the issues identified concern relevance of academic research to the needs of individual campuses and the ineffective communication of the findings to the institutions. As previously stated, Bensimon, Polkinghorne, Bauman, and Vallejo (2004), however, contended that the problem lies in the traditional research model used because it fails to account for the uniqueness and ever changing makeup of each local institution. Thus research findings cannot be generalized across institutions. The traditional research model also lacks any element of action research because leaders from individual institutions are not involved in the research. The results of national studies, therefore, "rarely provide a picture that reflects the reality of a particular place and particular people" (Bensimon, et al., 2004, p. 107). For example, Arum and Roska (2010) found in a national study that institutional difference varied a significant $29 \%$ across schools in terms of longitudinal gains in student learning (as measured by the Collegiate Learning Assessment before the freshman year and after the sophomore year). In the same study but comparing first-generation students as a group to continuing-generation students, the variance in learning gains was no longer significant after controlling for the institution attended; thus the uniqueness and quality of the undergraduate experience at an individual institution significantly related to student learning, especially important for 
disadvantaged students. A single institution study, therefore, is justified to better understand the four-year experience of first-generation students and provide results which could be used immediately by practitioners to improve learning and satisfaction.

Current research of student success in postsecondary education developed from four time periods beginning in the 1960s. This first period focused on understanding "who students are," then in the 1970s researchers investigated the "external influences on college students." The third period in the 1990s explained "what students do" in terms of curricular and cocurricular activities. Today's research, "what institutions do," helps institutions' personnel work together with students to foster stronger student engagement both in the classroom and through experiential learning (Swing, 2008, November). Universities and colleges use student feedback to strategically respond to concerns and target specific students by offering programs and services intended to provide a better chance of persistence and graduation. Practitioners also have begun to evaluate these efforts in terms of student learning, satisfaction, and employment and graduate school placement; however, a more comprehensive assessment of these metrics is needed to evaluate institutional effectiveness and better support at-risk students.

Since 1971 the proportion of first-time full-time first-generation students at fouryear institutions declined steadily because of increasing levels of educational attainment in the U.S. general population, as well as competition from shorter degree programs in the community technical college systems and proprietary institutions. Nevertheless, in 2005, first-generation students represented roughly one of three college students when considering students in all types of postsecondary institutions (NSSE, 2005), and overly represented Latino and low-income students (Choy, 2001; Kuh, et al., 2006; Saenz, et al., 
2007). Researchers and higher education practitioners identified first-generation students as high-risk for attrition (Chen, 2005; Choy, 2001; Horn \& Nunez, 2000; Nunez \& Cuccaro-Alamin, 1998; Warburton, et al., 2001). As first-generation students continue to decline as a percentage of the overall student population, they become an even higher risk for attrition as a minority group (Saenz, et al., 2007).

School leaders have focused their retention efforts in three primary areas of research (Pascarella, et al., 2004; Terenzini, et al., 1996). The first area addresses the precollege characteristics of first-generation students in regards to demographics, secondary preparation, college choice process, and expectations of college. A second emphasis of research focuses on a better understanding of transition from high school to college made by first-generation students. The third area of the research investigates firstgeneration student persistence in college, degree attainment, and early career labor outcomes.

Using data from the three areas of previous research as well as findings from a longitudinal study of first-generation students' experiences and learning in the first three years of college (Pascarella, et al., 2004; Pascarella \& Terenzini, 2005; Terenzini, et al., 1996), higher education practitioners focus their efforts in the new millennium on increasing student engagement through high impact practices (AAC\&U, 2007) or educationally purposeful activities (Kuh, et al., 2008) such as first-year seminars, study abroad, internships, learning communities, and capstone courses. These efforts proved increased retention and graduation rates at many institutions (Kuh, Kinzie, Schuh, \& Whitt, 2005a, 2005b). 
A substantial amount of literature exists, representing high school and college studies in longitudinal research throughout the U.S. education system, addressing access and persistence of first-generation students in college. These federally funded studies used sophisticated weighting systems to representatively sample students in all parts of the nation to make generalizations about all U.S. students. The conclusions were quite consistent. First-generation students remained high-risk for attrition; however, those students who persisted in college typically graduated and gained employment at similar income levels as continuing-generation students (Chen, 2005; Choy, 2001; Horn \& Nunez, 2000; Pascarella, et al., 2004; Saenz, et al., 2007; Terenzini, et al., 1996; Warburton, et al., 2001). Therefore, practitioner efforts are typically focused mostly on keeping first-generation students continuously enrolled. An important note, however, conclusions made regarding national student populations typically cannot be generalized for each unique higher education institution, nor can these studies comprehensively explore learning, engagement, and satisfaction over the four-year experience. Graduating first-generation students from four-year institutions does not necessarily indicate the same quality of college experience as that of continuing-generation students.

Researchers proved over decades of college studies that "what students do" in college positively affects student outcomes (Astin, 1993; Kuh, et al., 2006; Pascarella \& Terenzini, 2005). Researchers developed the concept of student engagement as not merely the student's responsibility, but a reciprocal relationship between the quality of the student effort (Pace, 1980) and how the institution organizes and resources student learning opportunities both in and outside the classroom (Kuh, 2001; Wolf-Wendel, et al., 2009). As previously stated, the research focus was on student retention and graduation, 
encouraging practitioners to create more meaningful engagement opportunities, given that these activities were proven to influence the percentage of students who successful retain and graduate (Ishitani, 2006; Kuh, et al., 2008)., There is a limited about amount of research studying the effects of various types of student engagement on direct measures of student learning (Pascarella, et al., 2004; Terenzini, et al., 1996) and satisfaction (Kim \& Sax, 2009; Lohfink \& Paulsen, 2005), after a four-year undergraduate college experience. Researchers typically studied only the positive effects of engagement on student learning gain through student self-report instruments such as the National Survey for Student Engagement (NSSE) (Gordon, et al., 2008; Kuh, 2003a; Pike, 2006a). Student satisfaction has rarely been considered an important research focus, even after establishing that satisfaction is a predictor of student learning and success (Kuh, et al., 2006).

The Astin I-E-O model (1970) frames this review of the existing literature into the three primary research areas of first-generation students. By using the Astin model, research findings can be contextualized within the broader literature of student success in college to help practitioners and faculty members convert data into action on-campus (Kuh, et al., 2006).

\section{The Astin Input-Environment-Outcome (I-E-O) Model}

For decades, researchers have used the Astin model (1970) as a conceptual framework for studying student development (Wolf-Wendel, et al., 2009). While Astin has made several refinements since the 1970s, the model's basic concepts remain unchanged. Inputs continue to represent the student characteristics at the time of entry into an institution. Environment addresses the various educational and cocurricular 
experiences to which a student is exposed, as well as relationships with student peers, faculty and staff members. Outcomes focus on student characteristics after the student experienced the environment. Since its inception, researchers have used the model to determine the influence of varying educational experiences on student development. Because of the complexity of the student experience during college, the Astin model became a tool to assess student growth holistically. Measuring the effectiveness of the educational environment included accounting for many simultaneous experiences as well as confounding factors such as student maturation. The model also responded to the challenge of making sense of the self-selection bias (Wolf-Wendel, et al., 2009), when using data intended to measure student engagement, learning and satisfaction. Similar to the three areas of first-generation student literature, researchers concluded in studying all college students from the 1960 s to 1990 s that four research areas accounted for the influence of college on students (Pascarella \& Terenzini, 1991): student demographics or precollege characteristics; organizational or structural influences of the institution; students' academic experiences; and students nonacademic experiences (Astin, 1993; Pascarella \& Terenzini, 1991). By using the Astin model for review of the literature, the research of first-generation college students was integrated as follows with the literature of the general population of college students into student inputs, environment, and outcomes.

\section{First-generation student input characteristics.}

Researchers traditionally defined first-generation college students as any student with neither parent experiencing postsecondary education (Billson \& Terry, 1982; Choy, 2001; Horn \& Nunez, 2000; Nunez \& Cuccaro-Alamin, 1998; Pascarella, et al., 2004; 
Saenz, et al., 2007; Terenzini, et al., 1996; Warburton, et al., 2001). College

administrators have identified first-generation students as a high-risk group for attrition; therefore their efforts have focused on retention and graduation in the following primary areas of research. The first areas addressed the precollege characteristics of firstgeneration students in regards to demographics, secondary preparation, access and the college choice process, and expectations of college. These research areas fit into the Astin I-E-O model (1970) as input characteristics, because the student arrives on-campus with attitudes and behaviors which will influence the college experience.

\section{Demographic characteristics.}

Over the past two decades, researchers extensively examined background characteristics of first-generation college students. First-generation college students at four-year universities were more likely to come from a lower socioeconomic background, to have a nonwhite ethnicity, to report pursuing higher education to help their family out financially after completing college, and to worry about paying for college (Bui, 2002; Lohfink \& Paulsen, 2005). The combination of these factors, as well as first-generation student status itself, positions these students as high-risk for attrition.

As summarized by Kuh, et al. (2006), U.S. first-generation students represented roughly one of three college students when considering all U.S. institution types. For comparison purposes, $39 \%$ of students reported that both of their parents completed a bachelor's degree (NSSE, 2005). Because of increasing levels of educational attainment in the general population, especially traditional age white students at four-year institutions, first-generation students have decreased in representation in the overall population since 1971 (Saenz, et al., 2007), and now disproportionately over-represent 
minority students (ethnic and low-income groups traditionally known as high-risk for attrition), especially black or foreign-born Hispanic students where English was not the primary language spoken in the home (Warburton, et al., 2001). More first-generation students than their peers attended high schools in small towns or rural areas.

In terms of all college-attending first-generation students (two-year and four-year institutions), almost half of Latino students had parents with less than a high school degree, compared with $18 \%$ of white students (Swail, Cabrera, Lee, \& Williams, 2005). Choy (2001), after controlling for other significant factors, found that parents' education level strongly related to the likelihood of students enrolling in postsecondary education. Some $59 \%$ of first-generation students who graduated from high school in 1992 enrolled in a higher education institution by 1994 . This percentage increased to $75 \%$ of students whose parents had some collegiate experience and to $93 \%$ for students who had at least one parent with a baccalaureate degree.

When researchers controlled for the high-risk factors of ethnicity (minority students) and socioeconomic status (students from low family incomes), parent education remained a key predictive characteristic in both college enrollment and degree completion (Nunez \& Cuccaro-Alamin, 1998; Pascarella \& Terenzini, 2005; Terenzini, et al., 1996; Warburton, et al., 2001). Most first-generation students enrolled at two-year institutions (Horn \& Nunez, 2000), and often this occurred several years after graduating from high school. Older married females with low incomes and multiple dependents represented most first-generation students (Nunez \& Cuccaro-Alamin, 1998). In 1995-96, first-generation students represented more students 24 years or older. Students younger than 24 years came from the lowest family income quartile (Choy, 2001). First- 
generation students also often enrolled part-time and noncontinuously, further increasing their risk for attrition (Chen, 2005).

Traditional freshmen consisted of only $16 \%$ of first-generation students enrolling at four-year institutions immediately after completing high school (Saenz, et al., 2007). Traditional freshman first-generation students at four-year institutions represented a wide range of ethnicities in 2005: 38.2\% Latino; $22.6 \%$ African American; $16.8 \%$ Native American; 19\% Asian; and 13.2\% white (Saenz, et al., 2007). For the purpose of this research, only traditional freshman first-generation students were studied. While this group represented just 16\% of the U.S. freshmen at four-year institutions in 2007 (Saenz, et al., 2007), first-generation students at individual private institution often represent the majority of the school's ethnic and socioeconomic diversity. Success of first-generation students at private institutions is thus typically considered critical to the mission of educating a diverse range of students in terms of socioeconomic status, race, and ethnicity, thereby increasing the institutions' success with at-risk students.

\section{Secondary preparation.}

Another important aspect of precollege characteristics, secondary preparation has been demonstrated to help predict success of first-generation students in college (Horn \& Nunez, 2000; Nunez \& Cuccaro-Alamin, 1998; Warburton, et al., 2001). As quoted by Kuh et al. (2006, p. 19) summarizing previous research (Horn \& Kojaku, 2001; Warburton, et al., 2001), the "quality of the academic experience and intensity of the high school curriculum affects almost every dimension of success in postsecondary education regardless of who they are, how much money they have, or where they go." Researchers (Chen, 2005; Thayer, 2000) found that, as a group, first-generation students enrolled at 
four-year institutions are less academically prepared and have more limited information about the collegiate experience than other students. Choy (2001) discovered only $15 \%$ of continuing-generation students (with at least one parent who completed a bachelor's degree) marginally qualified or unqualified after high school, compared with $49 \%$ of first-generation students. Saenz et al. (2007) also found a consistent gap in secondary preparation between first-generation students and continuing-generation students. The researchers found a significant variance in the amount of time spent studying in high school, the average grade point average (GPA) in high school, and students' academic self-confidence. First-generation students reported an even greater variance in comparison with peers in the "self-ratings" regarding math and writing ability. Choy (2001) reported that $40 \%$ of first-generation students scored in the lowest quartile on the SAT or ACT. Terenzini et al. (1996) found that first-generation students had lower critical thinking abilities as measured by a standardized exam, College Assessment of Academic Proficiency (CAAP), before the beginning of the freshman year of college.

Researchers (Choy, 2001; Horn \& Nunez, 2000) found high school mathematics coursework to be strongly associated with enrollment in a four-year institution for any student, especially first-generation students. Those first-generation students completing advanced math coursework (at least one math class after Algebra II) enrolled at a substantially higher rate (64\% versus $34 \%)$. Choy (2001) also found a highly correlated relationship between high school mathematics coursework and parents' education. Firstgeneration students who completed advance math courses in high school enrolled in fouryear institutions at a lower rate than continuing-generation peers with the same high school curriculum ( $64 \%$ versus $85 \%)$. 
Of course, many high school graduates lacked adequate academic preparation as determined by the percentage taking remedial coursework at four-year institutions. However, first-generation students enrolled in at least one remedial course at higher rates $(45 \%)$ than continuing-generation students with at least one parent who completed a bachelor's degree (21\%) (Chen, 2005).

Striplin (1999) concluded Hispanic student high school preparation for college particularly lacking. Hispanic students scored lower on standardized college admission tests and required more remedial English and math courses than white students. Firstgeneration students disproportionately represented Hispanics (38\%) in attendance of traditional freshmen at four-year institutions in 2005 (Saenz, et al., 2007).

As summarized by Kuh, et al. (2006), a rigorous high school preparation and curriculum lowered the persistence gap between first-generation and continuinggeneration students (Nunez \& Cuccaro-Alamin, 1998; Warburton, et al., 2001), with an even stronger effect on students who graduated with a class rank in the top quartile of their high school. First-generation students with a rigorous high school preparation performed similarly in terms of college grades and occurrence of remedial coursework. In contrast, Lohfink and Paulsen (2005) found that neither high school coursework practices nor college entrance exam scores significantly related to second year persistence for continuing-generation or first-generation students. Most researchers, however, found test scores and rigors of high school courses to be significant predictors of second year retention (Bui, 2002; Ishitani, 2006; Kahn \& Nauta, 2001). Practitioners use standardized test scores, high school grade point average (GPA), and a measure of the rigors of the high school curriculum to grant admission and predict persistence and graduation. 
First-first-generation status as an independent variable proved to be a significant predictor of second year persistence even while controlling for factors such as academic preparation (i.e. those completing calculus, pre-calculus, or trigonometry in high school or earning high scores on achievement tests) (Chen, 2005). However, the combination of the factors created a higher risk student for attrition. Ishitani's (2006) findings described first-generation students as higher risk for departure than their counterparts with similar academic attributes (high school rank, high school academic intensity), and factors such as family income and parents' completion of any college coursework were significant contributors to the second year persistence of first-generation students. Pascarella \& Terenzini (2005) found that even after controlling for institution type, socioeconomic status, and enrollment patterns, first-first-generation status had a negative effect on completion of degree. Specifically "students whose parents held a bachelor's degree or higher were five times more likely to earn a bachelor's degree than were similar firstgeneration students" (p.590).

The institution used for this study does not offer remediation courses, however student tutoring services are made available with a particular focus on freshmen and high-risk students. Even with intervention efforts, academic preparation for college remains the greatest predictor of retention and graduation for first-generation students in the research setting (a small, private university in the Midwest). Arum and Roksa (2010) concluded that students with stronger high school academic preparation (measured by grade point average and Advanced Placement coursework) performed better on a standardized direct measure of learning (Collegiate Learning Assessment 90-minute 
writing exam) before freshman year, with the gap significantly increasing over the course of the freshman and sophomore year.

\section{Access and the college choice process.}

Another important aspect of precollege characteristics, the process of choosing a college, differed for first-generation students than continuing-generation students. The likelihood of attending any postsecondary institution strongly related to parents' education level, according to National Education Longitudinal Study (NELS) of 1988 and 1992 (Choy, 2001). For those first-generation college students enrolled in 1995-1996, more than half $(50.2 \%)$ started postsecondary education at a two-year college (NCES, 1999) for various reasons, three of which were that (a) their academic preparation was not competitive enough to gain admission to a four-year institution; (b) they could not afford the tuition costs at a four-year institution; and (c) they needed the flexibility of class schedules at a two-year institution to meet their other responsibilities as workers, spouses, and/or parents (Bui, 2002; Zwerling \& London, 1992). First-generation students as well as other students from the lowest income quartile have been shown to successfully transfer from two-year institutions to four-year institutions at lower rates than continuing-generation students, with roughly one of four students transferring (Bailey, Jenkins, \& Leinbach, 2005). First-generation students typically had not considered a four-year degree unless encouraged by faculty members, citing a lack of understanding of transfer credits as a barrier (Cejda \& Kaylor, 2001). They also doubted their own academic and motivational abilities and sometimes were discouraged by their own family, which impeded the transfer (Striplin, 1999). 
Even for high school graduates who planned to attend a four-year institution, parent education level remained a significant factor in actual enrollment (Choy, 2001). Of college-bound high school seniors with parents achieving a bachelor's degree or higher, $87 \%$ enrolled compared to $65 \%$ of first-generation students, who were twice as likely to change their plans and attend a two-year public institution. Since 1971, first-generation students who enrolled at four-year institutions have relied more heavily on the advice of high school guidance counselors and relatives in deciding to attend a particular institution. Continuing-generation students, by contrast, have considered more closely the academic reputation of the university, the likelihood of gaining access to graduate school, and the national ranking of the institution. Most recently in 2005, first-generation students reported preparation for graduate school as a very important reason for attending college, which was an encouraging development (Saenz, et al., 2007) and pertinent to the research problem of this study. In subsequent sections of this review of the literature, fewer first-generation students who completed a bachelor's degree attended graduate school (Choy, 2001; Nunez \& Cuccaro-Alamin, 1998) .

Compared to students with parents who completed a baccalaureate degree, firstgeneration students were less likely to attend a selective institution (Pascarella, et al., 2004) or a private institution (Choy, 2001). Pascarella et al. (2004) concluded from their literature review from the 1970 s to 2000 s that bachelor's degree completion was positively enhanced by institutional selectivity (Pascarella \& Terenzini, 1991, 2005). In terms of public or private institutions, first-generation traditional freshmen were slightly less likely to enroll in a private four-year institution in 2005 (53\% public vs. $47 \%$ private), according to Saenz et al. (2007); however, Ishitani (2006) found that first- 
generations retained better at private institutions ( $30 \%$ to $54 \%$ less likely to withdraw from their private institution in the second and third year respectively) and were twice as likely to graduate in four years from a private institution than a public. Furthermore, according to The Council of Independent Colleges (CIC), the six-year graduation rate of first-generation students at independent institutions was $61 \%$ compared to $44 \%$ at public institutions (Wilcox, 2008). At many small, private, four-year colleges and universities, first-generation students represented the largest group of high-risk students and often included the majority of their ethnic and lower income students (Ishitani, 2006; Saenz, et al., 2007). Thus many of private school leaders identified first-generation students as an important student group for growth in the number of overall undergraduate degrees conferred and for institutional effectiveness by successfully graduating more diverse and under-privileged students.

However, other researchers contradicted these findings. For instance, Lohfink and Paulsen (2005) found that private institutions negatively correlated with second year persistence for first-generation students, yet institution size positively correlated. Possible explanations included higher costs at private institutions, less diversity, and cocurricular programs aimed at traditional students without considering the work and family obligations, which many first-generation students must juggle. First-generation students more often commuted to the university rather than living on-campus, which contrasts with the environment of many private liberal arts institutions, enrolling as they do mostly residential full-time undergraduate students. More research needs to be conducted to better understand this phenomenon. Smaller private institutions typically offer more individual attention, with faculty members focused on teaching and student learning. 
Small schools attempt to create an environment which encourages high-risk students and leads to better retention and graduation rates. Additional research is needed to guide these efforts specifically with regard to first-generation students who cited (as discussed in subsequent sections of this review of the literature) less of a need for social integration, and more academic integration such as faculty encouragement in the first year, identified as critical to success. Presumably these experiences influence first-generation learning and satisfaction throughout the baccalaureate experience.

Although the overall number of first-generation students who enrolled at a fouryear institution was lower than that of continuing-generation peers, first-generation students who were admitted to the four-institutions enrolled at the same rate as other students (Choy, 2001). Problems with access therefore, existed for first-generation students, stemming from the process of preparing and applying to the four-year collegiate institution. Berkner and Chavez (1997) described a sequential process which led to enrollment: (a) students first decide to pursue a postsecondary education and the type of institution; (b) students prepared academically for college work; (c) students took the ACT or SAT standardized exam; (d) students applied to the institution; and (e) gained admission and made financial and other arrangements to attend.

Studies show that parents without a postsecondary experience lack the social and cultural capital to provide support during the process. First-generation students therefore struggle with "navigating the higher education landscape" due to lack of access to "financial, informational, and social networks" (Saenz, et al., 2007, p. 3). Continuinggeneration students, on the other hand, have greater social and cultural capital from "family relationships and social networks" (Pascarella, et al., 2004, p. 252). Vargas 
(2004) found that first-generation students' parents often fail to make the enrollment process a priority for their children, in terms of the necessary preparation for standardized tests and completing the applications to appropriate institutions. The reasons typically stem from a failure to understand the process, and/or to make associations between career goals and educational requirements. Choy (2001) found first-generation families less frequently attend planning activities such as financial aid seminars and college visits. African American and Hispanic families, especially those with low income, overestimate the tuition costs, while underestimating the availability of financial aid (Tym, McMillion, Barone, \& Webster, 2004). Choy (2001) also found students whose parents had not attended college receive no additional help and guidance from their high school. Firstgeneration students cite cost-related reasons such as receiving financial aid, location (ability to live at home and commute) and work opportunities (either on-campus or offcampus) as key factors in choosing an institution (Nunez \& Cuccaro-Alamin, 1998).

For first-generation high school graduates interested in attending a four-year institution, additional research is needed to better understand how to recruit and enroll a greater percentage directly into four-year institutions, especially because many of these students are not successful in transferring from the two-year to the four-year institution. This research question was outside the dissertation, but it remains an important consideration. The first-generation students studied at this small, private university, had already overcome many obstacles by matriculating and persisting for four years. The purpose of a single institution study of first-generation students is to better understand the student experience, which then could inform faculty member and administrator decisionmaking to promote and foster a stronger learning environment. Single institution studies 
help practitioners make campus-level decisions in ways which national surveys and dataset studies cannot.

\section{Expectations of college.}

A final important aspect of precollege characteristics, expectations of college also affects the success of first-generation students. Parents of first-generation students often discourage their children from attending college and these students therefore describe themselves as having doubts as to whether they consider themselves "college material" (Striplin, 1999). First-generation students face "conflicting obligations" of study time and family duties, as family members do not understand the rewards of a college degree (Hsiao, 1992). Fortunately, over the past two decades, parental encouragement has increased dramatically as reported by first-generation college students. In the $2005 \mathrm{CIRP}$ (Cooperative Institute Research Program) survey (administered to incoming freshmen before the beginning of their four-year experience), first-generation students reported more often than continuing-generation students that parental encouragement was the reason for attending college (Saenz, et al., 2007). Surveys conducted by the U.S. Department of Education concluded that nine of ten parents, regardless of race (white, black, or Hispanic) or education level, expected their children to attend college. While parental encouragement changed over time, first-generation students continued to report considerable time spent with family obligations and working for pay to support college costs. Furthermore, even if encouraged by their parents to attend college, first-generation students typically have lacked the same "values, beliefs and expectations" to easily achieve status congruence with the college culture (Somers, Woodhouse, \& Cofer, 2004, p. 429 ). First-generation students thus have reported academic and social integration as 
more difficult, part of the reason for their attrition risk (Elkins, Braxton, \& James, 2000; Tinto, 1993). In terms of leadership measures from the CIRP, only a slight disparity exists in the social self-confidence; however, the difference is consistently larger for the self-rating of leadership ability, with first-generation students rating themselves lower (Saenz, et al., 2007).

Choy (2001) found that educational expectations varied as early as the $8^{\text {th }}$ grade in the NELS 1992 survey. Students typically formalized their education plans between the $8^{\text {th }}$ and $10^{\text {th }}$ grade, so intervention strategies must take place early in high school. Firstgeneration students compared unfavorably to students with at least one parent completing a bachelor's degree (55\% planned to attend college versus $91 \%$ ); similarly, $25 \%$ of firstgeneration students planned to take the ACT or SAT, compared to $73 \%$ of continuinggeneration students (Hossler, 1999).

First-generation students also reported lower degree aspirations and expected to need additional time to complete their degrees; however they showed more confidence in their initial choice of major (Terenzini, et al., 1996). Lohfink and Paulsen (2005) found that education aspirations influenced second year persistence for both first-generation and continuing-generation students, with first-generation students having lower education aspirations (Terenzini, et al., 1996). McCarthy and Kuh (2006) concluded that firstgeneration students whose father completed a bachelor's degree were three times more likely to cite completing a college degree as an educational goal than other firstgeneration students. If the students' mothers completed a bachelor's degree, the completion rate was twice as likely. Parental education level significantly predicted college predisposition among all students from low-income families (Hamrick \& Stage, 
2004). The "strength" of the relationship, however, differed by students' gender and race. For example, white students whose parents completed a bachelor's degree or higher found a significantly positive influence from their parents' expectation of college and grades, which created positive college aspirations in the students. Hispanic males' parent education level, by contrast, affected the students' predisposition to attend college only indirectly (Kuh, et al., 2006).

Researchers extensively examined students' reasons for pursuing a four-year degree in higher education. First-generation college students more likely reported pursuing postsecondary education to help their family out financially after they completed college, and worrying about financial aid for college, compared to students whose parents had some college experience with no degree and students whose parents had at least a bachelor's degree (Bui, 2002; Ishitani, 2006; Kuh, et al., 2008; Lohfink \& Paulsen, 2005; Terenzini, et al., 1996).

Given that family background has proven to be an important factor in college decision-making by first-generation students, faculty members and administrators at private, four-year colleges interested in recruiting and retaining these students need to work with high school students and guidance counselors as early as the sophomore year of high school. For those first-generation students planning to attend a four-year institution, a clear message must be sent. The best chance of success is to enroll in the most rigorous high school courses, prepare thoroughly for the ACT/SAT, and then work closely with the high school guidance department and university admission office to understand the application process and transition to college. This process may provide enough financial aid to allow first-generation students to begin at four-year institutions as 
traditional full-time freshmen, which would optimize their chances of success (for those first-generation students aspiring to complete a bachelor's degree).

\section{Environmental experiences of first-generation students.}

Because of unique precollege characteristics, first-generation students reported a different collegiate experience than continuing-generation students (Pascarella, et al., 2004; Terenzini, et al., 1996). The literature suggested that practitioners need to provide campus support services directly to first-generation students to address their unique challenges and concerns. The unique characteristics of first-generation students led to lower college persistence rates than the general student population and these students therefore are less likely to ultimately complete a bachelor's degree (Choy, 2001; Ishitani, 2006; Nunez \& Cuccaro-Alamin, 1998; Thayer, 2000).

University faculty members and administrators have focused their intervention and support efforts of first-generation students in the following time periods: the firstyear experience (transition from high school to postsecondary education); the secondyear experience; declaring a major; and the upperclassman experience. School leaders determined that "what colleges do" for students in the $21^{\text {st }}$ century is essential in developing an environment which fosters student engagement both inside and outside of the classroom. Practitioners have addressed this optimal learning environment by using high impact practices such as freshman seminars, learning communities, writingintensive courses, research with a faculty member, service learning, study abroad, internships and a senior capstone course and/or project (AAC\&U, 2007). While measures of engagement for first-generation students showed these students to be less involved in traditional cocurricular activities, high impact practices such as freshman seminars 
proved to be more important to first-generation students than continuing-generation students in terms of academic performance, retention, and graduation (Kinzie, et al., 2008). More research is needed to determine how these institutional efforts influence direct measures of student learning and satisfaction of first-generation students.

\section{The first-year experience.}

The importance of the first-year experience and how it influences second year retention rates stemmed from Pascarella's (2005) research, which concluded that fouryear universities lose a majority of their traditional freshmen in the first six weeks of the beginning fall semester. An additional majority of students not lost in the first six weeks typically dropped out or stopped out in the first four semesters (Thayer, 2000). Academically, student growth and development in critical thinking skills occurred primarily in the first year of college. There was no improvement in these skills after the first year (Pascarella \& Terenzini, 2005). Adelman (2006) found that students with less than a 2.25 GPA ( 4.0 scale) and fewer than 20 credit hours completed in the first year had a slim chance of degree completion, regardless of demographic characteristics such as first-first-generation status. Adelman additionally found that "continuous enrollment increases the probability of degree completion by 43\%" (p. 74), meaning that a stop out in the freshman year most likely led to attrition.

Tinto (1993) concluded that the institutional focus should be on the first-year student experience because the majority of institutional attrition occurs during the first year and prior to second year. Tinto (1998) recommended that institutions develop academic learning communities, which could serve as supportive units in what should be a school's multi-faceted retention effort. Tinto reported a first year attrition rate of $26.8 \%$ 
in four-year institutions in 1993 and suggested that student departure was a direct outcome of lack of integration into the academic and social communities of the college or university. Greater social and academic integration led to increased commitment to education goals and the institution, which, in turn, led to lower attrition (Beil, Reisen, Zea, \& Caplan, 1999).

Tinto (1993) concluded from Dutch anthropologist Arnold Van Gennep that the change of individuals from one group to another took place in three separate stages (model of college student departure): separation; transition; and incorporation. The separation stage, typically in the first semester, was affected by parent education level. Students achieved status congruency and successfully integrated into new groups often by their willingness to reject past attitudes and values and fully commit to the new institution. Support of past communities such as their parent and family life was shown to be significantly important in students successfully transitioning past the separation phase. Thus first-generation students often failed to achieve status congruence because they lacked the family support and the confidence that they belonged in the new academic community (Elkins, et al., 2000; Longwell-Grice \& Longwell-Grice, 2008; Tinto, 1993). Leaving the familiar unit and safety of the immediate family was reported as an additional barrier for first-generation students transitioning past the separation stage. Living at home and commuting to a local institution impeded the social integration process, which was more successful for residential students immersed in the new college culture. First-generation students who lived on-campus were retained at higher percentages in the first year and reported greater learning gains (Pike \& Kuh, 2005; Somers, et al., 2004). Similarly, students who worked a moderate number of hours on- 
campus made greater learning gains in the first two years of college; working more than 15 hours a week, whether on or off-campus, negatively associated with student learning (Arum \& Roksa, 2010).

Chen (2005) demonstrated a relationship between first-year success and overall success in college for first-generation students. The study found that higher grades earned in the first year, with fewer withdrawn or repeated courses, strongly associated with retention and degree completion. Terenzini et al. (1996) discovered significant differences in the first-year experience of first-generation students compared to continuing-generation students, even after controlling for other precollege characteristics. First-generation students completed fewer credit hours in their freshman year, enrolled in fewer art and humanities courses and studied fewer hours per week. First-generation students also received less feedback from instructors. Fewer first-generation students participated in honors programs. Terenzini et al. also found that first-generation students worked more hours off-campus for pay, participated less frequently in diversity workshops and more frequently reported incidents of discrimination. These large scale conclusions shaped national policy regarding the first-year experience of first-generation students; however, because of the unique student experience at each institution, a single institution study is needed to comprehensively explore the four-year experience of firstgeneration students at a small independent institution.

Muraskin (1998) noted the following elements which typically led to a successful first-year experience for at-risk students: strong participation in the admission and course selection processes; an intrusive advising and tutoring system with extended service hours; and a powerful message of success. 


\section{The concepts of involvement, engagement, social and academic integration.}

The following brief discussion of the research history and current definitions of involvement, engagement, social and academic integration, frames the discussion of firstgeneration college student experience. Four periods of research helped predict and enhance an understanding of the institution's and student's role in student success. Alexander Astin first designed an instrument to study incoming freshman personality and behavioral characteristics, CIRP at the University of California Los Angeles in 1968. Swing (2008, November) defined this first phase as the study of "who students are," which focused on the inputs of Astin's model. The second phase began in the 1970s, studying the external influences on college students, such as middle class U.S. families' ability to pay school tuition. The period researched how college costs impacted at highrisk students for attrition, such as first-generation, low-income, and ethnic minority students. Swing defined the third period as a focus on "what students do," which began a national trend towards the study of student engagement, primarily through the NSSE instrument. First participants completed the NSSE in the year 2002. The final and current phase of research of student persistence is what Swing called "what institutions do," with universities and colleges using data to strategically target students and offer programs and services to provide students with a better chance of persistence and graduation. These interventions primarily focused on freshmen enrolled in four-year institutions, commonly known as the first-year experience. Institutions began to take greater responsibility for the decisions their students made.

Kuh originated the concept of student engagement, defined as institutions and students involved in a reciprocal relationship for student success. Efforts to foster student 
engagement focus on all students, but particularly those at high-risk for attrition, such as first-generation students. More engaged students typically retain and graduate from the institution at a higher rate, learn more, and report a better overall experience (Kinzie, et al., 2008; Kuh, 2001, 2003a; Kuh, et al., 2006; Kuh, et al., 2005b).

Practitioners often use the concepts of student engagement, integration, and involvement interchangeably; however, these concepts developed over time from top researchers in the field with important distinctions (Wolf-Wendel, et al., 2009). From his previous work in the 1970s, Astin (1984) formally defined student involvement as the amount of physical and psychological energy a student devotes to his or her academic experience. The concept of involvement included both academic and cocurricular activities, with the latter becoming the focus of much additional research. Astin hypothesized that the more involved students are, the better their chances are for success. The concept of engagement built upon this research by measuring student involvement (Astin, 1984), the quality of the student effort (Pace, 1980), and indicators of good practice at the institution (Chickering \& Gamson, 1987). Engagement, in contrast to involvement, includes both the student participation measures as well as how institutions of higher education allocate resources to encourage students to participate and benefit (Kuh, 2001). NSSE attempts to measure this dynamic for continuous institutional improvement in fostering student learning and success.

Integration, another important concept that plays a key role in understanding student success was defined as the extent to which students share attitudes and beliefs with peers, faculty, and staff members. The concepts described by researchers as culture of the institution, measures by whether students adhere to the structural rules and 
requirements (Pascarella \& Terenzini, 1991; Wolf-Wendel, et al., 2009). Tinto (1993) used the concepts of social and academic integration to explain student withdrawals from the undergraduate experience and then developed a model to help practitioners with their intervention efforts. Similar to the concept of engagement, integration sheds light on both the institution and student role in retention efforts, with the latter focusing on sociology and cultural norms (Wolf-Wendel, et al., 2009).

Wolf-Wendel, et al. (2009) summarized Tinto's (1993) work on social and academic integration. Tinto concluded that the institutional focus should be on the firstyear student experience because the majority of institutional attrition occurs during the first year and prior to second year. He reported a first year attrition rate of $26.8 \%$ in fouryear institutions in 1993 and suggested that student departure is a direct outcome of lack of integration into the academic and social communities of the college or university, especially among high-risk students such as first-generation college students. Greater social and academic integration led to greater commitment to education goals and the institution, which, in turn, led to lower attrition. Tinto defined academic integration as a "full range of individual experiences which occurred in the formal and informal domains of the academic systems of the university" and social integration as the "formal and informal interactions" that students experienced at the university (p. 118). Tinto defined the concept of integration simply as a sense of belonging. Campus relationships are the foundation of both academic and social integration. As discussed later in this literature review, researchers found academic integration to be more important to first-generation students and thus their relationships with faculty members critical to their overall success. 
Practitioners often used the three terms (student engagement, integration, and involvement) interchangeably, but as stated earlier, important distinctions exist. Because of the unique precollege characteristics of first-generation students, the college environment presents a challenge in all three dimensions. Pike and Kuh (2005) found first-generation students generally less engaged overall than continuing-generation students, because they may not realize the importance of co-curricular activities or how to become involved. Because first-generation students cite academic integration as more important to their experience and success than social integration, more research is needed to determine how both academic and social integration influence learning and satisfaction.

For purposes of this research, first-generation student engagement will be measured using dimensions from all three concepts with the NSSE. By focusing key constructs such as the quality of campus relationships (with faculty members, administrative personnel and offices, and other students), student-faculty interaction, and active and collaborative learning, assessments can be made in terms of the quality of the academic and nonacademic experiences over a four year period. Engagement measures will be evaluated by overall satisfaction with the institution as well as directly measuring student learning through the Educational Testing Service (ETS) general education exam, Measure of Academic Proficiency and Progress (MAPP).

\section{Transition from high school to postsecondary education.}

As summarized by Terenzini (1996), first-generation students experience all the same "anxieties, dislocations, and difficulties of any college student," but feel conflicted between roles and obligations within their family and educational mobility (p. 2). As 
quoted by Tym, et al. (2004) from previous research (Schmidt, 2003), Mr. Arciniega, President of California State University at Bakersfield said "the biggest challenge that these kids have to face is, how do they balance what they see as their responsibility to help out at home now that they are young adults and, at the same time, follow their dream of going on to college" (p. 12). Thayer (2000) concluded that first-generation students are less likely to receive various forms of support from their families in attending a college or university, regardless of whether the parents encouraged them to attend. First-generation students described feelings of anguish and confusion as they grappled with this conflict, as well as a more difficult social and academic transition than their peers.

Social and cultural capital provided researchers with the basic understanding of the relationship between parent education level and academic student success. Lack of capital undermined first-generation students decision to attend a more selective college or a four-year institution, as well as decision-making in critical areas such as academic coursework, cocurricular, and extracurricular choices in the first year (Saenz, et al., 2007).

First-generation students reported similar levels of academic integration compared to continuing-generation students at four-year institutions, as determined by responses to questions regarding whether they attended career-related events, met with academic advisors, or participated in study groups. First-generation students, however, reported lower levels of social integration as measured by whether they attended events with friends from the institution or whether they participated in university clubs or organizations. Lower social integration occurred for first-generation students at both twoyear and four-year institutions (Nunez \& Cuccaro-Alamin, 1998). Because of less overall 
engagement of first-generation students, Pike and Kuh (2005) concluded that firstgeneration students self-report less learning and intellectual development, and the perception of the college environment as less supportive. The researchers presented these conclusions as a direct result of not living on-campus and having lower educational aspirations; however, these conclusions were only indirectly related to first-firstgeneration status. In other words, the results were less related to precollege characteristics (first-first-generation status) and more influenced by what the students do during college. Because first-generation students were generally less engaged in the overall college experience, the quality of the learning experience may have been influenced. The purpose of this study is to assess these findings with direct measures of student learning, rather than student self-reporting; however, this research will still focus on the key influences of student learning: living on-campus; diverse experiences; and student perceptions of support of the college environment (Pike \& Kuh, 2005).

Minority first-generation students attending an institution where the majority of students are racially, ethnically, or religiously different than their own, experience a different list of adjustment challenges. First-generation students raised in middle income families report fewer problems adjusting to college than first-generation students from ethnic minority or low-income backgrounds (Thayer, 2000).

As summarized by Kuh, et al. (2006) from previous research of students' overall college experience (Nunez \& Cuccaro-Alamin, 1998; Terenzini, et al., 1996; Thayer, 2000; Warburton, et al., 2001), first-generation students typically had less developed time management skills, less general family support for attending a postsecondary institution, less understanding of college finances and how to budget, and less understanding of 
university life in general and how to succeed there. Thus first-generation students dropped out or stopped out of college more frequently than continuing-generation students, particularly during the first year of college.

A better understanding of how to ease the transition from high school to college is essential in providing first-generation students an opportunity to succeed. This study focuses on an institution offering a freshman experience with both a freshmen seminar and a peer-mentoring program for first-generation students. The federally-funded studies on first-generation students concluded these programs are essential and more meaningful to high-risk students such as first-generation students. In a small private institutional setting, however, some school leaders are "wary of singling out students and perhaps reinforcing their doubts" (Lipka, 2010, p. 2). The purpose of this study is to understand if current interventions are effective in fostering a more supportive environment for learning and satisfaction.

\section{Interventions: educationally purposeful activities and high impact practices.}

In terms of measuring academic and social integration and, in a broader context, student engagement, many institutions use the NSSE, an instrument administered in the spring of freshman and senior undergraduate years to evaluate the overall education experience. Strong academic and social engagement is typically correlated with strong retention and graduation numbers. Conditions which foster student learning and development include frequent interactions both in and outside of the classroom between students, faculty, and staff members as well as between students and other students (Pascarella \& Terenzini, 2005). Researchers assessing NSSE results as well as influencing factors such as student demographic characteristics (race, ethnicity, first-first- 
generation status, etc.), precollege experiences and prior academic achievement (ACT score and high school grades), concluded that when students participated in educationally purposeful activities in the first year of college, the effects of demographics, precollege experiences and prior academic achievement were greatly diminished. Furthermore, the influence of parents' education level essentially "disappeared." Practitioners therefore considered the influence of educationally purposeful activities "compensatory" for highrisk students; that is, more influential for first-generation students than continuinggeneration students (Kuh, et al., 2008, p. 555) because high-risk students needed more affirmations that they were capable of doing college level work.

Schilling and Schilling (1999) studied cross sectional comparisons of economies of time of first-year and fourth-year students. Research has shown that time on task equals student learning. Therefore how students spend their time is critical to retention and degree completion. Schilling and Schilling found that the economies of time did not change between the first and fourth years of undergraduate study; students exchanged time within segments, rather than across segments. For example, if a student engaged in an educationally purposeful activity such as community service in the freshman year, the student may have changed to a different purposeful activity, but typically did not replace it with something else such as partying or sleeping. Therefore, establishing freshman programs where students spend their time in meaningful experiences, leads to persistence, degree completion, and fosters stronger campus relationships. These research findings hold true for both continuing-generation and first-generation students.

Institutions reported the greatest improvements in retention resulted from focusing on the admission selection process and an environment which fosters quality 
interactions after enrolling (Thayer, 2000). Most institutions reported an attempt to offer an educationally purposeful activity (Kinzie, et al., 2008) in the first year to encourage social and academic integration, which ultimately influences second year retention and degree completion rates. Such interventions include a first-year seminar, where students meet weekly in a small group setting with their freshman advisor. Many institutions also clustered their freshmen seminar, creating learning communities where faculty, staff, and peers remain together during the freshman year (Thayer, 2000). These efforts, described as high impact practices, enhance the student experience in and outside of the classroom and create an environment to foster optimal student learning. Other practices recommended by the Association of American Colleges and Universities (AAC\&U) (2007) for institutions to offer during the four-year experience include writing-intensive courses, research with a faculty member, service learning, study abroad, internships, and the senior capstone experience. These practices, particularly important for firstgeneration and other high-risk students, encourage engagement, student learning, retention, and degree completion. Additional practices include well-designed orientation, placement testing, intrusive advising, early warning systems, redundant safety nets, supplemental instruction, peer tutoring and mentoring, theme-based campus housing, adequate financial aid including on-campus work, service learning, and demonstrably effective teaching practices (Kuh, et al., 2005a).

Institutional leaders understand that effort alone to create such programs provide no guarantee of increased student retention. Each institution's unique culture and student needs must be considered to customize the actions to fit the mission of the institution (Kuh, et al., 2005a). Institutions effectively create a "interconnected learning support 
networks, early warning systems, and safety nets" for high-risk students such as firstgeneration (p. 25).

Therefore the uniqueness of each institution justifies the need for a dissertation study which focuses on a single institution. The uniqueness of small, private institutions make conclusions from national research of first-generation students difficult to generalize. Results from this dissertation may strengthen practitioner decision-making in small, private, four-year institutions to not only plan better retention efforts, but to create environments for improved student learning and satisfaction. Leaders from small independent schools are beginning to understand the attrition risk of first-generation students in their first year of college and the need to successfully focus their efforts on continuous enrollment through educationally meaningful programs and interventions. However, practitioners have a limited understanding of the overall experience of firstgeneration students in terms of learning and satisfaction. The quality of the learning experience both inside and outside of the classroom measures institutional effectiveness. Graduating more first-generation students from four-year institutions does not necessarily indicate the same quality experience as continuing-generation students.

\section{Declaring a major, the second year and the upperclassman experience.}

Pascarella et al. (2004) found that first-generation students experienced college differently than continuing-generations students, especially those with parents who completed a bachelor's degree or higher. This difference held true not only in the first year as previously described, but also in both the second and third years. First-generation students earned significantly fewer credit hours, while working more hours for pay either on-campus or off-campus in the second year. First-generation students lived off-campus 
more frequently and involved themselves in fewer extracurricular activities such as athletics or volunteerism in the second year. During the third year, first-generation students also typically lived off-campus and reported greater work responsibilities. Nonresident status most likely led to less engagement in nonacademic activities, as well as significantly fewer nonacademic interactions with peers during the third year. Firstgeneration students completed fewer credit hours even after the third-year, especially in areas such as arts and humanities, and social studies coursework. In a comparison of grade point averages after the third-year, first-generation students earned significantly lower grades than continuing-generation peers, even after controlling for precollege cognitive development, secondary school grades, and academic motivation. For purposes of this research, practitioners need to compare the quality of the entire four-year experience in terms of learning and satisfaction to continuing-generation students at the same institution.

Chen (2005) found that choosing an undergraduate major or field of study posed "a greater challenge" for first-generation students than continuing-generation students with at least one parent completing a baccalaureate degree. Approximately one of three first-generation students declared undecided as the primary major at the beginning of their postsecondary experience, compared with $13 \%$ of continuing-generation students. The first-generation students who declared a major, chose vocational or technical fields more frequently, compared with continuing-generation students who declared a field in science, mathematics, engineering, architecture, humanities, arts, or social sciences. Chen concluded that many factors influenced this variance such as insufficient academic 
preparation which may deter first-generation from math and science, and perceived lowearning potential, which may deter them from humanities, arts, and social sciences.

Kuh et al., (2008) used the NSSE survey to demonstrate an important relationship between student engagement and persistence of first-generation students. A research need exists however, to explore the relationships between first-generation students and faculty members especially in the second, third, and fourth years. These relationships are especially important because previous research found that first-generation students need validation from faculty members that they are capable of college level work (Lohfink \& Paulsen, 2005) and that much academic engagement takes place within the academic department in the sophomore, junior, and senior years. Faculty members may foster quality interactions with student peers in the classroom; in fact, faculty organization and preparation for class are associated with higher gains and cognitive development (Pascarella, 2006). This is a key relationship because of the student's respect established by the faculty member's ability to organize and lead the class.

Relationships between students and their peers also have proven to be vital to persistence. According to Astin (1993), a student's peer group has the most influence on growth and development in the undergraduate years. Furthermore, student relationships in the classroom with other students influences learning; Winston and Zimmerman (2003) stated that peer effects are significant in their influence on how much students learn. For example, undergraduate students with academically strong lab partners perform better academically than their SAT scores predicted. However, Arum and Roksa (2010) found studying alone positively correlated with student learning, while studying in groups 
or spending time in fraternities and sororities negatively associated with student learning in the first two years of college.

Private, four-year, small colleges already have a strong campus culture and are uniquely positioned to offer peer group experiences for first-generation students that could lead to increased rates of persistence and graduation; however, more research is needed to understand the single institution context. The quality of relationships with faculty members, other students, and administrators could be the key to the overall quality of the small school experience, fostering a caring, learning environment for firstgeneration students to succeed. Typically undergraduate students at small private institutions experience more frequent faculty interactions because of lower student-tofaculty ratios, a product of smaller student enrollment (Kim \& Sax, 2009) .

Academic engagement during undergraduate experience changes after the first year of college. In the first year, efforts toward engagement and retention focus on the entire freshman class, typically in the general education curriculum. In the second year, most students have declared a major, and engagement typically takes place within the academic department. Academic clubs, research with a faculty member, and community service within the major provide opportunities for students to embrace their education beyond the typical coursework of papers, exams, and class presentations.

Brint, Cantwell, and Hanneman (2008) found two distinct cultures in the upper division undergraduate experience, where engagement varies by discipline. Students who study humanities and social sciences focus on interaction with peers and faculty members, participation in class, and an interest in sharing creative ideas over and above the required work. Students in the natural sciences and engineering, on the other hand, 
focus on proficiency of quantitative and technical skills by collaborating with peers, on the job market after graduation, and concern themselves with less effort towards creativity. Arum and Roksa (2010) concluded that students majoring in math, science, social sciences, and humanities made significantly stronger gains in the first two years of college (measured by the Collegiate Learning Assessment) than those students majoring in education, human services, and business.

Although engagement varies across discipline, the key to overall student success in later undergraduate years may be in the quality of relationships with faculty members, regardless of institution type or the attrition risk factors associated with each student. Much research associates quality student-faculty interactions with a broad range of positive student outcomes (Astin, 1993; Kuh, et al., 2006; Pascarella \& Terenzini, 2005). First-generation students have reported feelings of intimidation with regard to seeking out faculty members for support, which ultimately results in less institutional support and lower retention (Longwell-Grice \& Longwell-Grice, 2008; Tinto, 1993). Kim and Sax (2009) concluded that first-generation students are also positively influenced by these relationships with some slight differences from their continuing-generation student counterparts. More continuing-generation students complete research projects with faculty members, communicate via email and interact during lecture class sessions. Continuing-generation students also were more satisfied with faculty advising and access to faculty members outside of class. However, the positive influence of student-faculty research experience on college GPA, degree aspirations, and gains in critical thinking and communication are equally strong for both first-generation and continuing-generation college students. Also significant for both student groups, course-related faculty 
interactions predict aspirations to earn advanced degrees, predict making larger gains in critical thinking and communication skills, and predict satisfaction with the overall college experience. In most cases, the effects of student-faculty interaction were significant and positive for both first and continuing-generation students. There is no statistical difference in the effects of student-faculty interaction on educational outcomes between the two student subgroups, with the exception of college GPA. For students whose parents attended college, course-related student-faculty interactions have a positive relationship with college GPA; however, this is not the case for students whose parents did not attend college. Overall, faculty expectation strongly associate with improvements and gains in student learning during the first two years of college (Arum \& Roksa, 2010).

To summarize environmental experiences of first-generation students, researchers found that academic integration in the first year effectively reduced the attrition risk factors to similar levels as that of continuing-generation students. Examples of educationally purposeful experiences in the first year include freshman seminar classes, a peer-mentor tutoring programs, and volunteer service projects. Because first-generation students cite social integration as less important, satisfaction and learning in the remaining undergraduate years may be predicated on their relationships with faculty members and students within the academic department. Further research is needed to better understand the overall four-year experience of first-generation students.

\section{College outcomes of the first-generation students.}

As summarized by Terenzini et al. (1996) and Pascarella et al. (2004), researchers intensively studied college outcomes of first-generation students during the 1980s and 
1990 s, such as their persistence in postsecondary education and degree attainment, as well as early career labor market outcomes and graduation school placement rates (Billson \& Terry, 1982; Choy, 2001; Nunez \& Cuccaro-Alamin, 1998; Warburton, et al., 2001). Surprisingly, these researchers infrequently investigated the college experience of first-generation students in terms of cognitive and psychosocial development. As stated previously, first-generation students withdraw more often at the end of the first year (at four-year institutions), are less likely to be on track after three years, and are less likely to stay enrolled or attain a bachelor's degree after five years. After degree completion, no significant differences existed in the early career earnings or job placement rates for firstgeneration students. First-generation students, however, enroll less frequently in a graduate or first professional program.

Terenzini et al. (1996) and Pascarella et al. (2004) researched the experience of first-generation students in college and the student learning outcomes associated with the postsecondary experience. Terenzini et al. studied the first-year experience and Pascarella et al. researched learning outcomes at the end of the second and third year. A limited amount of research literature existed with regard to the four-year experience of firstgeneration students comparing engagement, satisfaction, and learning to continuinggeneration students.

\section{Persistence, degree attainment, and learning measures.}

While career placement programs may be helpful to first-generation student outcomes in the final years of college, most research concluded that interventions correlate with graduation status during the beginning two years of the undergraduate experience. After students enter their third year of college, the majority of them already 
know how to navigate the system and understand what it takes to graduate. At four-year universities and colleges, researchers found first-generation students twice as likely as continuing-generation students to leave before their second year ( 23 vs. 10 percent), even after controlling for variables such as delaying enrollment after high school, working fulltime, social economic status, gender, and race/ethnicity (Chen, 2005; Choy, 2001; Nunez \& Cuccaro-Alamin, 1998). The amount of grant aid influences first-generation student persistence in the second year, but did not statistically influence continuing-generations students (Lohfink \& Paulsen, 2005). First-generation students withdraw more frequently because of accumulated debt from student loans, particularly problematic with the shift in the American financial aid model away from need-based grant aid to merit-based aid and loans (Somers, et al., 2004). When researchers broadened the degree attainment measure to include second year persistence, no difference exists between first-generation students and their peers (Chen, 2005). In summary, first-generations who persists into the second year at four-year institutions graduate at similar rates as the generation student population and gain similar employment opportunities (Nunez \& Cuccaro-Alamin, 1998).

Because first-generation bachelor degree completers gain similar employment success, merely retaining these high-risk students in the first year has become the focus of many undergraduate institutions attempting to increase the number of graduates (Kahn \& Nauta, 2001). Approximately half of $12^{\text {th }}$ graders who enrolled at a four-year institution in 1992 completed a bachelor's degree by the year 2000. In comparison, only $24 \%$ of first-generation students completed a bachelor's degree in the same time period (Chen, 2005). 
Researchers have focused on retention extensively. Lohfink and Paulsen (2005) found that $76.5 \%$ of first-generation students persisted at the same institution from the first to the second year, while $82.2 \%$ of continuing-generation students persisted. The authors arrived at some important conclusions regarding first-generation student persistence in the second year. For instance, $9.4 \%$ more males persisted than females and Hispanic students were $35.4 \%$ less likely than white students to persist. Each $\$ 10,000$ increase in family income was associated with a $2.0 \%$ increase in the probability of persistence. Students who expected to complete more than a bachelor's degree were $7.3 \%$ more likely to persist than those who expected to complete a bachelor's degree or less. Students who attended private higher education institutions were $12.3 \%$ less likely to persist from the first to the second year than those attending public institutions. For every 10,000 unit increase in enrollment size, first-generation students were $4.1 \%$ more likely to persist. For every one unit increase in GPA (on a four point scale), first-generation students were $12.8 \%$ more likely to persist from the first to the second year. Firstgeneration students who were satisfied with their social lives were $16.7 \%$ more likely to persist than those who were not satisfied. Finally, the research revealed that each $\$ 1,000$ increase in grant aid was associated with a $2.7 \%$ increase in the probability of persistence from the first to the second year. And for each $\$ 1,000$ increase in work-study aid, firstgeneration students were $6.4 \%$ more likely to persist.

In terms of measures of student learning, Pascarella et al. (2004) found that firstgeneration students reported a different experience in college; but that these experiences failed to translate into substantial differences in direct measures of learning outcomes. Only in "isolated" areas with an "inconsistent direction of the effects" did first-generation 
students vary (p. 265). The study revealed the most variance between first-generation students and continuing-generation students with both parents holding a baccalaureate degree. Pascarella et al. additionally found that no significant differences existed in second-year writing skills or third-year reading comprehension or critical thinking scores; however, a small difference existed in second-year science reasoning, a difference reduced to nonsignificant when the researchers accounted for the various college experiences. In a study of the first year of college, Terenzini et al. (1996) found that firstgeneration students differed from continuing-generation students in both precollege characteristics and colleges experiences; no significant differences existed in direct measures of student learning gains in math or critical thinking, but continuing-generation students made greater gains in reading only. In contrast, Pike and Kuh (2005) found that first-generation students in the first year of college self-report less learning and intellectual development. Consistent with the Terenzini (1996) findings, first-generations students perceived the college environment as less supportive and were generally less engaged. Pike and Kuh additionally concluded that "what students do" in college had similar effects regardless of first-first-generation status, in contrast to Terenzini's (1996) findings (p. 289). More specifically, Pike and Kuh found that less learning and intellectual development was a direct result of not living on-campus and having lower educational aspirations, and only indirectly related to first-first-generation status. Thus, results were less related to precollege characteristics (first-first-generation status) and more influenced by "what students do" during college (p. 289). The critical factors which influenced learning were the reported frequency of diverse experiences and the perceptions of the college environment. 
Arum and Roksa (2010) found similar results in a longitudinal study of 2,300 four-year college students from 24 private and public institutions. The research tracked a cohort at the beginning of the freshman year in 2005, tested again in 2007 at the end of the sophomore year. The instrument used as a direct measure of learning was the Collegiate Learning Assessment (CLA), a 90-minute writing task-based exam, which provides standardized scores in critical thinking, analytical reasoning, problem solving, and written communication. Figure 2.1, demonstrates that first-generation students started with lower CLA scores and gained less over the first two years than students with parents holding a graduate or professional degree (after controlling for aptitude with ACT or SAT scores). However, high school preparation and college experiences accounted for $40 \%$ of the gap; when removed, first-first-generation status was no longer statistically significant.

Arum and Roska (2010) plan to release senior scores from 2009 in a later publication. A research need exists for these additional direct measures of learning at the senior level, to assess student learning closer to completion of the baccalaureate degree. Furthermore, many studies use students' self reported gains in learning and cognitive development from instruments like NSSE (Pike \& Kuh, 2005), rather than direct measures of learning such as the ETS MAPP in conjunction with NSSE. 


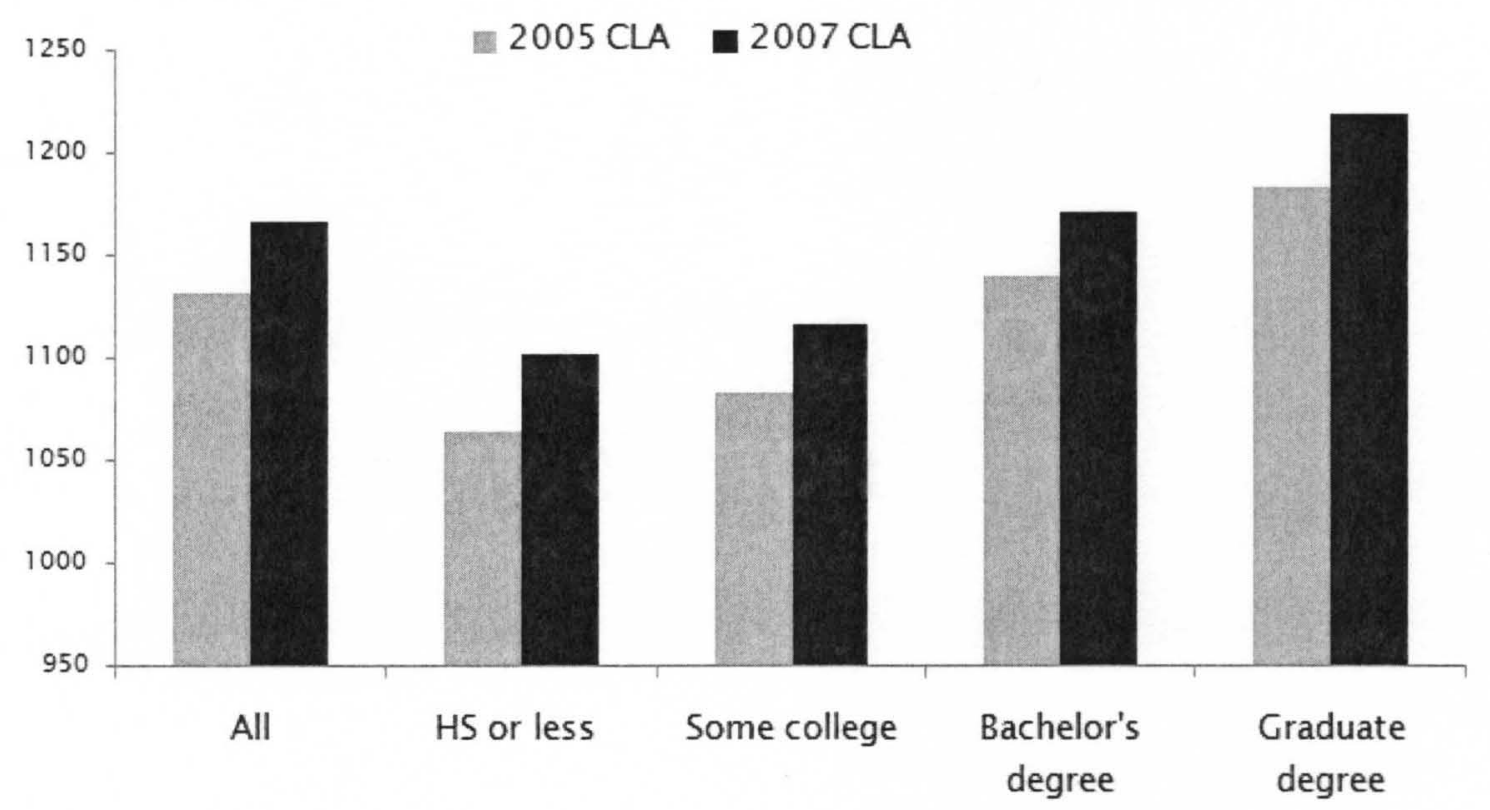

Figure 2.1. Arum and Roska (2010) based on a 2005-2007 student with a standard deviation of 187. Collegiate Learning Assessment (CLA) scores on the $\mathrm{y}$ axis by parent education level on the $\mathrm{x}$ axis.

Conclusions and generalizations from national studies of first-generation students help guide this single institution study. Learning and satisfaction outcomes, however, may vary for first-generation students when experienced in an intimate environment, shaped by faculty and other campus relationships. The personal experience of each student at a small college varies greatly from that of larger publicly funded institution; the experience most likely varies significantly even between similar institutions. Researchers must account for the uniqueness of the environment, rather than generalizing across institution type. Specifically, an important outcome for first-generation students involves their satisfaction and learning with the four-year small college experience, not only using graduation rates.

\section{Early career labor and graduate school outcomes.}

Nunez and Cuccaro-Alamin (1998) studied first-generation students who began in 1989-1990 and completed any type of postsecondary degree by 1994 . The proportion of 
first-generation students employed compared similarly to continuing-generation students, as well as average annual salaries among bachelor's degree completers. However, firstgeneration students who earned a baccalaureate degree were less likely than continuinggeneration students to be enrolled in graduate school ( 23 percent vs. 30 percent).

Pascarella et al. (2004) found educational degree plans created a negative effect through the second and third year, which the researchers explained as the possible effect of lower grades earned by first-generation students. While the employment and graduate school data will be outside of the scope of this study, the importance of these conclusions ties to the original reason first-generation students attend four- year institutions. That is, firstgeneration students often report attending a postsecondary institution to improve the financial situation for themselves and their families. Graduate school would delay this goal; furthermore, these students and their families may lack the cultural capital to fully understand the value of an additional degree, which in many cases, yields better financial results in the long term.

\section{Measuring success and satisfaction outcomes.}

As summarized by Gorgon et al. (2008), researchers and practitioners define success differently at each institution, depending on the desired outcomes in the institution's strategic plan and/or mission statement. Many institutions define academic success with student grades, persistence, and graduation rates, while others measure success with employment and graduate school metrics. Still other institutions define success solely by whether students report satisfaction with their college experience and having obtained marketable skills and knowledge at the time of graduation. Many institutions also solicit feedback from their alumni base, asking for constructive criticisms 
after the graduates have worked in a professional environment. This information may help determine whether the institution did an adequate job of preparing students for a first job or graduate school. Lastly, some institutions use the percentage of alumni donations as a determination of satisfaction (Pascarella \& Terenzini, 2005).

Because of the variations in determining student success and institutional effectiveness, Kuh et al. (2007) proposed defining student success in multidimensionally, considering "academic achievement, engagement in educationally purposeful activities, satisfaction, acquisition of desired knowledge, skills and competencies, persistence, attainment of educational objectives, and post-college performance" (p. 7). Regardless of how each institution defines success, students attending schools with a comprehensive system of effective educational practices have performed better academically, reported greater satisfaction, and graduated at higher rates (Kuh, et al., 2006; Kuh, et al., 2005b). As stated earlier, practitioners therefore consider these initiatives to be high impact practices (AAC\&U, 2007) because of the difference made in retention and graduation rates; however, these initiatives may also influence satisfaction and learning outcomes.

Although student engagement has been shown to positively correlate with student success and learning (Astin, 1993; Tinto, 1993), key differences exist between firstgeneration and continuing-generation students in terms of satisfaction. Lohfink and Paulsen (2005) concluded that first-generation students' satisfaction with their social life influenced second year persistence. However, the unique experience of first-generation students led researchers to believe that satisfaction with social life could be independent of the college experience, since many first-generation students chose a college close to 
home for a shorter commute and came from families where English was not the primary language spoken in the home. First-generation students, furthermore, reported key differences in the type of successful engagement in the campus community. Because of more time spent working off-campus and other family commitments, school clubs and social involvement did not positively correlate with persistence for first-generation students. Academic integration, such as the number or frequency of faculty-student interactions and the quality of the interaction, influenced first-generation student success more than social activities. First-generation students needed validation from faculty members that they can do college work (Lohfink \& Paulsen, 2005). Terenzini and Pascarella (1991) found that first-generation students were negatively influenced by hours worked (either volunteer service or to earn money), and more successful when enrolled continuous and full-time. These benefits were expressed in better learning (reading comprehension) and cognitive development (critical thinking skills).

The focus of practitioners and researchers often "overlooks" student satisfaction, but this measure may be important to student success, reflecting "quality of the undergraduate experience" (Kuh, et al., 2006, p. 44). Satisfaction can represent a feeling of belonging (Tinto, 1993), often correlated to engagement, persistence, and academic performance (Pascarella \& Terenzini, 1991). Kuh et al. (2006) summarized student satisfaction from previous research as a measure which strongly related to student achievement, and grades, but strong grades did not have as strong an influence on satisfaction scores.

The college environment has shown to influence satisfaction scores more than precollege characteristics (Astin, 1993). NSSE data (2005) demonstrated that the majority 
of four-year students rated the overall experience at least "good," with less than 5\% rating the experience as "poor." Quality and frequency of interactions with faculty and staff members, and other students, also influence student engagement and overall satisfaction scores (Astin, 1993; Kuh, 2003b; Kuh, et al., 2006). First-generation students report less satisfaction with academic advising and faculty access outside of class time than continuing-generation students at University of California four-year institutions; however, regardless of first-first-generation status, course-related faculty interaction significantly and positively predict student degree aspirations, a sense of belonging, gains in critical thinking and communication skills, and overall college satisfaction (Kim \& Sax, 2009).

Satisfaction scores remain only modestly researched, especially comparing firstgeneration students' satisfaction with their college experience to that of continuinggeneration students. Because the overall college experience of first-generation students varies from continuing-generations students, students' satisfaction may vary as well. The satisfaction of the student experience may be more contingent upon academic integration in terms of the frequency and quality of the classroom interactions, rather than the social and cocurricular experiences important to continuing-generation students (Kuh, et al., 2006). This particular comparison is important to this single institution study. A better understanding of the academic experiences of first-generation students could help faculty members and administrators make changes in their continuous effort to improve the learning environment. 


\section{Summary of the Implications for First-Generation Students}

First-generation students (defined as neither parent having a postsecondary experience) represent roughly one of three college students (when considering all institution types of U.S. postsecondary education) and over-represent a wide range of ethnicities and lower income students (Kuh, et al., 2006). First-generation students are considered high-risk for attrition because they tend to withdraw more often at the end of the first year at four-year institutions, are less likely to be on track after three years, and are less likely to stay enrolled or attain a bachelor's degree after five or six years (Chen, 2005). After bachelor's degree completion, however, no significant differences exist in the early career earnings or job placement rates for first-generation students. However, first-generation students enroll less frequently than continuing-generation students in a graduate or first professional program (Nunez \& Cuccaro-Alamin, 1998), a possible outcome of lower grades earned during college and lower reported educational degree plans (Pascarella, et al., 2004).

First-generation students report similar levels of academic integration when compared to continuing-generation students at four-year institutions, but report lower levels of social integration or engagement in cocurricular activities (Nunez \& CuccaroAlamin, 1998). First-generation students also report a difference in their four-year experience because of not living on-campus and time spent with family obligations and working off-campus (Pascarella, et al., 2004); institutional efforts to intervene with these students before attrition have proven highly effective. Programs such as freshman seminars where faculty members validate students' ability to complete college level work proved more meaningful to first-generation students than continuing-generation students. 
After experiencing an educationally purposeful activity early in the undergraduate years, first-generation students have been retained and graduated at similar levels as continuinggeneration students (Kuh, et al., 2008).

Over the past two decades, first-generation students reported a different experience in college, yet this finding failed to translate into substantial variance in direct measures of learning outcomes. Pascarella et al. (2004) found that no significant differences existed in second-year writing skills or third-year reading comprehension or critical thinking scores; however, a small difference existed in second-year science reasoning (which reduced to nonsignificant when researchers accounted for college experiences). Terenzini (1996) reported similar findings in the freshman year using the same student sample. In a study with both similar and contrasting results, Arum and Roska (2010) found first-generation students started with lower standardized test scores and gained less over the first two years of college than students with parents holding a graduate or professional degree (after controlling for aptitude with ACT or SAT scores). High school preparation and college experiences accounted for $40 \%$ of the gap, however when removed, first-first-generation status no longer was statistically significant. In a study of indirect measures of student learning, Pike and Kuh (2005) concluded that firstgeneration students self-reported less learning and intellectual development in the first year of college, as well as perceiving the college environment less supportive. These conclusions were a direct result of not living on-campus and having lower educational aspirations; however these conclusions were only indirectly related to first-firstgeneration status. Moreover, researchers concluded that the results related less to precollege characteristics (first-first-generation status) and were more influenced by what 
the students do during college. According to Pike and Kuh (2005), the critical factors which influenced learning were the reported frequency of diverse experiences and the perceptions of the college environment. Because first-generation students were generally less engaged in the overall college experience, the quality of the learning experience may be influenced. Additional research is needed using direct measures of learning in the senior level to assess student outcomes closer to the time of baccalaureate degree completion.

Figure 2.2 summarizes the key characteristics and influences from the literature which practitioners should consider in evaluating the overall experience of firstgeneration students. Highlighted in bold are the key characteristics from the literature which influence first-generation student learning in the freshman year (Pike \& Kuh, 2005). The key considerations for first-generation student learning in the first year of college are: living on-campus (direct effect with greatest influence); parents education level (indirect); integration of diverse experiences (direct); academic and social engagement (indirect mediated by integration, which is the extent students incorporate information from coursework into conversations with others on-campus); education aspirations (indirect); and perceptions of the college environment (direct). The model is adapted from the combination of models from Astin I-E-O (1970), Pascarella (1985), and Pike and Kuh (2005), as well as NSSE benchmarks. The premise of the model is based on research that student engagement in educationally purposeful activities positively influences learning (Astin, 1993; Pascarella \& Terenzini, 1991). Other characteristics and influences were added as a summary for the literature, not as an exact indication of variables considered in the Pike and Kuh (2005) study. No study can consider all of these 
variables simultaneously; however, each institution's administration and faculty can consider the appropriate variables for measuring outcomes of its first-generation student population. For the research setting in this project, variables were considered as follows: (a) inputs include parents' education level, expected family contribution (EFC), academic preparation (ACT composite score), miles from home, and living on-campus; (b) environment experiences include educationally purposeful activities, high impact practices (AAC\&U, 2007) or institution specific experiences, academic challenge, active and collaborative learning, student-faculty interactions, enriching educational experiences, supportive college environment, quality of relationships with students, faculty members and administrative offices and personnel, diverse experiences; and (c) outcome measures include learning and satisfaction.

Surprisingly, limited research exists on the first-generation students at one institution, where a comprehensive study explores learning, engagement, and satisfaction over the four-year experience. The literature fails to answer the basic questions of whether faculty members understand the special needs of first-generation students, not just in terms of retention, but with regard to the influence on learning and the overall quality of the four-year experience. Previous research focused on the predictors of persistence and graduation because outcomes are similar if first-generation students matriculate; however, persistence and graduation rates are not necessarily considered an indication of student learning and satisfaction. Previous studies of first-generation learning outcomes assessed students after the second and third year, which may be less conclusive than the four-year experience. Could learning improve if faculty members became more aware of the unique needs of first-generation students? 
Conflicting evidence exists as to whether small private institutions foster a better learning environment for first-generation students. Some research concluded that small private institutions aided high-risk students because of small class size and faculty members who were more focused on teaching. Other literature stated that first-generation students felt ostracized by a lack of ethnic and socioeconomic diversity, especially if they did not live on-campus with the other students.

Many faculty members and administrators from private institutions believe firstgeneration students have the best chance of success in a small intimate environment. Despite the lack of socioeconomic and ethnic diversity in the study body at many small private institutions, faculty members typically focus on the institution's mission of teaching, which could provide the affirmation to high-risk students that they are capable of doing college level work. Many faculty advisors and staff members at small institutions provide students their home addresses, cell phone numbers, and an open invitation to ask for help at any time. The focus of the study is to better understand the four-year student experience at a small private institution, which may encourage more first-generation students to explore this type of institution.

In 2008, the Wal-mart Foundation partnered with Council of Independent Colleges (CIC) and the Institute for Higher Education Policy (IHEP) to award nearly \$10-million, mostly to small private universities, in support of retaining and graduating more first-generation students (Lipka, 2010). The IHEP also helped Wal-mart assist historically black colleges and universities, Hispanic-serving institutions, and tribal colleges and universities, which served a large percentage of first-generation students (Lipka, 2010). The CIC "College Success Awards" program offers 20 CIC institutions a 
$\$ 100,000$ grant each, to develop expertise on-campus in how to achieve better successful outcomes for first-generation students at private institutions (Lipka, 2010). The Wal-mart Foundation is an example of an organization believing that more first-generation students could be successful at U.S. private institutions.

The institution in this dissertation applied for the Wal-mart/CIC grant and was awarded $\$ 100,000$ in the year 2008. The school created a new peer-mentor program for first-generation freshmen, titled "frontiers." Each participating upperclassman was assigned ten new first-generation freshmen to provide the needed support and guidance. Special activities were programmed into the academic calendar to nurture and develop peer-mentor relationships. The school's academic resource center oversaw the program and also managed the university's undergraduate advising system, tutoring services, and retention efforts through the freshman experience program. The institution therefore provided three groups to study: continuing-generation students; first-generation "frontier" students; and first-generation not participating in "frontiers" students. In conclusion, a gap in the literature exists regarding traditional aged first-generation students at a small private institution. The study will assess the engagement, satisfaction, and learning outcomes of four-year students through comprehensive quantitative measures. 


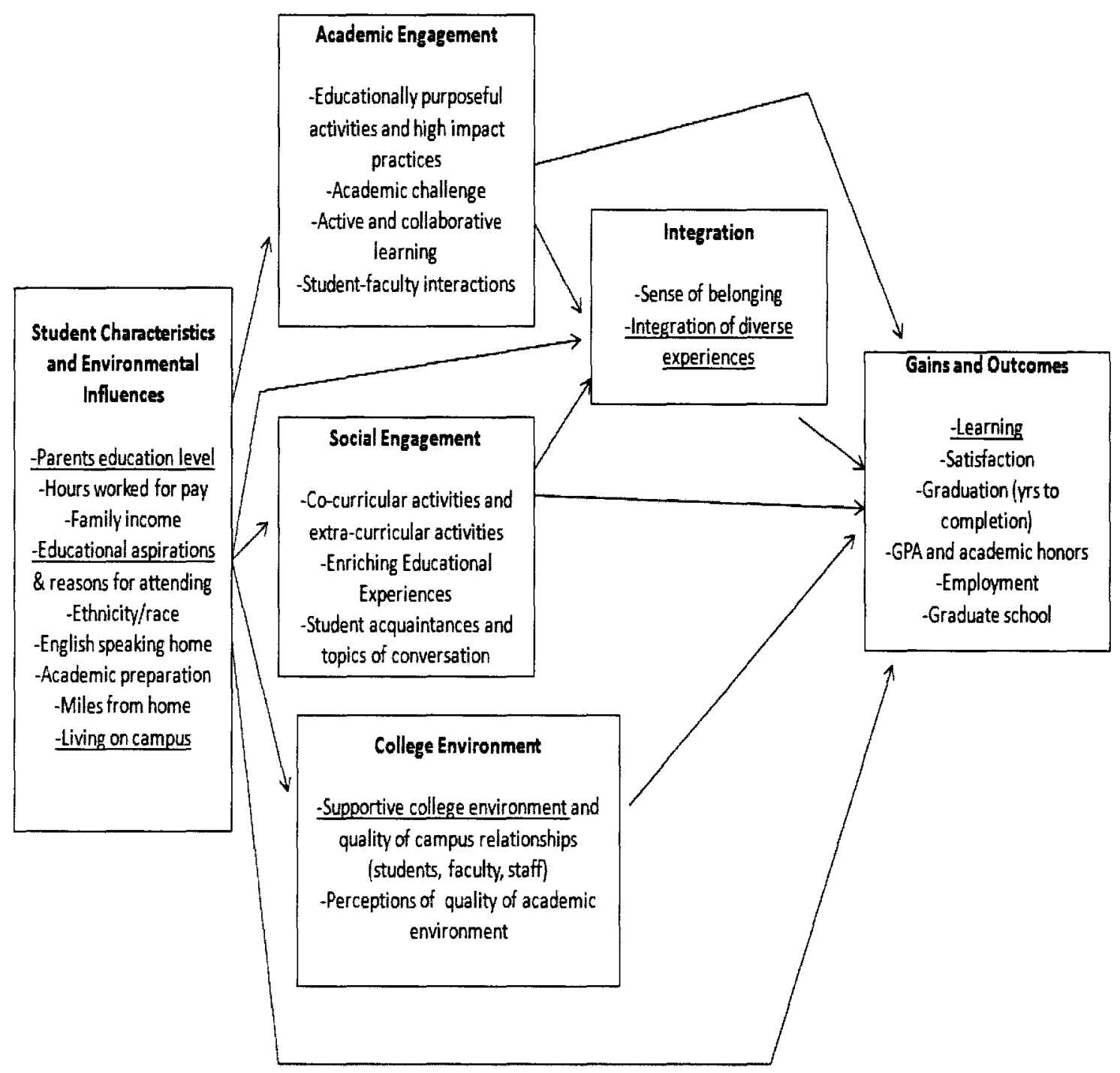

Figure 2.2. Underlined are the key characteristics and influences of first-generation student learning gains (Pike \& Kuh, 2005). The Astin I-E-O (1970), Pascarella (1985) and Pike and Kuh (2005) models were integrated for practitioners use in evaluating the characteristics and experiences which influence first-generation student learning gains. The premise is that a casual ordering exists of constructs engagement, integration and intellectual development. Academic and social engagement both directly and indirectly influence student learning gains. 


\section{CHAPTER III}

\section{METHODS}

The following chapter provides a detailed description of the research design based on Astin's I-E-O model (1970), the institution and the sample used, and the instruments used to measure engagement, satisfaction and learning of first-generation students. The seven headings are as follows: research design; population and sample; sampling procedures; instrumentation and data sources; data collection procedures; data analysis; and limitations. The purpose of the study was to better understand the four-year college experience of first-generation students and continuing-generation students at a small private institution by comparing their engagement, learning, and satisfaction. Using Astin's I-E-O model (1970), the following variables in the student experience were considered: precollege student characteristics (input); academic experiences, cocurricular involvement, campus relationships (environment); and satisfaction, learning measures (outcome). Results may be used to help practitioners at a small private four-year college to better engage first-generation students on campus. This purpose stemmed from the general research problem that national studies of first-generation students cannot be generalized to unique institutions, nor do the national studies investigate comprehensively student learning, satisfaction, and engagement over a four-year experience. 
Pascarella, Pierson, Wolniak, \& Terenzini (2004) found that first-generation students experienced college differently than continuing-generation students because of their unique family characteristics. Much previous research of U.S. first-generation students focused on second-year persistence and degree completion, by following longitudinally a nationally represented sample across multiple institution types. The U.S. Department of Education sponsored much of this research and the results influenced national policy for persistence at both two-year and four-year institutions (Chen, 2005; Choy, 2001; Horn \& Nunez, 2000; Nunez \& Cuccaro-Alamin, 1998; Warburton, et al., 2001). Small private school administrators need to better understand the four-year experience of first-generation students to develop programming and curriculum which will foster an experience which may be different than that of the general student population, but which would facilitate better learning and satisfaction for these high-risk students. This study comprehensively examined the four-year experience of firstgeneration students at a small, private Catholic university, by comparing their engagement, learning, and satisfaction to continuing-generation students.

Over the past decade, higher education leaders frequently discussed and debated the communication gap between research and practice. The issues identified were relevance of study problems to the needs of practitioners and the lack of adequate dissemination of research findings through practitioner communication channels. Bensimon, Polkinghorne, Bauman, and Vallejo (2004), however, contended that the problem lies in the traditional research model used, because it fails to account for the uniqueness and ever-changing makeup of each local institution. Traditional quantitative research does a tremendous job of working with large national datasets in "reducing 
complexity into manageable concepts" (Bensimon, et al., 2004, p. 107); however, the model oversimplifies the context of each individual institution by analyzing broad institution types together (for example four-year private institutions or public four-year research institutions). Thus research findings cannot be generalized across institutions. Furthermore, the traditional research model lacks any element of action research because leaders from individual institutions are not involved in the research. The results of national studies "rarely provide a picture that reflects the reality of a particular place and particular people" (Bensimon, et al., 2004 p. 107). Therefore in the case of firstgeneration students, a study is needed to better understand the four-year experience at a single institution to provide results which could be used immediately by practitioners to improve learning and satisfaction. Engagements models were suggested in support of practitioners' efforts to foster satisfaction and stronger learning environments for firstgeneration students. The study's research questions, as presented in Chapter I are:

1. Does a statistically significant difference exist in senior measures of learning between first-generation and continuing-generation students?

2. Do senior NSSE benchmark scores (engagement variables) significantly predict senior measures of learning for first-generation and/or continuinggeneration students?

3. Does a statistically significant difference exist in senior satisfaction measures between first-generation and continuing-generation students?

4. Do Pike "scalelets" generate a better predictive model of senior satisfaction than the engagement variables from high impact practices/university-specific activities? 
5. Is the quality of relationships (with other students, faculty members, and administrative personnel and offices) a significant predictor of senior satisfaction for first-generation and/or continuing-generation students?

6. Is the quality of relationships (with other students, faculty members, and administrative personnel and offices) a significant predictor of senior measures of learning for first-generation and/or continuing-generation students?

\section{Research Design}

A quantitative, ex post facto research design was used to compare the four-year experience of first-generation students to continuing-generation-students in terms of engagement, learning, and satisfaction. Ex post facto research design describes a study where the researcher cannot randomly assign students to each of two comparison groups because the students are in preexisting groups (Mertens, 1998). This type of research design requires a thorough understanding of the limitations which threaten internal and external validity, because the effects on the groups (first-generation students) cannot be controlled, manipulated, or constantly monitored (Isaac \& Michael, 1981).

The Astin I-E-O Model (1970) was used as a conceptual framework for understanding student development. While Astin has made several refinements since the 1960 s, the basic concepts of the model remain unchanged from its initial concept. Inputs represent the student characteristics at the time of entry into an institution. Environment addresses the various educational and cocurricular experiences to which a student is exposed, as well as relationships with student peers, faculty, and staff members.

Outcomes focus on student characteristics after the student experiences the environment. 
Since inception, researchers have used the Astin model to determine the influence of varying educational experiences on student development. Because of the complexity of the student experience during college, the model has become a tool to assess student growth holistically. Measuring the effectiveness of the educational environment includes accounting for many simultaneous experiences as well as confounding factors such as student maturation. The model also responds to the challenge of making sense of the selfselection bias, when using data intended to measure student engagement, learning, and satisfaction (Wolf-Wendel, et al., 2009).

Astin (1993) recommends using multiple outcome measures in assessing the impact of college on students, arguing that simple measures such as graduation rates or income levels of recent completers do not adequately assess the effectiveness of an institution. The college experience can affect any one of many aspects of a student; therefore simple measures are limited in their usefulness. Astin recommends studying both cognitive and affective domains of human performance, and suggests that researchers collect both psychological and behavioral data. Therefore, the data collected for this study originated from multiple sources in an effort to adequately assess the student experience over four years. The data sources include the university's student information system (SIS internal database), National Survey of Student Engagement (NSSE), and Educational Testing Service Measure of Academic Proficiency and Progress (ETS MAPP).

Multiple statistical methods were used to assess various measurements of the student four-year experience. The models were specially built using multiple regression techniques to identify predictor environmental variables of measures of student learning 
and satisfaction as well as multivariate statistical techniques including multivariate analysis of covariance (MANCOVA).

To answer the research questions of whether first-generation students differed from continuing-generation students in terms of learning and satisfaction, the first test was an analysis of variance of senior student measures comparing the two groups.

Regression models were built to better understand what engagement variables influence learning and satisfaction for each group. These models could then be used to suggest student programs and relationship development to promote learning and satisfaction.

Figure 3.1 frames the variables in context with the Astin I-E-O Model (1970).

\section{ENVIRONMENT}

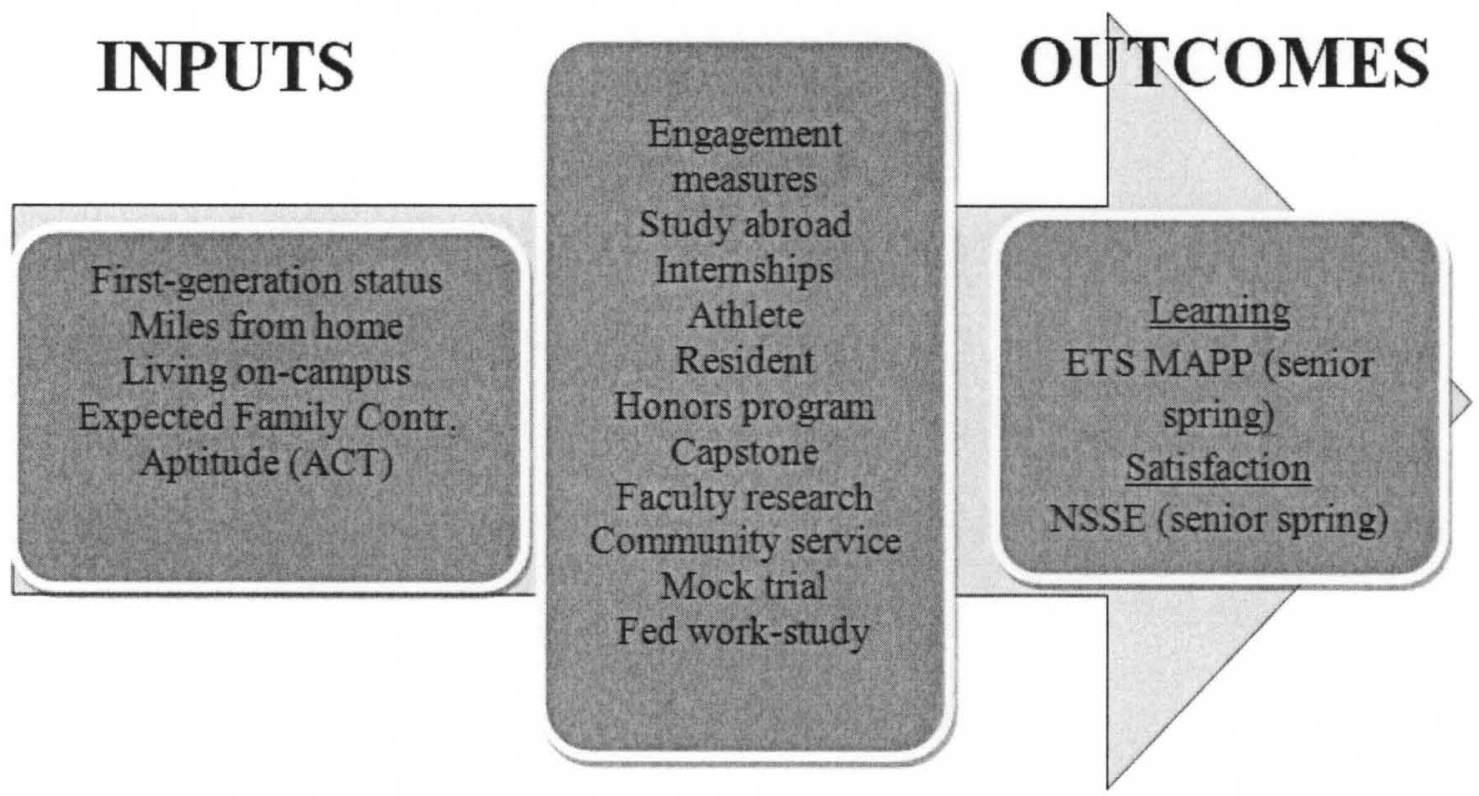

Figure 3.1. The Astin (1970) I-E-O model used to measure the four-year college experience. By accounting for students' precollege characteristics, researchers can better understand if the college experience influences outcomes. That is, by controlling for inputs or student characteristics in the freshman year, the influence of the four-year environment has on student outcomes can be more clearly studied. 


\section{Population and Sample}

The research was conducted using full-time undergraduate students participating in the NSSE and/or the direct measure of general education student learning, the ETS MAPP. The research setting was a small, private, Catholic university located in a large Midwestern city. In fall of 2009, the university enrollment included over 2000 full-time undergraduate students and nearly 700 graduate students. There were over 950 students living in the residence halls. Enrollment of first-generation students was substantial at the institution, somewhat unusual for a private Catholic Master's level institution. In fall 2009 , the freshman cohort included $40 \%$ first-generation students. The university defined a first-generation student as neither parent of the student having completed a baccalaureate degree. This definition was appropriate for the institution because it is a four-year institution. The institution's NSSE selected peers ( 25 small private schools used for benchmarking purposes) reported less than $30 \%$ first-generation students using this definition (NSSE, 2009). The entering first-time, full-time freshman cohort was composed of 602 students in fall 2009. The institution currently offers over 50 undergraduate degree programs (all bachelor's degrees) and over 20 graduate programs, mostly Master's degrees; two doctorate practitioner degrees (physical therapy known as DPT, nurse practice as DNP) are also offered. The most popular undergraduate degree programs are nursing (BSN), business administration, psychology, and biology. Table 3.2 displays the respondent numbers for the NSSE and ETS MAPP by year and classification. 
Table 3.2

Student Response Rate for NSSE and ETS MAPP, 2002-2010

\begin{tabular}{|c|c|c|c|c|c|c|c|c|}
\hline & \multicolumn{2}{|c|}{$\begin{array}{c}\text { NSSE } \\
\text { (freshmen) } \\
\end{array}$} & \multicolumn{2}{|c|}{$\begin{array}{c}\text { NSSE } \\
\text { (seniors) }\end{array}$} & \multicolumn{2}{|c|}{$\begin{array}{l}\text { ETS MAPP } \\
\text { (freshmen) }\end{array}$} & \multicolumn{2}{|c|}{$\begin{array}{c}\text { ETS MAPP } \\
\text { (seniors) }\end{array}$} \\
\hline & Resp. & Pop. & Resp. & Pop. & Resp. & Pop. & Resp. & Pop. \\
\hline SP02 & 94 & 329 & 107 & 320 & & & & \\
\hline SP03 & 101 & 326 & 90 & 433 & & & & \\
\hline SP04 & 58 & 518 & 82 & 382 & & & & \\
\hline SP05 & 210 & 442 & 219 & 582 & & & & \\
\hline SP06 & 241 & 589 & 170 & 497 & & & & \\
\hline FA06 & & & & & 48 & 554 & & \\
\hline SP07 & 217 & 554 & 142 & 345 & & & 72 & 345 \\
\hline FA07 & & & & & 58 & 568 & & \\
\hline SP08 & & & & & & & 54 & 350 \\
\hline FA08 & & & & & 114 & 562 & & \\
\hline SP09 & 278 & 562 & 170 & 367 & & & 111 & 367 \\
\hline FA09 & & & & & 101 & 602 & & \\
\hline SP10 & & & & & & & 105 & 306 \\
\hline Total & 1200 & 3320 & 980 & 2926 & 321 & 2286 & 343 & 1368 \\
\hline $\begin{array}{l}\text { Response } \\
\text { rate }\end{array}$ & $36 \%$ & & $33 \%$ & & $14 \%$ & & $25 \%$ & \\
\hline
\end{tabular}

\section{Sampling Procedures}

Because of the limited number of full-time undergraduate students at the institution, sampling was unnecessary because the entire population could easily be requested to participate. On designated years, the institution invited the entire freshman and senior populations to participate in the NSSE. Most of the freshmen and senior populations enrolled at the university as first-time, traditional age freshmen; however, all first-year students and senior students were invited, regardless of whether they enrolled as traditional freshmen, transfer, or re-admitted students. The university began NSSE testing in the spring 2002, as part of a project at Indiana University Center for Postsecondary Research to better understand how engaged the students are in academic 
and nonacademic settings and activities. After participating yearly through the spring of 2007 , the institution was satisfied that the data were relatively stable on a yearly basis. Issues facing the undergraduate students (as well as the strengths of the student experience) had not changed substantially over time. A new plan therefore emerged to track cohorts with longitudinal studies. For example, the traditional freshman cohort in the fall 2008 participated in the Beginning College Survey of Student Engagement (BCSSE) before enrolling, then the NSSE in the spring of their freshmen year (2009), and finally will participate in the NSSE again in the spring of their senior year (2012).

The institution also administered the ETS MAPP exam through freshman seminar and senior seminar courses. Administrators randomly sampled these seminar courses by inviting course instructors to offer ETS MAPP testing during class sessions when they would be absent. Similar to the NSSE administration, most of the freshman and senior populations enrolled at the university as first-time, traditional age freshmen; however, all first-year students and senior students were tested in each seminar class, regardless of whether they enrolled as traditional freshmen, transfer, or re-admitted students. Approximately 50 freshman participants and 50 senior participants comprised the entirety of the respondents in the fall of 2006 and the spring of 2007 . The overall university population was 554 freshmen (fall 2006) and 345 seniors (spring 2007). In the fall of 2007 , the institution intentionally increased its sample size to include over 100 students for each class. ETS MAPP testing began in the 2006-2007 academic year to prepare for a regional accreditation visit in 2008. The purpose was to establish an external assessment which could be used to compare the institution's students with similar institutions across the nation. There were many general education internal methods of assessing the school's 
ten general education outcomes, as well; however, these methods needed to be triangulated with an external reference. The institution continued to administer the ETS MAPP, gaining over 100 participants for each class to better represent the institution's student population. Similar to NSSE results, ETS MAPP data were very consistent across cohorts. Therefore combining NSSE and ETS MAPP results across multiple years proved appropriate for increasing respondent size for statistical methods of this study.

\section{Instrumentation and Data Sources}

Three primary sources of data provided the information for the study. The university's student information system (SIS) provided data for many of the input variables such as the estimated family contribution (EFC) from the U.S. federal government application for financial aid (FAFSA), ACT scores, and miles from campus to permanent home. The second data source was the Indiana University Center for Postsecondary Research instrument, NSSE, a survey collecting self-reported student information from freshmen and seniors in four-year institutions. The third source was the ETS MAPP, a direct measure of student learning in general education, scoring skills in math, critical thinking, reading and writing, as well as contextual discipline scores in social science, natural science, and humanities. The university administered the ETS MAPP abbreviated online form, which consists of a series of multiple choice questions completed in a 40 minute period under the supervision of a proctor in one of the university's computer labs. The following subsections provide details for each data source, including a discussion of validity and reliability. 


\section{Student information system.}

The university student information system (SIS) is continuously monitored by staff and faculty members in an effort to provide student services in a timely and accurate fashion. On three dates per year (one per semester) the university holds "census day," where data are checked for accuracy and then stored as a snapshot for enrollment counts and other purposes. Data from the SIS must be accurate before submitting reports to federal and state governments, a requirement for institutions providing Title IV federal student funding. While there may be some inaccuracies in the system, errors are limited in number. The student's application for university admission is the primary source of the SIS, followed by updates during the course registration process throughout the student's time at the institution. Furthermore, some manual data entry was needed in preparing the datasets for statistical methods, serving as another safeguard to correct inaccuracies before statistical procedures were performed. Overall, there was great confidence in the accuracy of the SIS student records.

\section{National Survey of Student Engagement (NSSE).}

Researchers derived the value of the NSSE instrument on the premise that "what students do" during college counts more in terms of desired outcomes than who they are or even where they go to college (Kuh, 2003a, p. 1). Kuh originated the concept of student engagement, where institutions and students used a reciprocal relationship for student success. Efforts to foster student engagement focus on all students, which have proven to be particularly helpful to high-risk students such as first-generation students. Research demonstrates more engaged students typically retain and graduate from the 
same institution at a higher rate, learn more, and report a better overall experience (Kinzie, et al., 2008; Kuh, 2001; Kuh, et al., 2006; Kuh, et al., 2005b).

The NSSE instrument contains 100 questions designed to "assess the extent to which students are engaged in empirically derived good educational practices and what they gain from their college experience" (Kuh, 2003a, p. 1). Students typically complete the NSSE within 30 minutes. A description of the NSSE questions in the context of Astin's I-E-O model (1970) is displayed in the Research Questions section of this chapter. NSSE groups five factors as national benchmarks common to learning and student success: active and collaborative learning (ACL); student-faculty interaction (SFI); enriching educational experiences (EEE); supportive campus environment (SCE); and level of academic challenge (LAC). NSSE uses a variety of Likert scales for survey items composing each construct (Appendix D). Researchers further analyzed NSSE items and built even richer and more meaningful constructs. Pike (2006a) built "scalelets" as follows: course challenge; writing; active learning; higher order thinking skills; collaborative learning; course interaction; out-of-class interaction with faculty; use of information technology; emphasis on diversity; varied educational experiences; support for student success; and interpersonal environment. Appendix $A$ is the NSSE 2009 instrument including all survey items.

NSSE Validity and Reliability.

Validity is commonly defined as whether a survey measures what is intended to be measured, while reliability refers to whether the survey responses are consistent and reproducible (Isaac \& Michael, 1981; Mertens, 1998). The main concern of practitioners in utilizing NSSE results involves the validity and creditability of student self-reports. 
Kuh (2003a) describes two general problems with self-reports. First, students must provide accurate feedback, based on an understanding of the question in context with the institution, which can be tough for freshmen with limited experience and understanding of the institution. Second, the students must be willing to provide truthful information. The Indiana University Center for Postsecondary Research designed NSSE from the content of The College Student Report, which proved valid if the five conditions (established from much previous research) were met: (1) information requested is known to respondents; (2) questions are phrased clearly and unambiguously; (3) questions refer to recent activities; (4) respondents think questions merit a serious and thoughtful response; and (5) answering questions does not threaten or embarrass the student. When these conditions are met, The College Student Report represented student behaviors highly correlated with learning and student development, establishing content validity for the NSSE instrument (Kuh, 2003a). Furthermore, items on the NSSE were derived not only from The College Student Report, but with several longstanding valid and reliable instruments, including the UCLA's Cooperative Institute Research Program (CIRP) and the Indiana University's College Student Experiences Questionnaire (CSEQ) Research Program. All of these instruments have proven to be quite successful in measuring the critical components of student success and thus establishing content validity.

The NSSE research team determined the instrument to have both high content and construct validity. Factor analysis (principal components extraction with oblique rotations) identified the underlying properties of items represented by The College Student Report (Kuh, 2003a). Researchers concluded that the NSSE instrument covers the following themes: students' reporting with regard to how often they participate in 
activities that "represent good educational practice;" students' perceptions of the environment associated with "satisfaction and achievement;" students' estimation of personal and educational growth since starting college; and students' information about background, age, gender, race/ethnicity, living arrangement, classification in college (freshman or senior), and major (NSSE, 2009). After factor analysis, cognitive interviews and focus groups also confirmed content validity. Students had little difficulty interpreting survey items, including those questions used to establish the NSSE five benchmarks (NSSE, 2009). NSSE items also proved to effective in measuring engagement for students of various ethnicity and race designations as well as across institution type (Kuh, et al., 2007). The overall responses comparing freshmen to seniors also followed previous research findings, another indication that the instrument measures intended aspects of the student experience. Seniors engaged in more activities such as career counseling and tutoring other students, while freshmen engaged in more cocurricular activities and understanding people from diverse backgrounds (NSSE, 2009).

The individual items used in the construction of these benchmarks were created with a blend of theory and empirical analysis. Principal components analyses (oblique rotation) were used initially in this exploration, with theory and practice being used subsequently to inform and determine the final benchmark item groupings. As in the past, only randomly sampled cases are included in the calculation of institutional benchmarks.

The Center of Postsecondary Research at Indiana University Bloomington calculated the 2009 NSSE Benchmarks in multiple steps. Items contributing to each benchmark were first converted to a 100 point scale. Items, for example, which contained 
four response options (never, sometimes, often, or very often) were re-coded with values of $0,33.33,66.67$, or 100 . The second step was to calculate student-level benchmark scores for each group of items from the mean of each student's scores (as long as the student completed three-fifths of the items in any particular benchmark). Third, institutional benchmarks were calculated with weighted averages of the student-level scores for each class (first-year students and seniors). Using only U.S. random samples from the 2009 NSSE survey administration, researchers examined the internal consistency of each NSSE benchmark using Cronbach's Alpha and benchmark intercorrelations. The results are contained in table 3.3 and Appendix $B$ for more granular information in terms of each individual item within the benchmark and appropriate code for each item. For a description of the code used to create each NSSE benchmark, see Appendix D.

Table 3.3

Internal Consistency of each NSSE 2009 Benchmark Using Cronbach's Alpha

First-Year (FY) Senior

\begin{tabular}{lll}
\hline Level of Academic Challenge (LAC) & .73 & .76 \\
Active and Collaborative Learning (ACL) & .66 & .66 \\
Student-Faculty Interaction (SFI) & .71 & .74 \\
Enriching Educational Experience (EEE) & .59 & .66 \\
Supportive Campus Environment (SCE) & .79 & .80 \\
\hline
\end{tabular}

Intercorrelations of NSSE 2009 Benchmarks

\begin{tabular}{lccccc}
\cline { 2 - 6 } & $\begin{array}{c}\text { Senior } \\
\text { LAC }\end{array}$ & $\begin{array}{c}\text { Senior } \\
\text { ACL }\end{array}$ & $\begin{array}{c}\text { Senior } \\
\text { SFI }\end{array}$ & $\begin{array}{c}\text { Senior } \\
\text { EEE }\end{array}$ & $\begin{array}{c}\text { Senior } \\
\text { SCE }\end{array}$ \\
\hline FY LAC & & .487 & .458 & .378 & .342 \\
FY ACL & .487 & & .582 & .453 & .334 \\
FY SFI & .470 & .612 & & .525 & .415 \\
FY EEE & .417 & .497 & .474 & & .308 \\
FY SCE & .385 & .343 & .392 & .339 & \\
\hline
\end{tabular}


Number of Respondents for NSSE 2009

\begin{tabular}{lcc}
\cline { 2 - 3 } & $\begin{array}{c}\text { FY } \\
\text { Respondents }\end{array}$ & $\begin{array}{c}\text { Senior } \\
\text { Respondents }\end{array}$ \\
\hline LAC & 148,470 & 167,918 \\
ACL & 160,012 & 175,423 \\
SFI & 149,949 & 169,036 \\
EEE & 145,033 & 165,030 \\
SCE & 141,704 & 162,391
\end{tabular}

Especially important for using the NSSE instrument in the proposed study, the five NSSE benchmarks highly correlated with self-reported student outcomes. This conclusion was reached from a random sample of NSSE 2006 participants, where an exploratory factor analysis identified the following five factors: practical competence; general education; personal and social development; satisfaction; and grades. Displayed in Table 3.4, these relationships proved content validity because the benchmarks are strongly associated with positive outcomes (NSSE, 2009).

Pike (2006a) developed 12 "scalelets," each representing a content area with a set of survey questions. To make generalizations about an area, one item will not suffice; thus, a group of survey questions increases the measure's richness of that element of the student experience. The "scalelets" attempt to strike a balance between the "breadth of generalizations," which would require many survey items, and the limited scope of one survey question. For assessment of student programs, "scalelets" are an appropriate measure because they were built to evaluate groups of students, not individual respondents. 
Table 3.4

Correlation of Student Engagement and Self-Reported Student Outcomes, 2006

\begin{tabular}{|c|c|c|c|c|c|c|c|c|c|c|}
\hline \multirow[b]{2}{*}{$\begin{array}{c}\text { NSSE } \\
\text { Benchmark }\end{array}$} & \multicolumn{2}{|c|}{$\begin{array}{l}\text { Practical } \\
\text { Competence }\end{array}$} & \multicolumn{2}{|c|}{$\begin{array}{l}\text { General } \\
\text { Education }\end{array}$} & \multicolumn{2}{|c|}{ Personal Social } & \multicolumn{2}{|c|}{ Grades } & \multicolumn{2}{|c|}{ Satisfaction } \\
\hline & $\begin{array}{l}\text { First- } \\
\text { Year }\end{array}$ & Senior & $\begin{array}{l}\text { First- } \\
\text { Year }\end{array}$ & Senior & $\begin{array}{l}\text { First- } \\
\text { Year }\end{array}$ & Senior & $\begin{array}{l}\text { First- } \\
\text { Year }\end{array}$ & Senior & $\begin{array}{l}\text { First- } \\
\text { Year }\end{array}$ & Senior \\
\hline $\begin{array}{l}\text { Level of } \\
\text { Academic }\end{array}$ & & & & & & & & & & \\
\hline $\begin{array}{l}\text { Challenge } \\
\text { Active and } \\
\text { Collaborative }\end{array}$ & .47 & .43 & .50 & .47 & .42 & .40 & .17 & .13 & .28 & .26 \\
\hline $\begin{array}{l}\text { Learning } \\
\text { Student } \\
\text { Faculty }\end{array}$ & .40 & .39 & .35 & .33 & .37 & .35 & .15 & .15 & .24 & .22 \\
\hline $\begin{array}{l}\text { Interaction } \\
\text { Enriching }\end{array}$ & .40 & .35 & .36 & .35 & .41 & .38 & .08 & .15 & .24 & .27 \\
\hline $\begin{array}{l}\text { Educational } \\
\text { Experience } \\
\text { Supportive } \\
\text { Campus }\end{array}$ & .33 & .27 & .30 & .29 & .36 & .34 & .11 & .13 & .21 & .21 \\
\hline Environment & .56 & .55 & .52 & .51 & .56 & .57 & .11 & .12 & .56 & .58 \\
\hline
\end{tabular}

Note. All correlations are significant at the $\mathrm{p}<.01$ level.

Pike (2006b) examined the dependability of NSSE "scalelets" in terms of generalizability of group means with samples of items and samples of students. Using 50 randomly selected senior students from 50 randomly selected institutions, Pike concluded that all "scalelets" had dependable group means $\left(E_{p}{ }^{2} \geq .70\right.$ with 25 to 50 respondents).

A second study attempted to determine convergent and discriminant validity scores (Pike, 2006a) to ensure that inferences were made appropriately. Results provided evidence of convergent validity for both NSSE benchmarks and Pike "scalelets." Outcomes from regression methods showed institutions' characteristics and NSSE benchmarks accounting for $78.0 \%$ of the variance in general education gains, with NSSE benchmarks alone accounting for $30.7 \%$. Pike "scalelets" and institutions' characteristics accounted for $81.3 \%$ of the variance in general education gains, with Pike "scalelets" 
alone accounting for $34.0 \%$. Engagement measures also yielded evidence of convergent validity, but, as expected, with some intercorrelation with institutional characteristics.

Pike (2006a) established discriminant validity through multiple regression results. The evidence stemmed from the highly differentiated relationship between Pike "scalelet" scores and gains, more than NSSE benchmarks and gains. For example, both "scalelets" course interaction and varied educational experiences uniquely contributed to the variance in general education gains, while NSSE benchmarks Student-Faculty Interaction and Enriching Education Experience did not.

Using only U.S. data from the 2009 NSSE survey administration, researchers examined the internal consistency of each Pike "scalelet" as well as the satisfaction score from two NSSE items, the composite score from NSSE quality of campus relationships, and the combined satisfaction and campus relationship relation composite score. The results are contained below in tables $3.5,3.6,3.7$, and 3.8. The following appendices provide more granular information in terms of individual items within each of the following composite scores: Appendix $B$ includes all NSSE composite scores and scales with intercorrelation tables; Appendix C displays how NSSE "scalelets" and other NSSE composite scores are calculated; and Appendix D displays how NSSE benchmarks are calculated. 
Table 3.5

Internal Consistency of Each NSSE Pike "Scalelets" Using Cronbach's Alpha

\begin{tabular}{lll} 
& First-Year (FY) & Senior \\
\cline { 2 - 3 } & & .59 \\
\hline Course Challenge & .57 & .62 \\
Writing & .54 & .49 \\
Active-Learning Experiences & .47 & .83 \\
Higher Order Thinking Skills & .82 & .50 \\
Collaborative Learning Experience & .53 & .64 \\
Course-Related Interactions with Faculty & .63 & .59 \\
Out-of-Class Interactions with Faculty & .49 & .51 \\
Use of Information Technology & .49 & .68 \\
Diversity & .67 & .63 \\
Varied Educational Experiences & .51 & .78 \\
Support for Student Success & .78 & .71 \\
Interpersonal Environment (quality of & .73 & \\
$\quad$ relationships: students; faculty members; & & \\
$\quad$ and administrative personnel, offices) & & \\
\hline
\end{tabular}

Table 3.6

Internal Consistency of NSSE Satisfaction Score Using Cronbach's Alpha

First-Year (FY) Senior

\begin{tabular}{lll}
\hline Overall Satisfaction Score & .75 & .81 \\
\hline
\end{tabular}

Note. Overall satisfaction score composed of two NSSE 2009 items. How would you evaluate your entire educational experience at this institution? If you could start over again, would you go to the same institution you are now attending? 
Table 3.7

Internal Consistency of NSSE Quality of Campus Relationships Using Cronbach's Alpha

\begin{tabular}{lcc}
\cline { 2 - 3 } & First-Year (FY) & Senior \\
\hline $\begin{array}{l}\text { Overall Quality of Campus } \\
\text { Relationships Score }\end{array}$ & .73 & .72 \\
\hline
\end{tabular}

Note. Overall Quality of Campus Relationships Score composed of three NSSE 2009 items: Mark the box that best represents the quality of your relationships with people at your institution; relationships with other student; relationships with faculty members; and relationships with administrative personnel, and offices (7 point Likert scale from 1=unfriendly, unsupportive, sense of alienation to $7=$ friendly, supportive, sense of belonging).

Table 3.8

Internal Consistency of NSSE Combined Score of Quality of Campus Relationships and Satisfaction Using Cronbach's Alpha

\begin{tabular}{lcc}
\cline { 2 - 3 } & $\begin{array}{c}\text { First-Year } \\
\text { (FY) }\end{array}$ & Senior \\
\hline $\begin{array}{l}\text { Combined Score of Quality of } \\
\text { Campus Relationships and }\end{array}$ & .81 & .82 \\
Satisfaction & & \\
\hline
\end{tabular}

Note. Combined Score of Quality of Campus Relationships and Satisfaction includes two NSSE 2009 satisfaction items. How would you evaluate your entire educational experience at this institution? If you could start over again, would you go to the same institution you are now attending? Quality of Campus Relationships Score composed of three NSSE 2009 items. Mark the box that best represents the quality of your relationships with people at your institution. Relationships with other student, relationships with faculty members, relationships with administrative personnel and offices ( 7 point Likert scale from $1=$ unfriendly, unsupportive, sense of alienation to $7=$ friendly, supportive, sense of belonging). 
The NSSE research team considered reliability of the NSSE student responses with test-retest analysis and stability analysis, both at the institutional level. NSSE researchers completed the test-retest of 1,226 participants who completed the paper form over a period of several months. Reliability coefficients ranged from 0.74 to 0.78 on all five NSSE benchmarks. The analysis was completed again with 1,536 NSSE participants in both paper and web format in the year 2005. Similar results were found comparing reliability coefficient ranges. NSSE benchmark, level of academic challenge was .69 compared to .74 for enriching educational experience benchmark (NSSE, 2009).

In terms of institutional stability of NSSE scores from one year to the next, researchers conducted a study of 214 institutions participating in years 2002 and 2003. The NSSE research team calculated benchmark scores using un-weighted student responses. Correlations ranged from 0.81 to 0.93 . A second study was conducted for 236 institutions participating in 2004 and 2005 NSSE, yielding correlations ranging from 0.81 to 0.93 . A final study conducted for 283 institutions participating in 2008 and 2009 NSSE yielded similar correlations ranging from 0.74 to 0.94 . All three studies provided evidence that NSSE benchmark scores for each institution were stable from year to year (NSSE, 2009). See Appendix D for how each NSSE benchmark is calculated.

Lastly in terms of reliability of survey data, an important possible limitation could be nonresponse bias, typically described as one of several possible psychometric biases. That is, do nonparticipants not represented in the dataset vary from those students who did participate in an institutional NSSE study? In a telephone study conducted by NSSE researchers in 2001 and again in 2005, researchers interviewed over 1900 nonrespondents from 45 institutions. Surprisingly, the research team found students who did not 
participate in NSSE slightly more engaged than those students who did participate. No consistent trends or substantial score variations existed. Researchers expected the opposite of these findings in terms of measuring student engagement; students, who would participate in a survey such as NSSE, were expected to be more engaged in all aspects of their education and have a more productive collegiate experience.

\section{ETS Measure of Academic Proficiency and Progress (ETS MAPP).}

ETS MAPP, a direct measure of student learning in general education, yields eight norm-referenced (scaled) scores as follows: total score (400-500 range); skills subscores in math, critical thinking, reading, writing (100-130 range); and context sub-scores in social sciences, natural sciences, humanities (100-130 range). The university administered a proctored abbreviated online form, which consists of 36 multiple choice questions completed in a 40-minute period under the supervision of a proctor in a university computer lab. Reading and critical thinking questions are associated with a short passage the students read.

For any measurement of direct learning, construct validity is the most important issue to determine the quality of the assessment. Validity depends on how the assessment will be used, the participant characteristics, and the evidence accumulated after usage of the instrument. For example, a valid instrument for college admission decisions, may not be a valid instrument for placement within a major (Young, 2007). The university used the ETS MAPP to evaluate student learning by comparing freshman to senior scores in each academic year.

Marr (1995) established ETS MAPP validity by studying 5,092 students enrolled at four-institutions in the U.S. Students represented all four year classifications 
(freshman, sophomore, junior, senior) and six postsecondary majors (business, education, humanities/arts, natural sciences, social sciences, and math/engineering). Marr's conclusions created credibility for the instrument as a direct measure of general education skills (math, critical thinking, reading, and writing) in three content areas (social science, natural science, and humanities). Marr found that test scores increased with the percentage of the core curriculum completed by student respondents. College juniors and seniors scored significantly higher than freshmen. The ETS MAPP measures general education skills. Therefore, the upperclassmen who have completed most of their general education curriculum should score significantly better. Students completing additional advanced courses beyond the core general education curriculum scored no higher than typical juniors and seniors. Higher ETS MAPP scores were explained almost in entirety by the completion of core curriculum, disputing critiques who claimed upper-classman scores were a product of the intellectual maturation effect. Klein, Liu and Sconing (2009) also compared freshman to senior ETS MAPP scores, controlling with ACT and SAT scores. Seniors yielded higher mean scores than freshmen on all ETS MAPP skills tested. Effect sizes ranged from about one quarter to one half of a standard deviation. When ETS MAPP was compared to similar instruments, but with varying formats (multiple choice rather than constructed response such as an essay question), effect sizes were not systematically related to the construct tested (math, critical thinking writing, reading), response format, or test publisher. For example, the average effect size across constructs for the ACT's CAAP (Collegiate Assessment of Academic Proficiency), Council for Aid to Education's (CAE) Collegiate Learning Assessment (CLA) and ETS MAPP measures were $0.33,0.31$, and 0.34 , respectively. 
In terms of construct validity, Marr (1995) also concluded that ETS MAPP scores correlated with skills required by specific disciplines. For example, engineering students scored higher on the ETS MAPP math score than humanities majors. ETS MAPP scores also correlated with student grade point average; students earning higher grades scored higher on the ETS MAPP assessment. Klein, Liu, and Sconing (2009) found that the pattern of correlations among CAAP, CLA and ETS MAPP supported construct validity, especially when the unit of analysis was individual students. Generally results were consistent, concluding that tests purporting to measure the similar constructs did indeed measure those constructs. Correlations revealed that two tests of the same construct usually correlated higher with each other than they did with measures of other constructs. For example, the average correlation between multiple-choice tests of reading $(r=.76)$, was higher than the average correlation between all multiple-choice tests of different constructs $(\mathrm{r}=.70)$. Even when the same construct was measured against a test using a different format (multiple choice versus essay), the correlation was greater. For example, the same critical thinking construct with a different format $(\mathrm{r}=.53)$ yielded a greater correlation than a different construct and different format $(r=.45)$. See Table 3.9 for additional information.

Regarding reliability, Klein, Liu, and Sconing (2009) concluded that multiple choice instruments such as the ETS MAPP, when assessed at school level (unit of analysis), have sufficient reliability. ETS MAPP reliability scores were quite high across constructs, ranging from .91 to .94 in Table 3.10 . Score reliability was not considered a serious concern. Klein, Liu, and Sconing suggested that, for value-added assessments such as the ETS MAPP, every effort be made to gain a true random sample. 
Table 3.9

Average Student-level Correlations by Construct of ETS MAPP Compared with CAAP, $C L A$

\begin{tabular}{|c|c|c|c|c|}
\hline & $\begin{array}{c}\text { Same } \\
\text { Construct } \\
\text { Same } \\
\text { Format }\end{array}$ & $\begin{array}{c}\text { Same } \\
\text { Construct } \\
\text { Different } \\
\text { Format }\end{array}$ & $\begin{array}{c}\text { Different } \\
\text { Construct } \\
\text { Same } \\
\text { Format } \\
\end{array}$ & $\begin{array}{c}\text { Different } \\
\text { Construct } \\
\text { Different } \\
\text { Format }\end{array}$ \\
\hline ETS MAPP Critical Thinking & .75 & .53 & .71 & .45 \\
\hline ETS MAPP Writing & .72 & .44 & .66 & .49 \\
\hline ETS MAPP Math & .76 & & .61 & .44 \\
\hline ETS MAPP Reading & .76 & & .70 & .49 \\
\hline
\end{tabular}

Table 3.10

ETS MAPP Reliability Scores

\begin{tabular}{lc}
\cline { 2 - 2 } & $\begin{array}{c}\text { Reliability } \\
\text { Score }\end{array}$ \\
\hline Critical Thinking & .93 \\
Writing & .91 \\
Math & .94 \\
Reading & .91
\end{tabular}

\section{Data Collection Procedures}

For each year the NSSE was administered, a data file was uploaded through the NSSE website in the winter before the spring survey launch. The dataset contained each student's first name, last name, institutional ID number, email address, classification (freshman or senior), full-time or part-time status, gender, and ethnicity. The Indiana University Center for Postsecondary Research reviewed each dataset, looking for errors in email addresses and ensuring only freshman and senior participation. After approval, the institution designated a spring date for the launch, then three subsequent reminder dates before the survey closes in Bloomington. The center launched the survey by sending an invitation to all email addresses; the language of the invitation was 
customized by the institution. Some language was required, such as explaining the voluntary nature of the survey and the purpose of the instrument, but the school expressed the importance of participation and how the institution uses the results. After the student received the email, he or she clicked on the link to the instrument online and typically completed the questions in less than 30 minutes.

The institution decided the format and testing environment for ETS MAPP administration. In the academic year 2006-2007, the institution administered the exam with the ETS abbreviated paper form. Each instructor of freshman or senior seminar courses who agreed to participate was given the paper exams and proctored it during a class period of the instructor's choice. A seminar course had fewer than 15 registered students and was offered as a 50-minute course three times per week or 75 minutes twice weekly. Students completed the abbreviated ETS MAPP exam in 40 minutes. After reconsidering the paper format in the summer of 2007 , the institution elected to begin administering the ETS MAPP online in computer labs in the fall of 2007. This change in process was made because too much time was spent by ETS processing the completed paper exams after the institution shipped the forms to the center. Furthermore, the paper format became a burden on the administrative staff at the institution. The online format presented the problem of reserving available computer labs; however, the results were then available immediately and the overall process became more efficient. A proctor remained in the computer lab during all testing periods.

\section{Data Analysis}

The statistical procedures for each research question are presented in this section. The author determined research methods by determining which tests would best assess 
the entire college experience of the students in terms of engagement, satisfaction, and learning. Research methods were determined after consideration of a limited sample size because of the single institution study. Because the institution's undergraduate student demographics and characteristics were very consistent since 2002, cohorts were collapsed to increase sample size. This technique was justified because no substantial changes occurred in the following measures of university freshmen from 2002-2009: the average ACT Composite score of 24; average high school grade point average 3.5 ( 4.0 scale); and high school class rank (over 50\% of enrolled freshmen ranked in the top quarter of their high school class). Demographics were consistent, as well. Traditional aged full-time students compose the overwhelming majority of undergraduates, with a typical freshman class consisting of one third from the local city, one third from outside the city but instate, and the remaining third of the class from out-of-state. The student body was composed of mostly white students in terms of race, with approximately $8 \%$ nonwhite (Asian, African American, Hispanic, and Native American) and 2\% international students. Female students composed over $60 \%$ of each freshman class.

To best assess the entire college experience of the students in terms of engagement, satisfaction, and learning, the primary analyses were limited to a combination of the following student groups participating in multiple assessments: (a) students participating in NSSE both in the first-year and senior year; or (b) students participating in both ETS MAPP and NSSE in the senior year; and (c) students with ACT scores available to control for aptitude. 


\section{Research Questions}

Table 3.11 presents a summary of the statistical methods used for the six research questions; the table is found after the detailed narrative below. Also see Figure 3.12, which displays the variables considered in this research, framed from the literature regarding how student integration and engagement influence successful college outcomes.

Research Question One: Does a statistically significant difference exist in senior measures of learning between first-generation and continuing-generation students? A one-way MANCOVA was used comparing first-generation students to continuinggenerations students with two levels of the independent variable (IV) and seven senior ETS MAPP scores (dependent variables (DVs) which include skill sub-scores in critical thinking, reading, writing and math, as well as context-based sub-scores in humanities, social science and natural sciences). The MANCOVA controlled for aptitude with ACT composite score (covariate). The Astin model (1970) suggests accounting for variance in inputs or precollege characteristics. In this case, controlling for precollege aptitude (inputs) makes possible an equitable comparison of senior test scores (outcomes) for the two groups near the end of the four-year college experience (environment). The sample consisted of first-generation and continuing-generation students from the following senior classes: spring $2007(n=72)$; spring 2008( $n=54)$; spring $2009(n=111)$; and spring $2010(n=105)$. The total sample was 342 senior students. Only senior students who completed $75 \%$ of the questions were included in the sample. After MANCOVA was completed using only the seven ETS MAPP sub-scores, the ETS MAPP total score was checked with an analysis of covariance (ANCOVA) in a separate procedure. 
Additional methods included ANOVA comparisons of first-generation students to continuing-generation students with ACT composite score, ACT science, ACT English, ACT reading, ACT math, high school GPA, and cumulative college GPA in the student's senior year. A multiple regression model was built as a final procedure to investigate whether the hours worked variable was related to ETS MAPP total score. The model considered ACT composite score, first-first-generation status, and hours worked as possible predictors.

Research Question Two: Do senior NSSE benchmark scores (engagement variables) significantly predict senior measures of learning for first-generation and/or continuing-generation students? A hierarchical multiple regression model was built, first entering control variables aptitude (ACT composite score), freshman year expected family contribution (EFC), and miles from home in five categorical levels (Appendix E), as inputs in the Astin I-E-0 model (1970). The model then considered possible predictor environment variables (five NSSE benchmarks: EEE; SCE; ACL; LAC; and SFI) and finally considered the input variable, first-generation status. The outcome DV was the ETS MAPP total score. The data source was comprised of senior student respondents participating in both NSSE 2007 and ETS MAPP 2007 (30 students), as well as NSSE 2009 and ETS MAPP 2009 (45 students). The two cohorts were collapsed, thus creating a total respondent number of 75 students. Ten possible predictor variables were considered: aptitude (ACT composite score); freshman year EFC; living on-campus in the freshman year; miles from home (in five categorical levels); five NSSE benchmarks; and firstgeneration status. (See Appendix D for how NSSE benchmarks are calculated). 
Research Question Three: Does a statistically significant difference exist in senior satisfaction measures between first-generation and continuing-generation students? A one-way MANCOVA was used to compare first-generation students to continuinggeneration students ( 2 levels of the IV), using two senior satisfaction NSSE items (DV): evaluate your entire educational experience; and would you attend the same institution. The covariate was aptitude (ACT composite score). The respondent dataset consisted of students who participated in both the freshman and senior NSSE, totaling 182 students: spring 2002 to spring 2005 ( $n=41)$; spring 2003 to spring $2006(n=45)$; spring 2004 to spring $2007(n=18)$; and spring 2006 to spring $2009(n=78)$.

Research Question Four: Do Pike "scalelets" generate a better predictive model of senior satisfaction than the engagement variables from high impact practices/universityspecific activities? A composite NSSE satisfaction score was created as the outcome by combining the two NSSE satisfaction items (evaluate your entire educational experience and would you go to the same institution) into one score (Appendix $C$ ), reducing the number of models built. The $R^{2}$ (coefficient of determination for statistical models) was calculated for both multiple regression models, determining which would be a better overall predictive model for satisfaction. $R^{2}$ is the proportion of variability in a dataset accounted for by the model, thus providing a measure of how well the future outcome was predicted. The first model considered environment experiences, using 12 Pike "scalelets" as follows: course challenge; writing; active-learning experiences; higher order thinking skills; collaborative learning experiences; course-related interactions with faculty; out-of-class interaction with faculty; use of information technology; diversity; varied educational experiences; support for student success; and interpersonal 
environment. The second model considered environment experiences, that is, high impact practices/ university-specific activities as follows: capstone; study abroad; research with a faculty member; community service; honors program; Brown scholars (a leadership and volunteer service program); mock trial team; athlete; and work-study. Originally, the variables "frontier" scholar and major of study were proposed for consideration. However, a comparison for each major was not possible because of sample size. The "frontier" program data were not available in the four-year student dataset because the program began in 2008 . Therefore, an additional regression model was built to investigate the first-year experience, assessing whether the program influenced satisfaction in the spring of the freshman year (236 freshman students participating in the BCSSE and NSSE in the 2008-2009 academic year). All models attempted to identify predictive variables for each group (first-generation and continuing-generation students). A hierarchical multiple regression was used, first entering the input or control variables, aptitude (ACT composite score), EFC in six categorical variables (Appendix E), living on-campus in freshman year, and miles from home in five categorical levels (Appendix $E)$. Environmental variables were entered next (block two), followed by first-firstgeneration status (block three). Participation consisted of students who completed both the freshman and senior NSSE, totaling 182 students as follows: spring 2002 to spring $2005(n=41)$; spring 2003 to spring $2006(n=45)$; spring 2004 to spring $2007(n=18)$; and spring 2006 to spring $2009(n=78)$.

Research Question Five: Is the quality of relationships (with other students, faculty members, and administrative personnel and offices) a significant predictor of senior satisfaction for first-generation and/or continuing-generation students? Multiple 
hierarchical regression models were built to determine whether the environmental variables (entered in block two), quality of campus relationships (with other student, faculty members, and administrative personnel and offices), were significant predictors of outcome variable satisfaction (combined NSSE satisfaction score). First-generation status was considered last, entered in block three of the hierarchical multiple regression; the precollege variables or inputs were entered first in block one (aptitude ACT composite score, EFC in six categorical levels, living on-campus in the freshman year, and miles from home in five categorical levels). Participation consisted of 182 students who participated in both the freshman and senior year as follows: spring 2002 to spring 2005 ( $n=41)$; spring 2003 to spring 2006 ( $n=45)$; spring 2004 to spring $2007(n=18)$; and spring 2006 to spring $2009(n=78)$. The analysis provided a satisfaction assessment of the four-year experience. As an additional analysis, the three quality of campus relationship items were combined into one composite score (Appendix $C$ ) to evaluate the effect of all campus relationships on satisfaction of first-generation and continuinggeneration students.

Research Question Six: Is the quality of relationships (with other students, faculty members, and administrative personnel and offices) a significant predictor of senior measures of learning for first-generation and/or continuing-generation students? A hierarchical multiple regression model was built to determine if environmental variables, quality of campus relationships (with other students, faculty members, and administrative personnel and offices), were significant predictors of the senior learning outcome variable (ETS MAPP total score). Precollege characteristics or inputs were entered first in block one (aptitude ACT composite score, freshman year EFC, living on-campus in the 
freshman year, and miles from home in five categorical levels). The quality of campus relationship variables were entered next in block two, and finally, first-first-generation status was entered in block three. The data source was comprised of 75 senior respondents participating in both NSSE 2007 and ETS MAPP 2007 (30 students), as well as NSSE 2009 and ETS MAPP 2009 (45 students). The two cohorts were collapsed to create a respondent list of 75 students. As an additional analysis, composite scores were created as environment variables; three quality of relationship questions were combined with the two NSSE satisfaction items to create a composite score including both satisfaction and quality of campus relationships, as well as NSSE composite satisfaction score. (The SPSS code used to calculate satisfaction and quality of relationship composite scores is located in Appendix C).

\section{Limitations}

The number of respondents limited the number of variables considered in the student experience. While the sample appropriately represented the population at the university (both first-generation and continuing-generation students), a larger sample may have allowed for similar methods to be considered comparing students within major or discipline.

Independence of sample was certainly a consideration, as NSSE online participation was not proctored. With a large enough sample, institutions typically do not account for the independence of sample question because researchers assume most students complete the survey individually. The self-reporting issue was discussed by the NSSE research team, and the conclusion was reached that student self-report does not pose a threat to validity on national scale (NSSE, 2009). At a single institution, however, 
this could be a factor to consider. The NSSE research team also considered the self-select bias (Kuh, 2003a), but at a small private institution, this too is to consider.

The ETS MAPP assessment proved a reliable and valid direct measure of student learning in general education; however, sample size was important on the abbreviated form because the assessment was only 40 minutes in length. Also, in terms of vulnerability, the writing sub-score was considered valid in measuring student's ability to determine sentence structure, but most language experts suggest that actual writing skills cannot be assessed with multiple choice questions.

The Astin I-E-O model (1970) was used as a tool to assess the student experience by accounting for some of the complexity in determining if student development occurred based on programs and experiences at the institution. Astin suggested several considerations in terms of using the model. First, a single institution study was limited by the question of whether the same student development would have occurred at another institution or if the student had not attended college at all. The purpose of this study was to determine first-generation student development compared to continuing-generation student development at a single institution. Astin thus implies that a follow-up study may be appropriate at another similar institution to compare results. Second, multiple outcomes should be used to assess the student experience. This research project used learning and satisfaction as outcome measures, but there are additional measures appropriate for subsequent research. The purpose of the results was to inform researchers, practitioners, and policymakers of additional outcomes worthy of further consideration. Third, the basic premise of the Astin model is to determine the inputs characteristics of students to assess if the college experience has made a difference in student development. 
While many input student characteristics and control variables were used in this study, there were more that could not be considered, because of small sample size and the limited scope of the study. Finally, confounding variables were considered such maturation or student development, both of which can be induced by society. Because this research investigated the four-year experience, the time and intensity of the environmental experience was somewhat understood; however, individual experiences differed in time spent or intensity of exposure. For example, a student athlete who only participated in the freshman year had a different treatment effect than the four-year athlete. To account for this, each variable was specifically defined for consistent results. For example, a student athlete was considered as such only if designated as a varsity athlete in his or her senior NSSE response, rather than using a freshman NSSE survey, because this status could change in the second or third year of college.

The final limitation was in studying the four-year experience only. Students who did not persist for four years may have withdrawn because of academic struggles related to factors such as first-generation status. However, the purpose of this research was to determine if engagement, learning, and satisfaction measures were influenced over the course of the entire collegiate experience due to first-generation status. 
Table 3.11

Summary of Variables Used in Research Questions

\begin{tabular}{|c|c|c|c|c|}
\hline $\begin{array}{l}\text { Research } \\
\text { question }\end{array}$ & $\begin{array}{l}\text { Input } \\
\text { variables or independent } \\
\text { variables }\end{array}$ & $\begin{array}{l}\text { Environmental } \\
\text { variables or covariates }\end{array}$ & $\begin{array}{l}\text { Outcome } \\
\text { variables }\end{array}$ & $\begin{array}{l}\text { Statistical } \\
\text { analysis }\end{array}$ \\
\hline 1 & First-generation status & $\begin{array}{l}\text { Aptitude (ACT } \\
\text { composite score) }\end{array}$ & $\begin{array}{l}\text { Seven ETS } \\
\text { MAPP scores }\end{array}$ & MANCOVA \\
\hline 2 & $\begin{array}{l}\text { First-generation status, aptitude } \\
\text { (ACT composite score), EFC, } \\
\text { miles from home, living on- } \\
\text { campus in the freshman year }\end{array}$ & $\begin{array}{l}\text { Five senior NSSE } \\
\text { benchmarks }\end{array}$ & $\begin{array}{l}\text { ETS MAPP total } \\
\text { score }\end{array}$ & $\begin{array}{l}\text { Multiple } \\
\text { regression }\end{array}$ \\
\hline 3 & First-generation status & $\begin{array}{l}\text { Aptitude (ACT } \\
\text { composite score) }\end{array}$ & $\begin{array}{l}\text { Two senior } \\
\text { NSSE } \\
\text { satisfaction items }\end{array}$ & MANCOVA \\
\hline $4 \mathrm{~A}$ & $\begin{array}{l}\text { First-generation status, aptitude } \\
\text { (ACT composite score), EFC, } \\
\text { miles from home, living on- } \\
\text { campus in the freshman year }\end{array}$ & 12 Pike "scalelets" & $\begin{array}{l}\text { Combined senior } \\
\text { NSSE } \\
\text { satisfaction score }\end{array}$ & $\begin{array}{l}\text { Multiple } \\
\text { regression }\end{array}$ \\
\hline $4 \mathrm{~B}$ & $\begin{array}{l}\text { First-generation status, aptitude } \\
\text { (ACT composite score), EFC, } \\
\text { miles from home, living on- } \\
\text { campus in the freshman year }\end{array}$ & $\begin{array}{l}\text { High impact/ } \\
\text { university-specific } \\
\text { activities }\end{array}$ & $\begin{array}{l}\text { Combined senior } \\
\text { NSSE } \\
\text { satisfaction score }\end{array}$ & $\begin{array}{l}\text { Multiple } \\
\text { regression }\end{array}$ \\
\hline 5 & $\begin{array}{l}\text { First-generation status, aptitude } \\
\text { (ACT composite score), EFC, } \\
\text { miles from home }\end{array}$ & $\begin{array}{l}\text { Three NSSE quality of } \\
\text { relationship items }\end{array}$ & $\begin{array}{l}\text { Combined senior } \\
\text { NSSE } \\
\text { satisfaction score }\end{array}$ & $\begin{array}{l}\text { Multiple } \\
\text { regression }\end{array}$ \\
\hline 6 & $\begin{array}{l}\text { First-generation status, aptitude } \\
\text { (ACT composite score), EFC, } \\
\text { miles from home, living on- } \\
\text { campus in the freshman year }\end{array}$ & $\begin{array}{l}\text { Three NSSE quality of } \\
\text { relationship items, } \\
\text { combined senior NSSE } \\
\text { satisfaction score, } \\
\text { NSSE combined quality } \\
\text { of relationship and } \\
\text { satisfaction score }\end{array}$ & $\begin{array}{l}\text { ETS MAPP total } \\
\text { score }\end{array}$ & $\begin{array}{l}\text { Multiple } \\
\text { regression }\end{array}$ \\
\hline
\end{tabular}

Note. The analysis of research questions $4 \mathrm{~A}$. and $4 \mathrm{~B}$. involved comparing and contrasting the models developed for the two analyses, specifically the size of $R^{2}$ and the amount of variance in the outcome variable accounted for by the environmental variables. 


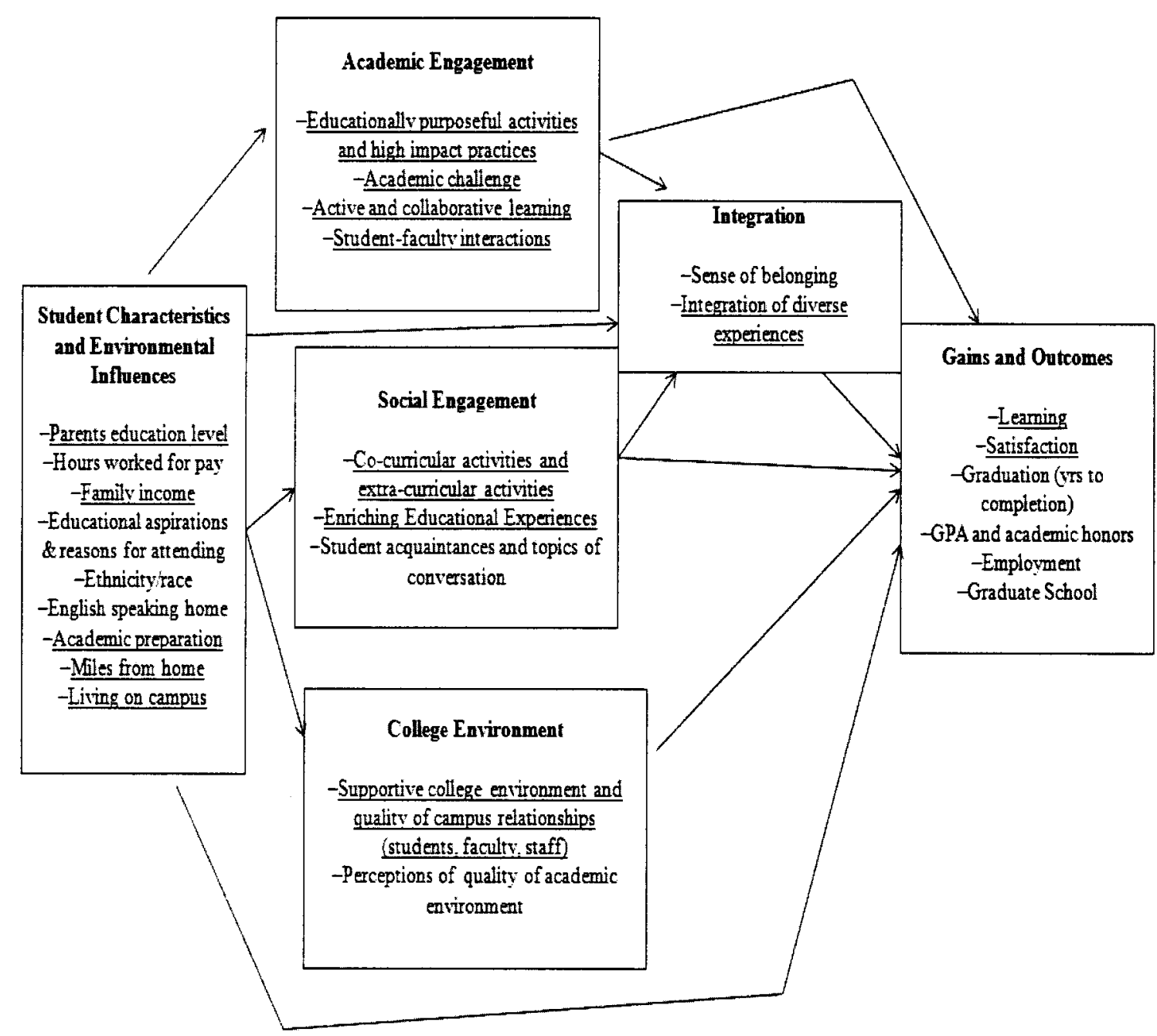

Figure 3.12. Model of factors investigated to determine influence on first-generation student learning and satisfaction The Astin (1993) I-E-O, Pascarella (1985) and Pike and Kuh (2005) models were integrated for practitioners' use in evaluating the characteristics and experiences which influence first-generation student learning and satisfaction. Underlined are those factors investigated for in the research. 


\section{CHAPTER IV}

\section{RESULTS}

Results of the study are presented in sections that correspond to the research questions. Within each section are presented details of the data that were analyzed including demographic information on participants. All data that were analyzed came from existing records and files that were available at the research setting.

\section{Research Question One}

Does a statistically significant difference exist in senior measures of learning between first-generation and continuing-generation students?

No significant difference existed in senior measures of learning between firstgeneration and continuing-generation students $(p<.05)$. Learning measures considered were ETS MAPP sub-scores in the senior year after controlling aptitude (ACT composite), the ETS MAPP Total score in the senior year after controlling aptitude (ACT composite), and the cumulative senior grade point average $(p<.05)$.

Research question one addressed whether learning measures after the four-year college experience were significantly different between the first-generation student group and the continuing-generation student group after controlling for aptitude. The sample consisted of first-generation and continuing-generation students from the following senior classes: spring $2007(n=72)$; spring $2008(n=54)$; spring $2009(n=111)$; and spring $2010(n=105)$. The total sample consisted of 342 senior students with the 
following demographic composition: $26 \%$ first-generation students; $89 \%$ white; $95.9 \%$ full-time students; and $78.9 \%$ who transferred zero hours into the institution. The firstgeneration group was $88 \%$ white, compared to $90 \%$ white of continuing-generation students.

A one-way multivariate analysis of covariance (MANCOVA) was completed where first-generation students were compared to continuing-generation students, using two levels of the IV (first-generation student group, continuing-generation student group) with seven DVs (senior ETS MAPP sub-scores: critical thinking; reading; writing; math; humanities; social science; and natural sciences), and controlling with covariate aptitude (ACT composite score).

Two assumptions of MANCOVA were met. First, the primary MANCOVA assumption was tested, determining whether a significant relationship existed between DVs ETS MAPP sub-scores and the CV ACT composite score. A significant multivariate relationship was found, Hotelling's trace $=1.40, F(7,279)=55.96, p<.01$. This relationship determined that a MANCOVA was appropriate to create a meaningful reduction of error variance in the DVs. Also, a significant Pearson correlation existed between each EST MAPP sub-score and the ACT composite score at $p=.001$. The Astin model (1970) suggests accounting for variance in inputs or precollege characteristics. In this case, controlling for precollege aptitude (inputs) allowed for an equitably comparison of senior test scores (outcomes) for the two groups after the four-year experience of college (environment). A second assumption was tested to determine if there was equality of regression coefficients for the two groups, a critical assumption for a valid MANCOVA (Stevens, 2002). To meet this assumption, there should be no significant 
interaction effect between the covariate (ACT composite score) and the treatment effect on the two groups. If DVs are graphed for each of the two groups, parallel lines demonstrates that the assumption is met. In this case, a nonsignificant multivariate test proved no significant interaction effect, Hotelling's trace $=.017$, approximate $F(7,278)=$ $.69, p=.68$.

The overall results of the MANCOVA were not significant. No significant effect of first-generation status on DVs (7 ETS MAPP sub-scores) were found, after controlling for ACT composite score as follows: Hotelling's trace $=.041, F(7,279)=1.65, p=.122$. Table 4.1 shows the adjusted means as well as the cumulative college grade point average (GPA) for each group. In summary, no significant difference existed in the adjusted ETS MAPP sub-scores between first-generation students and continuing-generation students.

Table 4.1 (RQ1)

Comparison of Adjusted Means of ETS MAPP Sub-Scores for First-generation and Continuing-generation students $(n=288)$

\begin{tabular}{lcc}
\cline { 2 - 3 } & $\begin{array}{c}\text { First- } \\
\text { generation }\end{array}$ & $\begin{array}{c}\text { Continuing- } \\
\text { generation }\end{array}$ \\
\hline ETS MAPP Total Score (400-500 point scale) & 459.40 & 456.55 \\
ETS MAPP Writing (100-130 point scale) & 117.54 & 116.69 \\
ETS MAPP Reading (100-130 point scale)* & 123.16 & 121.51 \\
ETS MAPP Math (100-130 point scale) & 115.11 & 115.37 \\
ETS MAPP Critical Thinking (100-130 point scale) & 115.50 & 115.18 \\
ETS MAPP Humanities (100-130 point scale) & 118.31 & 117.65 \\
ETS MAPP Social Science (100-130 point scale)* & 117.62 & 116.08 \\
ETS MAPP Natural Science (100-130 point scale) & 118.81 & 118.39 \\
Cumulative College GPA (0-4 point scale) & 3.36 & 3.36 \\
\hline
\end{tabular}

Note. ETS MAPP mean scores were adjusted from MANCOVA with covariate ACT composite score. ${ }^{*} p<.05$. 
The ETS MAPP total score (DV) was checked with an ANCOVA in a separate procedure, which also served to confirm the overall MANCOVA test of significance. No significance difference existed between ETS MAPP total score means, comparing the first-generation student group (IV) and the continuing-generation student group (IV) after controlling for ACT composite score (CV), $p=.06$. Both ANCOVA assumptions were met.

The analysis of variance procedures were repeated without using the ACT composite score as a covariate. The results were the same; no significant difference existed in mean ETS MAPP total score or sub-scores between first-generation and continuing-generation students at $p=.05$.

Because the overall MANCOVA was not significant, univariate differences were limited. As expected from the overall MANCOVA results, no significant difference existed in adjusted means between first-generation and continuing-generation on DVs (seven ETS MAPP sub-scores) with the exception of reading $(p=.013)$ and social sciences $(p=.024)$ scores, where first-generation students scored slightly higher than continuing-generation students. However the effect sizes were quite small in reading $\left(\eta_{p}{ }^{2}\right.$ $=.022)$ and social sciences $\left(\eta_{p}{ }^{2}=.018\right)$; therefore, the two sub-scores were not considered significant conclusions.

Additional statistical methods were performed which flowed from the research question in terms of differences in high school preparation between the two student groups. ANOVA comparisons were made between the first-generation student group and the continuing-generation student group for ACT composite score, ACT science, ACT English, ACT reading, ACT math, high school GPA and cumulative college GPA in the 
student's senior year. No differences in the means between the groups was found ( $p=$ .05). Practically speaking, there appeared to be a difference in all ACT scores serving as precollege characteristics or inputs (Astin, 1970), where first-generation students had lower mean scores than continuing-generation students. However even considering a higher significance threshold $(p<.1)$, only ACT math was significantly different, where first-generation students scored lower. Also at the higher significance threshold $(p<.1)$, but in contrast to ACT math findings, high school grade point average (GPA) was greater for first-generation than continuing-generation students. Again these findings were worth noting, but not significant conclusions. See Appendix $F$ for mean ACT scores and high school GPA.

An additional analysis was performed which also flowed from research question one. The dataset included a question before the ETS MAPP test asking for the hours a student worked weekly while enrolled at the university. Because the literature stated that first-generation students typically work more hours per week, affecting learning and the college experience (Arum \& Roksa, 2010; Pascarella \& Terenzini, 1991), an additional analysis was completed to determine if hours worked weekly influenced the ETS MAPP total score. Results from Pearson correlations and a multiple regression were conclusive that this variable, hours worked weekly, was not significantly related to first-generation status or the ETS MAPP total score (learning measures) at $p<.05$. The model was significant, but nearly all of the variance was accounted by ACT composite score $\left(R^{2}=\right.$ .577), with no significant influence from hours worked weekly or first-generation status $\left(\Delta R^{2}=.006\right), F(3,282)=131.45, p<.1$. First-generation students, however, reported working more hours than continuing-generation students, with $47 \%$ of first-generation 
reporting that they worked 16 or more hours per week compared with $39 \%$ of continuinggeneration students. More continuing-generation students worked 1-15 hours (45\%) compared to first-generation students ( $40 \%)$ or worked no hours at all (15\% vs. $14 \%)$. Overall both groups worked a substantial number of hours per week, but without an effect on the ETS MAPP total score.

A final analysis was performed also related to student learning, but investigating a topic which could not be addressed by research question one. First-generation students typically choose professional majors leading to immediate employment rather than arts and science majors which prepared them for graduate school (Nunez \& Cuccaro-Alamin, 1998; Pascarella, et al., 2004; Terenzini, et al., 1996). Results from this study showed that first-generation students had a slightly greater frequency than continuing-generation students of majoring in professional studies (business, accounting, health and medical sciences) rather than traditional arts and sciences disciplines ( $36 \%$ of first-generation students chose professional majors compared to $33 \%$ of continuing-generation students).

\section{Research Question Two}

Do senior NSSE benchmark scores (engagement variables) significantly predict senior measures of learning for first-generation and/or continuing-generation students?

NSSE benchmarks (considered as environment variables) did not significantly influence senior measures of learning (ETS MAPP Total score) for either the firstgeneration student group or the continuing-generation student group. NSSE benchmarks (EEE, SCE, ACL, LAC, SFI), added only a very small $\Delta R^{2}=.038$ with no significant predictors $(p<.05)$. 
A hierarchical multiple regression model was built by entering control variables first (aptitude ACT composite score, freshman year expected family contribution (EFC), living on-campus in the freshman year, and miles from home at five levels) in block one as inputs in the Astin I-E-0 model (1970). The model then considered possible predictor variables (five NSSE benchmarks: EEE; SCE; ACL; LAC; and SFI) as block two. Each environment variable was a NSSE calculated composite score representing the benchmark, unadjusted by NSSE for part-time students because the vast majority of the sample was composed of full-time students (97\%) and students who completed four years at the same institution ( $85 \%$ ). The final block considered input variable, first-generation status. The outcome DV was the ETS MAPP total score. The data came from senior student respondents participating in both NSSE 2007 and ETS MAPP $2007(n=30)$, as well as NSSE 2009 and ETS MAPP $2009(n=45)$. The two cohorts were combined, thus creating a total respondent number of 75 students.

Two models were built because many of the student participants had a blank EFC (there were students who did not complete the Free Application for Federal Student Aid known as the FAFSA). When EFC was removed as an input variable, the sample size was $n=63$; when EFC was included, the sample size was $n=39$. The remaining 12 students had missing data in one of the input or environment variables.

Regarding the dataset which included EFC as a possible predictor variable $(n=$ $39)$, three predictors were significantly related in terms of Pearson correlations $(p<.05)$ with the DV ETS MAPP total score: aptitude ACT composite score $(r=.72)$; firstgeneration status $(r=.30)$; and miles from home $(r=-.35)$. The hierarchical regression yielded only two significant predictor variables $(p<.05)$ because the model controlled for 
all of other possible predictor variables, which changes the relationship from that of a Pearson correlation. Table 4.2 displays all the model's regression coefficients. Aptitude ACT composite score $(\beta=.69)$ and first-generation status $(\beta=.25)$ were significant predictors of DV ETS MAPP total score. The final model was significant $F(9,29)=6.71$, $p<.1$. The $R^{2}$ for the final regression equation was .676 , thus accounting for approximately $68 \%$ of the variance of ETS MAPP total score.

Block one precollege characteristics or inputs was significant; however, only aptitude (ACT composite score) was a significant predictor $F(3,35)=16.76, p<0.1, R^{2}$ $=.554$. Block two considered the environment variables, NSSE benchmarks (EEE, SCE, ACL, LAC, SFI) but added only a very small $\Delta R^{2}=.038$ with no significant predictors ( $p$ $<.05$ ). Finally, block three considered first-generation status, which was significant $(p<$ $.05)$, but with a limited effect $\left(\Delta R^{2}\right.$ from block two to block three of .048 or approximately $5 \%$ of the variance).

To summarize the model which included EFC as a possible predictor variable ( $n=$ 39), first-generation status was positively associated with ETS MAPP test performance. NSSE benchmark scores (environmental variables) were not significantly related or significant predictors of the ETS MAPP total score. Furthermore, other precollege characteristics (input variables), including EFC, living on-campus in the freshman year, and miles from home, were also not significant predictors of ETS MAPP total score. Plots of the data revealed that no serious violations of normality, homoscedasticity, or linearity. 
Table 4.2 (RQ2)

Model Considering NSSE Benchmarks as Predictors of ETS MAPP Total Score (students with Expected Family Contribution Data EFC) $(n=39)$

\begin{tabular}{|c|c|c|c|c|c|c|}
\hline Predictor Variables of & Step & $\mathrm{B}$ & SEB & $\beta$ & $T$ & $p$ \\
\hline Constant & 1 & 368.01 & 16.46 & & 22.35 & .000 \\
\hline ACT Composite & & 3.74 & .61 & .70 & 6.13 & .000 \\
\hline Living On-Campus in Freshman & & -6.75 & 4.09 & -.19 & -1.65 & .108 \\
\hline \multicolumn{7}{|l|}{ Year } \\
\hline EFC & & .00 & .00 & -.22 & -1.98 & .056 \\
\hline Miles from Home & & -1.25 & 1.43 & -.10 & -.87 & .390 \\
\hline \multirow[t]{2}{*}{ Constant } & & 389.35 & 23.53 & & & \\
\hline & 2 & & & & 16.54 & .000 \\
\hline ACT Composite & & 3.48 & .72 & .65 & 4.81 & .000 \\
\hline Living On-Campus in Freshman & & -3.96 & 5.03 & -.11 & & \\
\hline Year & & & & & -.79 & .436 \\
\hline EFC & & -.00 & .00 & -.15 & -1.24 & .224 \\
\hline Distance & & -2.21 & 1.61 & -.18 & -1.37 & .180 \\
\hline NSSE Benchmark LAC (Level of & & -.178 & .185 & -.13 & & \\
\hline Academic Challenge) & & & & & -.96 & .343 \\
\hline NSSE Benchmark ACL (Active and & & -.113 & .176 & -.11 & & \\
\hline Collaborative Learning) & & & & & -.64 & .524 \\
\hline NSSE Benchmark SFI (Student- & & -.027 & .159 & -.03 & & \\
\hline Faculty Interaction) & & & & & -.17 & .864 \\
\hline NSSE Benchmark EEE (Enriching & & .015 & .15 & .02 & & \\
\hline Educational Experience) & & & & & .01 & .922 \\
\hline NSSE Benchmark SCE (Supportive & & .073 & .12 & .08 & & \\
\hline Campus Environment) & & & & & .60 & .556 \\
\hline \multirow[t]{2}{*}{ Constant } & & 373.07 & 23.66 & & & \\
\hline & 3 & & & & 15.77 & .000 \\
\hline ACT Composite & & 3.67 & .69 & .69 & 5.30 & .000 \\
\hline Living On-Campus in Freshman & & -2.44 & 4.82 & -.07 & & \\
\hline Year & & & & & -.51 & .617 \\
\hline EFC & & -.00 & .00 & -.14 & -.29 & .772 \\
\hline Distance & & -1.31 & 1.59 & -.11 & -.83 & .415 \\
\hline NSSE Benchmark LAC (Level of & & -.14 & .18 & -.10 & & \\
\hline Academic Challenge) & & & & & -.77 & .446 \\
\hline NSSE Benchmark ACL (Active and & & -.04 & .17 & -.04 & & \\
\hline Collaborative Learning) & & & & & -.22 & .828 \\
\hline NSSE Benchmark SFI (Student- & & -.01 & .15 & -.01 & - & \\
\hline Faculty Interaction) & & & & & .07 & .949 \\
\hline NSSE Benchmark EEE (Enriching & & .00 & .15 & .00 & & \\
\hline Educational Experience) & & & & & .01 & .992 \\
\hline NSSE Benchmark SCE (Supportive & & .06 & .12 & .07 & & \\
\hline Campus Environment) & & & & & .55 & .588 \\
\hline First-Generation Status & & 9.31 & 4.48 & .25 & 2.08 & .047 \\
\hline
\end{tabular}

Note. For step $1, R^{2}=.590$ (adjusted $R^{2}=.554$ ). For step $2, R^{2}=.627$ (adjusted $R^{2}=.528$ ). For step $3, R^{2}=$ $.676\left(\right.$ adjusted $\left.R^{2}=.575\right)$. 
There was little evidence of multicollinearity between the two predictor variables. Aptitude (ACT composite score) was not significantly related $(p<.05)$ to first-generation status, with a small Pearson correlation value $(r=-.32)$. The collinearity statistic tolerance for first-generation status was .786 , which is not considered problematic. Menard (1995) recommends investigating tolerance less than .1 as a potential multicollinearity problem.

This sample was limited to students who only completed a FAFSA (where EFC was available $(n=39)$. First-generation students had greater financial need with $42.8 \%$ Pell eligible $(E F C<\$ 5273)$ compared to $13.3 \%$ of continuing-generation students. The $M_{\mathrm{FG}}=\$ 14,584 \mathrm{EFC}$ was substantially greater than $M_{\mathrm{CG}}=\$ 27,033$. Note that this was a positive relationship; first-generation students performed better on senior learning measures (ETS MAPP total score) when the sample size was limited to the students with greater financial need.

Regarding the model which excluded EFC as a possible predictor variable $(n=$ 63), two predictors were significantly related in terms of Pearson correlation $(p<.05)$ to the DV ETS MAPP total score: aptitude ACT composite score $(r=.68)$; and miles from home $(r=-.28)$. However, the hierarchical regression yielded only one significant predictor variable $(p<.05)$, which occurred in block one. Table 4.3 displays all the model's regression coefficients. Aptitude ACT composite score $(\beta=.66)$ was a significant predictor of DV ETS MAPP total score. Block one was significant as follows: $F(2,60)=$ $27.23, p<.1$. The $R^{2}$ for the regression equation in block one was .473 , thus accounting for approximately $47 \%$ of the variance of the ETS MAPP Total score predicted from variable aptitude ACT composite score. The increase in $R^{2}$ from block one to block two 
was a .026 change; there was a .004 change from block two to three. The variance predicted by first-generation status was not significant as a predictor in block three, nor were NSSE benchmark scores (environment variables) in block two. Furthermore, other precollege characteristics (input variables) in block one (EFC, miles from home, living on-campus in the freshman year), also were not significant predictors of ETS MAPP total score. Plots of the data revealed that no serious violations of normality, homoscedasticity, or linearity.

Table 4.3 (RQ2)

Model Considering NSSE Benchmarks as Predictors of ETS MAPP Total Score (excluding Expected Family Contribution Data EFC as a variable) $(n=63)$

\begin{tabular}{|c|c|c|c|c|c|c|}
\hline Predictor Variables of & Step & $\mathrm{B}$ & SEB & $\beta$ & $t$ & $p$ \\
\hline Constant & 1 & 368.56 & 14.55 & & 25.33 & .000 \\
\hline ACT Composite & & 3.66 & .54 & .66 & 6.77 & .000 \\
\hline Living On-campus in Freshman year & & -2.78 & 3.97 & -.07 & -.70 & .487 \\
\hline Miles from Home & & -1.26 & 1.36 & -.09 & -.93 & .354 \\
\hline Constant & 2 & 388.11 & 20.90 & & 18.57 & .000 \\
\hline ACT Composite & & 3.45 & .58 & .62 & 5.96 & .000 \\
\hline Living On-campus in Freshman year & & -1.75 & 4.41 & -.04 & -.40 & .693 \\
\hline Distance & & -1.72 & 1.44 & -.12 & -1.20 & .237 \\
\hline NSSE Benchmark LAC (Level of & & -.12 & .186 & -.07 & & \\
\hline Academic Challenge) & & & & & -.62 & .540 \\
\hline NSSE Benchmark ACL (Active and & & -.239 & .165 & -.21 & & \\
\hline Collaborative Learning) & & & & & -1.45 & .152 \\
\hline NSSE Benchmark SFI (Student- & & .146 & .135 & .17 & & \\
\hline Faculty Interaction) & & & & & 1.08 & .285 \\
\hline NSSE Benchmark EEE (Enriching & & .01 & 13 & .01 & & \\
\hline Educational Experience) & & & & & .08 & .940 \\
\hline NSSE Benchmark SCE (Supportive & & -.02 & .11 & -.02 & & \\
\hline Campus Environment) & & & & & -.16 & .877 \\
\hline Constant & 3 & 383.29 & 22.20 & & 17.26 & .000 \\
\hline ACT Composite & & 3.53 & .59 & .64 & 5.95 & .000 \\
\hline Living On-campus in Freshman year & & -1.50 & 4.43 & -.04 & -.34 & .736 \\
\hline Distance & & -1.57 & 1.46 & -.11 & -1.08 & .287 \\
\hline $\begin{array}{l}\text { NSSE Benchmark LAC (Level of } \\
\text { Academic Challenge) }\end{array}$ & & -.10 & .19 & -.07 & -.55 & .584 \\
\hline $\begin{array}{l}\text { NSSE Benchmark ACL (Active and } \\
\text { Collaborative Learning) }\end{array}$ & & -.22 & .17 & -.19 & -1.30 & .199 \\
\hline $\begin{array}{l}\text { NSSE Benchmark SFI (Student- } \\
\text { Faculty Interaction) }\end{array}$ & & .15 & .14 & .18 & $1: 11$ & .271 \\
\hline NSSE Benchmark EEE (Enriching & & .00 & .13 & .00 & .03 & .977 \\
\hline
\end{tabular}


Educational Experience)

NSSE Benchmark SCE (Supportive

Campus Environment)

First-generation status

$\begin{array}{lllll}-.02 & .11 & -.02 & -.17 & .864\end{array}$

$\begin{array}{lllll}2.74 & 4.09 & .07 & .67 & .506\end{array}$

Note. For step $1, R^{2}=.476$ (adjusted $R^{2}=.458$ ). For step $2, R^{2}=.502$ (adjusted $R^{2}=.439$ ).

For step $3, R^{2}=.506$ (adjusted $R^{2}=.433$ ).

A question that flowed from this research question was whether additional

variables which influenced student satisfaction models would also significantly influence senior measures of learning (ETS MAPP total score). The additional NSSE variables considered were select Pike "scalelets" (higher order thinking skills, diversity), composite score for general education gains (Appendix C), composite satisfaction score (Appendix C), hours spent weekly studying for class (NSSE, 2009), and the number of papers written in an academic year with at least 20 pages of text (NSSE, 2009). No significant relationships were found $(p<.05)$.

\section{Research Question Three}

Does a statistically significant difference exist in senior satisfaction measures between first-generation and continuing-generation students?

No significant difference existed in senior measures of satisfaction between firstgeneration and continuing-generation students after controlling for aptitude $(p<.05)$. Satisfaction measures were adjusted senior means from the following NSSE items: (a) how would you evaluate your entire educational experience at this institution; and (b) if you could start over again, would you go to the same institution you are now attending. The control or covariate (CV) was aptitude (ACT composite).

Research question three addressed whether satisfaction measures after the fouryear college experience were significantly different at a small private institution in the Midwest, after controlling for aptitude between the first-generation student group and the 
continuing-generation student group. The sample consisted of first-generation and continuing-generation students participating in the NSSE both in the freshman and senior year: spring 2002 to spring 2005 ( $n=41)$; spring 2003 to spring $2006(n=45)$; spring 2004 to spring 2007 ( $n=18)$; and spring 2006 to spring $2009(n=78)$. The total sample consisted of 182 senior students. First-generation students represented $50 \%$ of the sample. The first-generation student group was $79 \%$ female, $46 \%$ lived on-campus as freshmen, $91 \%$ white, $96 \%$ full-time students. Continuing-generation students were quite similar on demographic variables: $78 \%$ female; $58 \%$ living on-campus in the freshman year; $88 \%$ white; and $99 \%$ full-time students.

A one-way Multivariate Analysis of Covariance (MANCOVA) was completed. First-generation students were compared to continuing-generations students, using two levels of the IV (first-generation student group, continuing-generation student group) with two NSSE satisfaction scores: (a) how would you evaluate your entire educational experience at this institution; and (b) if you could start over again, would you go to the same institution you are now attending. The control or covariate (CV) was aptitude (ACT composite).

Two assumptions of MANCOVA were met. First, the primary MANCOVA assumption was tested, determining whether a significant relationship existed between NSSE satisfaction scores and the CV ACT composite score. A significant multivariate relationship was not found, Hotelling's trace $=.00425, F(2,171)=.36, p=.696$. This relationship determined that the MANCOVA did not reduce error variance in the DVs. A second assumption was tested to determine if there was equality of regression coefficients for the two groups, a critical assumption for a valid MANCOVA (Stevens, 2002). To 
meet this assumption, there should be no significant interaction effect between the CV and the treatment effect on the two groups. If DVs are graphed for each of the two groups, parallel lines demonstrate that the assumption is met. In this case, the assumption was met. A nonsignificant multivariate test proved no significant interaction effect, Hotelling's trace $=.033$, approximate $F(2,170)=2.83, p=.062$. Overall, however, the controlling for aptitude (ACT composite) was unnecessary because no significant correlation existed between CV aptitude and the NSSE satisfaction items (DVs).

The overall results of the MANCOVA were not significant. Table 4.4 includes the adjusted means from NSSE satisfaction items comparing the two student groups. No significant effect of first-generation status was found on DVs (NSSE satisfaction items), after controlling for ACT composite score as follows: Hotelling's trace $=.008, F(2,171)$ $=.718, p=.489$. Thus, no significant difference existed in the adjusted NSSE satisfaction items between first-generation students and continuing-generation students. The NSSE satisfaction item, evaluate your experience at this institution, the adjusted mean score for continuing-generation students $\left(M_{\mathrm{CG}}=116.65\right)$ was not significantly different than the adjusted mean of the first-generation students $\left(M_{\mathrm{FG}}=113.05\right)$. Regarding NSSE satisfaction item, if you could start over again, would you go to the same institution you are now attending, the adjusted mean score for continuing-generation students $\left(M_{\mathrm{CG}}=110.99\right)$ was not significantly different than the adjusted mean of the firstgeneration students $\left(M_{\mathrm{FG}}=107.66\right)$. 
Table 4.4 (RQ3)

Comparison of Adjusted Means of NSSE Satisfaction Items for First-generation and Continuing-generation students $(n=171)$

\begin{tabular}{lcc}
\cline { 3 - 3 } & $\begin{array}{c}\text { First- } \\
\text { generation }\end{array}$ & $\begin{array}{c}\text { Continuing- } \\
\text { generation }\end{array}$ \\
\hline $\begin{array}{l}\text { Evaluate Your Entire Educational Experience at this } \\
\quad \text { Institution. }\end{array}$ & 113.05 & 116.65 \\
$\begin{array}{l}\text { Would You Go to the Same Institution You Are } \\
\text { Now Attending? }\end{array}$ & 107.66 & 110.99 \\
\hline
\end{tabular}

Note. ETS MAPP mean scores were adjusted from MANCOVA with covariate ACT composite score.

Although the overall MANCOVA was not significant, a simple t-test was run for an additional analysis because the covariate (aptitude ACT composite score) was not related to the DVs. The t-test confirmed that no difference existed in NSSE satisfaction items between first-generation and continuing-generation student groups. Regarding NSSE satisfaction item, evaluate your entire educational experience at this institution, the insignificant t-test was as follows: $t=1.16, p=.247$ (2-tailed). The Levene test of equality of variances was not significant $(p<.981)$. Regarding NSSE satisfaction item, if you could start over again, would you go to the same institution you are now attending, the insignificant t-test was as follows: $t=.725, p=.470$ (2-tailed). The Levene tests of equality of variances was not significant $(p<.378)$.

\section{Research Question Four}

Do Pike "scalelets" generate a better predictive model of senior satisfaction than the engagement variables from high impact practices/university-specific activities?

The high impact practices/university-specific activities model was not significant predictor of student satisfaction in the senior year $(F(12,161)=1.037, p=.417)$. No variables considered were significant predictors of outcome satisfaction score $(p<.05)$. 
The model yielded an adjusted $R^{2}$ of .003 . In contrast, the Pike "scalelets" model was a significant predictor of senior student satisfaction: $F(17,157)=10.26, p<.001$. The $R^{2}$ for the entire equation was .526 (adjusted $R^{2}=.478$ ). Thus, approximately $48 \%$ of the variance in combined satisfaction score was associated with Pike "scalelets." The following "scalelets" (environmental variables) had statistically significant partial regression coefficients $(p<.05)$ : higher order thinking skills $(\beta=.14)$; varied education experience $(\beta=-.18)$; support for student success $(\beta=.17)$; and interpersonal environment $(\beta=.59)$.

The two models were compared to evaluate factors which predict satisfaction in college seniors. A composite NSSE satisfaction score was created as the outcome by combining the two NSSE satisfaction items (evaluate your entire educational experience at this institution and if you could start over again, would you go to the same institution you are now attending). An $R^{2}$ was calculated for both multiple regression models, determining which would be a better overall predictive model for satisfaction. The first model considered environment experiences using 12 Pike "scalelets" as follows: course challenge; writing; active-learning experiences; higher order thinking skills; collaborative learning experiences; course-related interactions with faculty; out-of-class interaction with faculty; use of information technology; diversity; varied educational experiences; support for student success; and interpersonal environment. Appendix $C$ includes the details regarding how each Pike "scalelet" was calculated. The second model considered environment variables which were either high impact practices or university-specific activities. The following variables were considered in the model: capstone; study abroad; research with a faculty member; community service; honors program; Brown scholars 
(leadership and volunteer service program); mock trial team; athlete; and work-study. As an additional analysis, a third model was built for the "frontier" program, where data were only available in the first-year experience. The additional model assessed whether the program influenced satisfaction in the spring of the freshman year. All models attempted to identify predictive variables for each group (first-generation and continuinggeneration students).

A hierarchical multiple regression was used, first entering the input or control variables (block one): aptitude (ACT composite score); EFC in six categorical variables; living on-campus in the freshman year; and miles from home in five categorical levels. Environment variables were entered next (block two), followed by first-generation status (block three). Participation consisted of students who completed both the freshman and senior NSSE, totaling 182 students as follows: spring 2002 to spring 2005 ( $n=41)$; spring 2003 to spring $2006(n=45)$; spring 2004 to spring $2007(n=18)$; and spring 2006 to spring 2009 ( $n=78)$. Regarding demographics, the first-generation student group was $79 \%$ female, $46 \%$ living on-campus as freshmen, $82 \%$ local students (from less than 50 miles away), $9 \%$ from more than 200 miles away, $91 \%$ white, $96 \%$ full-time students. Continuing-generation students were quite similar on demographic variables: $78 \%$ female; $58 \%$ living on-campus in the freshman year; $72 \%$ local students; $9 \%$ from more than 200 miles away; $88 \%$ white; and $99 \%$ full-time students.

Considering the high impact practices/university-specific activities model in three steps from the Astin I-E-O model (1970), the input variables were entered in the first block. The results demonstrated that these background characteristics (Aptitude ACT composite score, freshman year EFC in six categorical levels, living on-campus in the 
freshman year, and miles from home at five categorical levels) did not significantly predict satisfaction. See Table 4.5 displaying all three insignificant steps. Thus the overall high impact practices/university-specific activities model was not significant, with no variables related to outcome satisfaction score in the regression $(F(12,161)=1.037$, $p=.417$ ) with an adjusted $R^{2}$ of .003 . The addition of first-generation status in the third step of the analysis did not result in a significant increase in variance.

Table 4.5

Results of Regression for high impact practices/university-specific activities as Predictors of NSSE Senior Satisfaction Score (outcome)

\begin{tabular}{lccc}
\hline & $R^{2}$ & $\begin{array}{c}\text { Adjusted } \\
R^{2}\end{array}$ & $\begin{array}{c}\text { Change in } \\
\text { Adjusted } R^{2}\end{array}$ \\
\hline $\begin{array}{l}\text { Step 1 } \\
\text { Precollege Characteristics (Inputs) }\end{array}$ & .010 & .000 & .000 \\
$\begin{array}{l}\text { Step 2 } \\
\text { High Impact Practices/University-specific } \\
\text { Activities (Environmental Variables) }\end{array}$ & .060 & .000 & .000 \\
$\begin{array}{l}\text { Step 3 } \\
\text { First-Generation Status }\end{array}$ & .072 & .003 & .003 \\
\hline
\end{tabular}

Note. ${ }^{a}$ Four variables: aptitude (ACT composite); EFC in six categorical levels; living on-campus; and miles from home. ${ }^{b}$ Seven variables. ${ }^{\mathrm{c}}$ One variable. ${ }^{*} p<.05$.

In summary, the overall high impact practices/university-specific activities model was not significant, with no variables related to outcome satisfaction score in the regression $(F(12,161)=1.037, p=.417)$ with an adjusted $R^{2}$ of .003 . See Table 4.6 listing all insignificant $(p<.05)$ regression coefficients. 
Table 4.6

Regression Coefficients of High Impact Practices/University-specific Activities $(n=174)$

\begin{tabular}{|c|c|c|c|c|c|c|}
\hline Predictor Variables Considered & Step & B & SEB & $\beta$ & $t$ & $p$ \\
\hline Constant & 1 & 111.09 & 12.19 & & 9.12 & .000 \\
\hline ACT Composite & & .01 & .49 & .00 & .02 & .988 \\
\hline Living On-campus in Freshman year & & 2.39 & 3.22 & .06 & .74 & .458 \\
\hline $\mathrm{EFC}$ (in 6 categories) & & .40 & .97 & .03 & .41 & .680 \\
\hline Miles from Home & & -1.29 & 1.18 & -.09 & -1.09 & .275 \\
\hline Constant & 2 & 104.50 & 15.38 & & 6.80 & .000 \\
\hline ACT Composite & & .16 & .50 & .03 & .32 & .749 \\
\hline Living On-campus in Freshman year & & .125 & 3.58 & .00 & .04 & .972 \\
\hline $\mathrm{EFC}$ (in 6 categories) & & .77 & 1.02 & .06 & .75 & .452 \\
\hline Miles from Home & & -1.57 & 1.20 & -.10 & -1.31 & .194 \\
\hline Capstone Senior Experience & & -1.06 & 1.88 & -.05 & -.56 & .575 \\
\hline Study Abroad & &. .96 & 1.86 & .04 & .51 & .608 \\
\hline Research with a Faculty Member & & -2.49 & 1.80 & -.11 & -1.38 & .169 \\
\hline Volunteer Service & & 2.57 & 1.85 & .11 & 1.39 & .165 \\
\hline $\begin{array}{l}\text { Learning Community (Honors, Brown } \\
\text { Scholars, Mock Trial) }\end{array}$ & & -3.46 & 3.47 & -.08 & -.10 & .320 \\
\hline Athlete & & 3.35 & 4.26 & .06 & .79 & .433 \\
\hline Work Study Position & & 4.55 & 3.89 & .10 & 1.17 & .245 \\
\hline Constant & 3 & 109.18 & 15.68 & & 6.96 & .000 \\
\hline ACT Composite & & .19 & .50 & .03 & .38 & .707 \\
\hline Living On-campus in Freshman year & & -.54 & 3.60 & -.01 & -.15 & .881 \\
\hline EFC (in 6 categories) & & .31 & 1.07 & .03 & .29 & .776 \\
\hline Miles from Home & & -1.69 & 1.20 & -.11 & -1.40 & .163 \\
\hline Capstone Senior Experience & & -1.18 & 1.88 & -.05 & -.63 & .53 \\
\hline Study Abroad & & .78 & 1.85 & .03 & .42 & .674 \\
\hline Research with a Faculty Member & & -2.44 & 1.80 & -.11 & -1.36 & .177 \\
\hline Volunteer Service & & 2.73 & 1.84 & .12 & 1.48 & .141 \\
\hline $\begin{array}{l}\text { Learning Community (Honors, Brown } \\
\text { Scholars, Mock Trial) }\end{array}$ & & -4.06 & 3.48 & -.10 & -1.17 & .245 \\
\hline Athlete & & 4.06 & 4.27 & .08 & .95 & .343 \\
\hline Work Study Position & & 4.27 & 3.89 & .09 & 1.10 & .273 \\
\hline First-generation status & & -4.96 & 3.48 & -.12 & -1.42 & .156 \\
\hline
\end{tabular}

Considering the Pike "scalelets" model in three steps from the Astin I-E-O model (1970), the input variables were entered in the first block. The results showed that these background characteristics (Aptitude ACT composite score, freshman year EFC in six categorical levels, living on-campus in the freshman year, and miles from home at five 
categorical levels) did not significantly predict satisfaction. Block one for the Pike "scalelets" model was insignificant as follows: $F(4,170)=.441, p=.78$. The Pike "scalelets" model became a significant predictive model in block two, where environment variables ("scalelets") added in the second step resulted in a regression model that was statistically significant $F(16,158)=10.97, p<.001$. Finally, the addition of firstgeneration status in the third step of the analysis did not result in a significant increase in variance, $F(1,157)=.009, p=.924$. See Table 4.7 for variance of each step.

Table 4.7

Results of Regression for Pike "Scalelets" as Predictors of NSSE Satisfaction Score (outcome)

\begin{tabular}{lccc}
\hline & $R^{2}$ & $\begin{array}{c}\text { Adjusted } \\
R^{2}\end{array}$ & $\begin{array}{c}\text { Change in } \\
\text { Adjusted } R^{2}\end{array}$ \\
\hline $\begin{array}{l}\text { Step 1 } \\
\text { Precollege Characteristics (Inputs) }\end{array}$ & .010 & .000 & .000 \\
$\begin{array}{l}\text { Step 2 } \\
\text { Pike "Scalelets" (Environmental }\end{array}$ & .526 & $.478^{*}$ & .478 \\
$\begin{array}{l}\text { Variables) } \\
\text { Step 3" } \\
\text { First-Generation Status }\end{array}$ & .526 & .478 & .000 \\
\hline
\end{tabular}

Note. ${ }^{\text {a}}$ Four variables: aptitude (ACT composite); EFC in six categorical levels; living on-campus; and miles from home. ${ }^{b}$ Twelve variables. ${ }^{\mathrm{c}}$ One variable. ${ }^{*} p<.001$.

The overall regression equation for the Pike "scalelets" model was statistically significant, $F(17,157)=10.26, p<.001$. The $R^{2}$ for the entire equation was .526 (adjusted $\left.R^{2}=.478\right)$. Thus, approximately $48 \%$ of the variance in combined satisfaction score was associated with Pike "scalelets." Table 4.8 displays all variables considered in each step of the Pike "scalelets" model. The following Pike "scalelets" (environmental variables) had statistically significant partial regression coefficients: higher order thinking skills ( $\beta$ $=.14)$; varied education experience ( $\beta=-.18)$; support for student success $(\beta=.17)$; and interpersonal environment $(\beta=.59)$. 
Table 4.8

Regression Coefficients Pike "Scalelets" as Predictors of NSSE Satisfaction ( $n=175)$

\begin{tabular}{|c|c|c|c|c|c|c|}
\hline Predictor Variables Considered & Step & $\mathrm{B}$ & SEB & $\beta$ & $t$ & $p$ \\
\hline Constant & 1 & 111.13 & 12.19 & & 9.12 & .000 \\
\hline ACT Composite & & .01 & .49 & .00 & .03 & .978 \\
\hline Living On-Campus in Freshman Year & & 2.16 & 3.21 & .05 & .67 & .501 \\
\hline EFC (in 6 categories) & & .43 & .97 & .04 & .44 & .659 \\
\hline Miles from Home & & -1.33 & 1.18 & -.09 & -1.13 & .260 \\
\hline Constant & 2 & 42.80 & 14.71 & & 2.91 & .004 \\
\hline ACT Composite & & .502 & .37 & .08 & 1.36 & .176 \\
\hline Living On-Campus in Freshman Year & & -1.75 & 2.37 & -.04 & -.74 & .462 \\
\hline $\mathrm{EFC}$ (in 6 categories) & & -.77 & .72 & -.06 & -1.06 & .290 \\
\hline Miles from Home & & -.39 & .90 & -.03 & -.43 & .667 \\
\hline Higher Order Thinking Skills & & .15 & .07 & $.14^{*}$ & 2.08 & .039 \\
\hline Collaborative Learning Experience & & .02 & .09 & .01 & .18 & .860 \\
\hline Course-Related Interactions with Faculty & & -.13 & .08 & -.12 & -1.56 & .120 \\
\hline Out-of-Class Interactions with Faculty & & .05 & .03 & .12 & 1.56 & .121 \\
\hline Use of Information Technology & & .10 & .08 & .09 & 1.16 & .246 \\
\hline Diversity & & -.12 & .06 & -.12 & -1.88 & .063 \\
\hline Varied Educational Experiences & & -.22 & .08 & $-.18^{* *}$ & -2.87 & .005 \\
\hline Support for Student Success & & .16 & .07 & .17 & 2.27 & .025 \\
\hline $\begin{array}{l}\text { Interpersonal Environment (quality of } \\
\text { campus relationships) }\end{array}$ & & .70 & .09 & $.59^{* * *}$ & 8.21 & .000 \\
\hline Course Challenge & & -.07 & .06 & -.07 & -1.08 & .281 \\
\hline Writing & & -.17 & .10 & -.11 & -1.77 & .079 \\
\hline Active-Learning Experiences & & .03 & .08 & .03 & .42 & .672 \\
\hline Constant & 3 & 43.07 & 15.04 & & 2.86 & .005 \\
\hline ACT Composite & & .50 & .37 & .08 & 1.35 & .178 \\
\hline Living On-Campus in Freshman Year & & -1.77 & 2.39 & -.04 & -.74 & .460 \\
\hline EFC (in 6 categories) & & -.79 & .76 & -.07 & -1.04 & .301 \\
\hline Miles from Home & & -.39 & .90 & -.03 & -.44 & .663 \\
\hline Higher Order Thinking Skills & & .15 & .07 & $.14^{*}$ & 2.08 & .040 \\
\hline Collaborative Learning Experience & & .02 & .09 & .01 & .19 & .853 \\
\hline Course-Related Interactions with Faculty & & -.13 & .08 & -.12 & -1.56 & .121 \\
\hline Out-of-Class Interactions with Faculty & & .05 & .03 & .12 & 1.55 & .122 \\
\hline Use of Information Technology & & .10 & .08 & .08 & 1.15 & .252 \\
\hline Diversity & & -.12 & .06 & -.13 & -1.87 & .063 \\
\hline Varied Educational Experiences & & -.22 & .08 & $-.18 * *$ & -2.86 & .005 \\
\hline Support for Student Success & & .16 & .07 & $.17^{*}$ & 2.25 & .026 \\
\hline $\begin{array}{l}\text { Interpersonal Environment (quality of } \\
\text { campus relationships) }\end{array}$ & & .70 & .09 & $.59 * * *$ & 8.13 & .000 \\
\hline Course Challenge & & -.06 & .06 & -.07 & -1.06 & .289 \\
\hline Writing & & -.17 & .10 & -.11 & -1.76 & .081 \\
\hline Active-Learning Experiences & & .03 & .08 & .03 & .427 & .670 \\
\hline First-generation status & & -2.44 & 2.56 & -.01 & -.10 & .924 \\
\hline
\end{tabular}

Note. Regression coefficients taken from Pike "scalelets" prediction model. Precollege characteristics and first-generation status were also considered. ${ }^{*} p<.05 .{ }^{* *} p<.01 .{ }^{* * *} p<.001$. 
Further analysis of the Pike "scalelets" (environmental variables) which were statistically significant partial regression coefficients helped to determine the individual NSSE items of importance within each composite score. See Appendix $G$ for the NSSE items used to calculate each significant Pike "scalelet." By creating a similar model with the individual NSSE questions used by the significant Pike "scalelets," more granular conclusions could be made. Higher order thinking skills $(\beta=.14)$ had a similar positive relationship with satisfaction from three of the four items used to create the score (perceived coursework emphasize on analyzing, applying and making judgments about information, concepts and ideas). Varied education experience $(\beta=-.18)$ used nine NSSE items to create the Pike "scalelet." Foreign language was a significant negative predictor $(p<.05)$, while attending campus events was a positive $(p<.05)$, each with a similar effect. Ratings of learning community experiences were negative in relation to satisfaction score, but only individually significant $(p<.01)$. For Pike "scalelet" support for student success $(\beta=.17)$, the important positive relationship was the perceived academic support provided by the university $(p<.05)$, rather than social or nonacademic support. Finally, Pike "scalelet" interpersonal environment $(\beta=.59)$ was created with the three quality of campus relationship items, which is the same as research question five. All three items were significant at $(p<.05)$ and strong positive predictors of satisfaction.

There is evidence that the equation met the assumptions of multiple regression. The histogram of the residuals approximated a normal distribution in shape. Furthermore, inspection of the scatterplot of the studentized residual values plotted against standardized predicted values showed that the data met the assumptions of homoscedasticity, linearity, and normality. 
There was little evidence of multicollinearity. The tolerance statistics of collinearity for the environment variables were all above .890 , which is not considered problematic. Menard (1995) recommends investigating tolerance less than .1 as a potential multicollinearity problem.

A final method was a check of the "frontier" (peer-mentor first-generation student) program during the first-year experience. The sample consisted of students that participated in both the BCSSE in the summer before their freshman year and the NSSE in the spring near the end of the first year $(n=257)$. A hierarchical multiple regression equation was built using the outcome variable, NSSE composite satisfaction score (Appendix C). Block one, precollege characteristics or inputs, was not significant, considering aptitude (ACT composite score), freshman year EFC in six categorical levels, living on-campus in the freshman year, and miles from home at five categorical levels. Block one was as follows: $F(4,231)=.0735, p=.569$ and $R^{2}=.013$. Block two considered the environment variables, NSSE quality of campus relationships (students, faculty members, and administrative personnel and offices); block two added a significant $\Delta R^{2}=.326$, with two of the three relationship items loading as significant positive predictors at $p<.05$ (campus relationships with students $\beta=.32$, campus relationships with faculty members $(\beta=.38)$. Resident status (living on-campus in the freshman year) was a significant negative predictor $(\beta=-.15)$. Block two was as follows: $F(3,228)=37.49635, p<.01$. Finally, block three considered the "frontier" program, which was significant at $p<.05$, but with a limited effect $\left(\Delta R^{2}\right.$ from block two to block three was .011 or approximately $1 \%$ of the variance). Block three was statistically significant: $F(1,227)=3.954, p<.05$. Plots of the data revealed no serious violations of 
normality, homoscedasticity, or linearity. The final model was significant: $F(8,227)=$ $15.286, p<.01$ with an $R^{2}$ of .35 . There was no evidence of multicollinearity between the two predictor variables. The lowest collinearity statistic tolerance for the significant variables was .589 , which is not considered problematic. Menard (1995) recommends investigating tolerance less than .1 as a potential multicollinearity problem.

The research question compared the two engagement models. Because the Pike "scalelets" model was a significant predictor of senior satisfaction, an obvious subsequent question was whether the "scalelet" mean for each of the two groups was different. A Multivariate Analysis of Variance (MANOVA) was completed where first-generation students were compared to continuing-generation students, using two levels of the IV (first-generation student group, continuing-generation student group) with twelve DVs Pike "scalelets." An assumption was tested to determine if the covariance matrices generated by each level of the IV was equal. The Box's test of equality of covariance matrices was insignificant $(p=.54)$, but the Bartlett's test of sphericity was significant ( $p$ $<.001)$; thus a MANOVA was warranted. The overall results of the MANOVA were not significant. The research found no significant effect of first-generation status on DVs (Pike "scalelets") as follows: Hotelling's trace $=.089, F(12,165)=1.22, p=.678$. Thus, no significant difference existed in the overall multivariate tests of Pike "scalelets" between first-generation students and continuing-generation students. Two Pike "scalelets" were subsequently reviewed with an independent samples t-test because they were significantly different when comparing individual "scalelets" in the MANOVA (interpersonal environment/quality of campus relationships and support for student success). In each case, continuing-generation students reported stronger relationships and 
experiences than first-generation students $(p<.05)$. Interpersonal environment $M_{\mathrm{FG}}=$ 89.17 was lower than $M_{\mathrm{CG}}=92.38$. Support for student success $M_{\mathrm{FG}}=83.40$ was lower than $M_{\mathrm{CG}}=90.26$. Levene's test of equality of variances was insignificant for both t-tests $(p=.357)$

In a final analysis of engagement variables, a MANOVA was completed where first-generation students were compared to continuing-generations students, using two levels of the IV (first-generation student group, continuing-generation student group) with five DVs (NSSE benchmarks). An assumption was tested to determine if the covariance matrices generated by each level of the IV was equal. The Box's test of equality of covariance matrices was insignificant $(p=.33)$, but the Bartlett's test of sphericity was significant $(p<.001)$; thus a MANOVA was warranted. The overall results of the MANOVA were not significant. No significant effect of first-generation status was found on DVs (NSSE benchmarks: LAC; ACL; SFI; EEE; and SCE) as follows: Hotelling's trace $=.021, F(5,165)=.69, p=.632$. Thus, no significant difference existed in the overall multivariate tests of NSSE benchmarks between first-generation students and continuing-generation students. There was no need for further analysis of individual NSSE benchmarks because none were significantly differently $(p=.185)$.

\section{Research Question Five}

Is the quality of relationships (with other students, faculty members, and administrative personnel and offices) a significant predictor of senior satisfaction for first-generation and/or continuing-generation students?

The quality of campus relationships (considered as environment variables) were significant predictors of senior student satisfaction (NSSE composite satisfaction score) 
for both first-generation and the continuing-generation students. Campus relationships added $\Delta R^{2}=.422$, with all three NSSE quality of relationship items (with other students, faculty members, and administrative personnel and offices) significant partial regression coefficients $(p<.001)$. First-generation status was not significant $(p<.05)$; thus there was no significant influence of student satisfaction because of parent education attainment level.

A hierarchical multiple regression model was built by entering control variables first (Aptitude ACT composite score, freshman year EFC in six categorical levels, living on-campus in the freshman year, and miles from home at five categorical levels) in block one as inputs in the Astin I-E-0 model (1970). The model then considered three possible predictor variables as block two (quality of campus relationships with other student, faculty members, administrative personnel and offices). The final block considered input variable, first-generation status. The outcome DV was a composite satisfaction score calculated from two NSSE items: (a) evaluate your entire educational experience at this institution; and (b) if you could start over again, would you go to the same institution you are now attending). The SPSS code used to calculate composite scores is in Appendix $C$.

The sample consisted of first-generation and continuing-generation students participating in the NSSE both in the freshman and senior year: spring 2002 to spring $2005(n=41)$; spring 2003 to spring $2006(n=45)$; spring 2004 to spring $2007(n=18)$; and spring 2006 to spring 2009 ( $n=78)$. The total sample consisted of 182 senior students.

The first-generation student group was $79 \%$ female, $46 \%$ living on-campus as freshmen, $91 \%$ white, $96 \%$ full-time students. Continuing-generation students were quite similar in 
demographics: $78 \%$ female; $58 \%$ living on-campus in the freshman year; $88 \%$ white; and $99 \%$ full-time students.

Table 4.9 displays the regression coefficients for the senior satisfaction model. Regarding the input variables as the first block entered, results showed these background characteristics (Aptitude ACT composite score, freshman year EFC in six categorical levels, living on-campus in the freshman year, and miles from home at five categorical levels) did not significantly predict satisfaction, $F(4,170)=.441, p=.779$. The environment variables (NSSE items regarding quality of campus relationships with other student, faculty members, administrative personnel and offices) added in the second step resulted in a regression model that was statistically significant $F(7,167)=18.18, p<$ .001 . Finally, the addition of first-generation status in the third step of the analysis did not result in a significant increment in variance, $F(1,166)=0.001, p=.969$.

The final regression equation was statistically significant, $F(8,166)=15.82, p<$ .001 . The $R^{2}$ for the entire equation was .433 (adjusted $R^{2}=.405$ ). Thus, approximately $41 \%$ of the variance in combined satisfaction score was associated with the predictor variables (quality of campus relationships with other students, faculty members, and administrative personnel and offices). Each of the environment variables had statistically significant partial regression coefficients $(p<.001)$.

There is evidence that the equation met the assumptions of multiple regression. The histogram of the residuals approximated a normal distribution in shape. Furthermore, inspection of the scatterplot of the studentized residual values plotted against standardized predicted values showed that the data met the assumptions of homoscedasticity, linearity, and normality. 
The DV combined NSSE satisfaction score (Appendix C) related to quality of campus relationships (measured by Pearson correlations) with other students $(r=.48)$, faculty members $(r=.55)$, and administrative personnel and offices $(r=.47)$, significant $(p<.001)$. There was no evidence of multicollinearity problems despite the three predictor variables' significant Pearson correlations $(p<.001)$. Campus relations with other students correlated with campus relations with faculty members $(r=.47)$, campus relations with other students correlated with campus relations administrative personnel and offices $(r=.36)$, and campus relationships with faculty members correlated with administrative personnel and offices $(r=.42)$. The tolerance statistics of collinearity for the quality of campus relationship items were all above .921 , which is not considered problematic. Menard (1995) recommends investigating tolerance less than .1 as a potential multicollinearity problem.

An additional analysis was created combining the three NSSE relationship items into one quality of campus relationships composite score (Appendix C). The same method was used, yielding a nearly identical model. 
Table 4.9 (RQ5)

Model Considering NSSE Quality of Campus Relationships as Predictors of NSSE Composite Satisfaction Score $(n=175)$

\begin{tabular}{|c|c|c|c|c|c|c|}
\hline Predictor Variables Considered & Step & B & SEB & $\beta$ & $t$ & $p$ \\
\hline Constant & 1 & 111.12 & 12.18 & & 9.12 & .000 \\
\hline ACT Composite & & .01 & .49 & .00 & .03 & .978 \\
\hline Miles from Home & & -1.33 & 1.18 & -.09 & -1.13 & .260 \\
\hline Living On-campus in Freshman year & & 2.16 & 3.21 & .05 & .67 & .501 \\
\hline EFC & & .43 & .97 & .04 & .44 & .659 \\
\hline Constant & 2 & 31.64 & 11.98 & & 2.641 & .009 \\
\hline ACT Composite & & .413 & .39 & .07 & 1.07 & .285 \\
\hline Miles from Home & & -1.60 & .90 & -.11 & -1.78 & .077 \\
\hline Living On-Campus in Freshman Year & & -1.92 & 2.54 & -.05 & -.75 & .452 \\
\hline $\mathrm{EFC}$ & & -.54 & .75 & -.04 & -.72 & .472 \\
\hline $\begin{array}{l}\text { NSSE Quality of Campus Relationships } \\
\text { with Other Students }\end{array}$ & & .13 & .03 & .27 & 3.83 & .000 \\
\hline $\begin{array}{l}\text { NSSE Quality of Campus Relationships } \\
\text { with Faculty Members }\end{array}$ & & .19 & .04 & .32 & 4.48 & .000 \\
\hline $\begin{array}{l}\text { NSSE Quality of Campus Relationships } \\
\text { with Adm. Personnel \& Offices }\end{array}$ & & .10 & .03 & .26 & 3.89 & .000 \\
\hline Constant & 3 & 31.52 & 12.43 & & 2.535 & .012 \\
\hline ACT Composite & & .41 & .39 & .07 & 1.07 & .287 \\
\hline Miles from Home & & -1.60 & .91 & -.11 & -1.77 & .079 \\
\hline Living On-campus in Freshman year & & -1.91 & 2.56 & -.05 & -.74 & .458 \\
\hline $\mathrm{EFC}$ & & -.53 & .78 & -.04 & -.68 & .500 \\
\hline $\begin{array}{l}\text { NSSE Quality of Campus Relationships } \\
\text { with Other Students }\end{array}$ & & .13 & .03 & .27 & 3.81 & .000 \\
\hline $\begin{array}{l}\text { NSSE Quality of Campus Relationships } \\
\text { with Faculty Members }\end{array}$ & & .19 & .04 & .32 & 4.47 & .000 \\
\hline $\begin{array}{l}\text { NSSE Quality of Campus Relationships } \\
\text { with Adm. Personnel \& Offices }\end{array}$ & & .10 & .03 & .26 & 3.87 & .000 \\
\hline First-Generation Status & & .10 & 2.65 & .00 & .04 & .969 \\
\hline
\end{tabular}

Note. For step $1, R^{2}=.010$ (adjusted $R^{2}=-.013$ ). For step $2, R^{2}=.433$ (adjusted $R^{2}=.409$ ). For step $3, R^{2}$ $=.433\left(\right.$ adjusted $\left.R^{2}=.405\right)$. 


\section{Research Question Six}

Is the quality of relationships (with other students, faculty members, and administrative personnel and offices) a significant predictor of senior measures of learning for first-generation with/or continuing-generation students?

NSSE quality of campus relationships (considered as environment variables) did not significantly influence senior measures of learning (ETS MAPP Total score) for either the first-generation student group or the continuing-generation student group. Campus relationships added only a very small $\Delta R^{2}=.041$, with no significant predictors $(p<.05)$.

A hierarchical multiple regression model was built, first entering input variables (aptitude ACT composite score, freshman year EFC, living on-campus in the freshman year, and miles from home at five categorical levels) in block one, following the Astin IE-0 model (1970). The model then considered possible environment variables as block two (quality of campus relationships with other student, faculty members, administrative personnel and offices, composite score for three quality of relationships with two satisfaction scores, and composite satisfaction score). The final block considered input variable, first-generation status. The outcome DV was ETS MAPP total score. The SPSS code used to calculate composite scores is located in Appendix $C$.

The data were obtained from senior student respondents participating in both NSSE 2007 and ETS MAPP 2007 ( $n=30)$, as well as NSSE 2009 and ETS MAPP 2009 $(n=45)$. The two cohorts were combined, thus creating a total respondent number of 75 students. 
Two models were built because many of the students had a blank EFC (students who did not complete the Free Application for Federal Student Aid (FAFSA). When EFC was removed as an input variable, the sample size was $n=63$; when $E F C$ was included $n=39$. The remaining 12 students had missing data in one of the input or environment variables.

Regarding the dataset which included EFC as a possible predictor variable ( $n=$ $39)$, three predictors were significantly related in terms of Pearson correlation $(p<.05)$ to the DV ETS MAPP total score: aptitude ACT composite score $(r=.72)$; first-generation status $(r=.30)$; and miles from home $(r=-.35)$. The hierarchical regression yielded only two significant predictor variables $(p<.05)$ because the model controls for all of other possible predictor variables, which changes the relationship from that of a Pearson correlation. Table 4.10 shows regression coefficients for all variables considered. Aptitude ACT composite score $(\beta=0.72)$ and first-generation status $(\beta=.31)$ were significant predictors of DV ETS MAPP total score. The final model was significant $F(9$, $29)=7.36, p<0.1 . R^{2}$ for the final regression equation was .696, thus accounting for approximately $70 \%$ of the variance of ETS MAPP total score. Block one precollege characteristics or inputs was significant; however, only aptitude (ACT composite score) was a significant predictor $F(3,35)=16.76, p<0.1$ with a strong $R^{2}=.59$. Block two considered the environment variables, NSSE quality of campus relationships (students, faculty members, administrative personnel and offices, composite score for the three quality of relationships with two satisfaction items, and composite satisfaction score); however block two added only a very small $\Delta R^{2}=.029$, with no significant predictors $(p$ $<.05)$. Finally, block three considered first-generation status, which was significant ( $p<$ 
$.05)$, but with a limited effect $\left(\Delta R^{2}\right.$ from block two to block three of .077 or

approximately $8 \%$ of the variance).

Table 4.10 (RQ6)

Model Considering NSSE Quality of Campus Relationships as Predictors of ETS MAPP

Total Score (students with Expected Family Contribution Data EFC) $(n=39)$

\begin{tabular}{|c|c|c|c|c|c|c|}
\hline Predictor Variables of & Step & B & SEB & $\beta$ & $t$ & $p$ \\
\hline Constant & 1 & 368.01 & 16.46 & & 22.35 & .000 \\
\hline ACT Composite & & 3.74 & .61 & .70 & 6.13 & .000 \\
\hline Living On-campus in Freshman Year & & -6.75 & 4.09 & -.19 & -1.65 & .108 \\
\hline $\mathrm{EFC}$ & & .00 & .00 & -.22 & -1.98 & .056 \\
\hline Miles from Home & & -1.25 & 1.43 & -.10 & -.87 & .390 \\
\hline Constant & 2 & 371.22 & 20.85 & & 17.80 & .000 \\
\hline ACT Composite & & 3.65 & .68 & .68 & 5.38 & .000 \\
\hline Living On-campus in Freshman Year & & -7.12 & 5.27 & -.20 & -1.35 & .187 \\
\hline $\mathrm{EFC}$ & & .00 & .00 & -.18 & -1.43 & .163 \\
\hline Miles from Home & & -1.03 & 1.55 & -.08 & -.66 & .512 \\
\hline $\begin{array}{l}\text { NSSE Quality of Campus Relationships } \\
\text { with Other Students }\end{array}$ & & -.11 & 2.34 & -.01 & -.05 & .964 \\
\hline $\begin{array}{l}\text { NSSE Quality of Campus Relationships } \\
\text { with Faculty Members }\end{array}$ & & -.65 & 3.05 & -.04 & -.21 & .834 \\
\hline $\begin{array}{l}\text { NSSE Quality of Campus Relationships } \\
\text { with Adm. Personnel \& Offices }\end{array}$ & & 1.11 & 2.43 & .11 & .46 & .651 \\
\hline $\begin{array}{l}\text { NSSE Composite of Three Qual. of Rel. } \\
\text { with Two Satisfaction Scores }\end{array}$ & & -.46 & .65 & -.48 & -.71 & .481 \\
\hline $\begin{array}{l}\text { NSSE Composite Score for Two } \\
\text { Satisfaction Items }\end{array}$ & & .39 & .39 & .49 & 1.02 & .314 \\
\hline Constant & 3 & 360.30 & 19.37 & & 18.60 & .000 \\
\hline ACT Composite & & 3.86 & .62 & .72 & 6.21 & .000 \\
\hline Living On-campus in Freshman Year & & -.689 & 5.71 & -.02 & -.12 & .905 \\
\hline EFC & & -.00 & .00 & -.14 & -.29 & .772 \\
\hline Miles from Home & & -.37 & 1.4 & -.03 & -.26 & .799 \\
\hline $\begin{array}{l}\text { NSSE Quality of Campus Relationships } \\
\text { with Other Students }\end{array}$ & & 1.45 & 2.21 & .11 & .66 & .52 \\
\hline $\begin{array}{l}\text { NSSE Quality of Campus Relationships } \\
\text { with Faculty Members }\end{array}$ & & -2.40 & 2.85 & -.15 & -.84 & .407 \\
\hline $\begin{array}{l}\text { NSSE Quality of Campus Relationships } \\
\text { with Adm. Personnel \& Offices }\end{array}$ & & 2.10 & 2.24 & .21 & .94 & .357 \\
\hline $\begin{array}{l}\text { NSSE Composite of Three Qual. of Rel. } \\
\text { with Two Satisfaction Scores }\end{array}$ & & -.58 & .59 & -.60 & -.98 & .335 \\
\hline $\begin{array}{l}\text { NSSE Composite Score for Two } \\
\text { Satisfaction Items }\end{array}$ & & .48 & .35 & .59 & 1.353 & .186 \\
\hline First-Generation Status & & 11.78 & 4.35 & .31 & 2.71 & .011 \\
\hline
\end{tabular}


To summarize the model which included EFC as a possible predictor variable $(n=$ 39), first-generation status was positively associated with ETS MAPP test performance. NSSE campus relationship items (environmental variables) were not significantly related or significant predictors of ETS MAPP total score. Furthermore, other precollege characteristics (input variables) including EFC, living on-campus in the freshman year, miles from home, were also not significant predictors of ETS MAPP total score. Plots of the data revealed that no serious violations of normality, homoscedasticity, or linearity.

There was little evidence of multicollinearity between the two predictor variables. Aptitude (ACT composite score) was not significantly related $(p<.05)$ to first-generation status, with a small Pearson correlation value $(r=-.32)$. The collinearity statistic tolerance for first-generation status was .783 , which is not considered problematic. Menard (1995) recommends investigating tolerance less than .1 as a potential multicollinearity problem.

This sample was limited to only students who completed a FAFSA (where EFC was available $(n=39)$. Financial characteristics of the two student groups varied substantially in the freshman year. First-generation students had greater financial need, with $42.8 \%$ Pell eligible (EFC $<\$ 5273$ ), compared to $13.3 \%$ of continuing-generation students. The $M_{\mathrm{FG}}=\$ 14,584 \mathrm{EFC}$ was substantially greater than $M_{\mathrm{CG}}=\$ 27,033$. Note that this was a positive relationship; first-generation students performed better on senior learning measures (ETS MAPP total score) when sample size was limited to the students with greater financial need.

Regarding the model which excluded EFC as a possible predictor variable $(n=$ 63), two predictors were significantly related in terms of Pearson correlation $(p<.05)$ to 
the DV ETS MAPP total score: aptitude ACT composite score $(r=.68)$; and miles from home $(r=-.28)$. However, the hierarchical regression yielded only one significant predictor variable $(p<.05)$, which occurred in block one; Table 4.11 shows regression coefficients for all variables considered. Aptitude ACT composite score $(\beta=.66)$ was significant predictor of DV ETS MAPP total score. Block one was significant as follows: $F(2,60)=27.23, p<.1$. The $R^{2}$ for the regression equation in block one was .476 , thus accounting for approximately $48 \%$ of the variance of ETS MAPP total score predicted from variable aptitude ACT composite score. The increase in $R^{2}$ from block one to block two was a .041 change, and from block two to three was a .003 change. The variance predicted by first-generation status was not significant as a predictor in block three, nor were NSSE campus relationship items (environment variables) in block two.

Furthermore, other precollege characteristics (input variables) in block one (EFC, living on-campus in the freshman year, miles from home), were also not significant predictors of ETS MAPP total score. Plots of the data revealed that no serious violations of normality, homoscedasticity, or linearity. 
Table 4.11 (RQ6)

Model Considering NSSE Quality of Campus Relationships as Predictors of ETS MAPP Total Score (excluding Expected Family Contribution Data EFC) ( $n=63)$

\begin{tabular}{|c|c|c|c|c|c|c|}
\hline Predictor Variables of & Step & B & SEB & $\beta$ & $t$ & $p$ \\
\hline Constant & 1 & 368.56 & 14.55 & & 25.33 & .000 \\
\hline ACT Composite & & 3.66 & .54 & .66 & 6.77 & .000 \\
\hline Living On-Campus in Freshman Year & & -2.78 & 3.97 & -.07 & -.70 & .487 \\
\hline Miles from Home & & -1.26 & 1.36 & -.09 & -.93 & .354 \\
\hline Constant & 2 & 370.04 & 17.88 & & 20.69 & .000 \\
\hline ACT Composite & & 3.46 & .56 & .62 & 6.19 & .000 \\
\hline Living On-Campus in Freshman Year & & -4.48 & 4.41 & -.11 & -1.02 & .314 \\
\hline Miles from Home & & -1.03 & 1.55 & -.08 & -.66 & .512 \\
\hline $\begin{array}{l}\text { NSSE Quality of Campus Relationships } \\
\text { with Other Students }\end{array}$ & & -.80 & 1.95 & -.06 & -.411 & .683 \\
\hline $\begin{array}{l}\text { NSSE Quality of Campus Relationships } \\
\text { with Faculty Members }\end{array}$ & & 3.97 & 2.87 & .23 & 1.38 & .173 \\
\hline $\begin{array}{l}\text { NSSE Quality of Campus Relationships } \\
\text { with Administrative Personnel and } \\
\text { Offices }\end{array}$ & & .66 & 2.06 & .06 & 32 & .749 \\
\hline $\begin{array}{l}\text { NSSE Composite Score of Three Quality } \\
\text { of Relationships with Two Satisfaction } \\
\text { Scores }\end{array}$ & & -.54 & .52 & -.48 & -1.05 & .299 \\
\hline $\begin{array}{l}\text { NSSE Composite Score for Two } \\
\text { Satisfaction Items }\end{array}$ & & .31 & .24 & .34 & 1.30 & .200 \\
\hline Constant & 3 & 367.56 & 18.52 & & 19.85 & .000 \\
\hline ACT Composite & & 3.52 & .57 & .63 & 6.15 & .000 \\
\hline Living On-Campus in Freshman Year & & -4.13 & 4.56 & -.10 & -.91 & .370 \\
\hline Miles from Home & & -.95 & 1.41 & -.07 & -.68 & .799 \\
\hline $\begin{array}{l}\text { NSSE Quality of Campus Relationships } \\
\text { with Other Students }\end{array}$ & & -.66 & 1.97 & -.05 & -.33 & .74 \\
\hline $\begin{array}{l}\text { NSSE Quality of Campus Relationships } \\
\text { with Faculty Members }\end{array}$ & & 3.83 & 2.90 & .22 & 1.32 & .192 \\
\hline $\begin{array}{l}\text { NSSE Quality of Campus Relationships } \\
\text { with Administrative Personnel and } \\
\text { Offices }\end{array}$ & & .72 & 2.08 & .06 & .348 & .729 \\
\hline $\begin{array}{l}\text { NSSE Composite Score of Three Quality } \\
\text { of Relationships with Two Satisfaction } \\
\text { Scores }\end{array}$ & & -.53 & .52 & -.47 & -1.03 & .310 \\
\hline $\begin{array}{l}\text { NSSE Composite Score for Two } \\
\text { Satisfaction Items }\end{array}$ & & .30 & .24 & .33 & 1.25 & .219 \\
\hline First-generation status & & 2.23 & 3.91 & .06 & .57 & .572 \\
\hline
\end{tabular}

Note. For step $1, R^{2}=.476$ (adjusted $\left.R^{2}=.458\right)$. For step $2, R^{2}=.516\left(\right.$ adjusted $\left.R^{2}=.455\right)$. For step $3, R^{2}=$ .519 (adjusted $R^{2}=.448$ ). 
The following is a brief summary of the study's results. Table 4.12 displays the finding in the order of the six research questions.

Table 4.12 Summary of Analyses for Six Research Questions

\begin{tabular}{|c|c|c|}
\hline Research Question & Analysis & Results \\
\hline $\begin{array}{l}\text { 1. Does a statistically significant } \\
\text { difference exist in senior } \\
\text { measures of learning between } \\
\text { first-generation and continuing- } \\
\text { generation students? } \\
\end{array}$ & $\begin{array}{l}\text { MANCOVA: } 7 \text { ETS MAPP } \\
\text { sub-scores by student first- } \\
\text { generation status with ACT } \\
\text { composite as covariate. }\end{array}$ & $\begin{array}{l}\text { No significant difference } \\
\text { between first-generation and } \\
\text { continuing-generation } \\
\text { students on adjusted ETS } \\
\text { MAPP sub-scores. }\end{array}$ \\
\hline $\begin{array}{l}\text { Do senior NSSE benchmark } \\
\text { scores (engagement variables) } \\
\text { significantly predict senior } \\
\text { measures of learning for first- } \\
\text { generation and/or continuing- } \\
\text { generation students? }\end{array}$ & $\begin{array}{l}\text { Multiple regression } \\
\text { using (a) } 4 \text { input variables; (b) } \\
5 \text { NSSE benchmark scores; and } \\
\text { (c) student first-generation } \\
\text { status predicting ETS MAPP } \\
\text { Total Score. }\end{array}$ & $\begin{array}{l}\text { Model 1. Containing students } \\
\text { with EFC data: Significant } \\
\text { positive predictors were ACT } \\
\text { composite score and student } \\
\text { first-generation status. } \\
\text { Model } 2 \text {. Containing students } \\
\text { without EFC data: Significant } \\
\text { positive predictor was ACT } \\
\text { composite score. }\end{array}$ \\
\hline $\begin{array}{l}\text { 3. Does a statistically significant } \\
\text { difference exist in senior } \\
\text { satisfaction measures between } \\
\text { first-generation and continuing- } \\
\text { generation students? }\end{array}$ & $\begin{array}{l}\text { MANCOVA: } 2 \text { NSSE items by } \\
\text { student first-generation status } \\
\text { with ACT composite as } \\
\text { covariate. }\end{array}$ & $\begin{array}{l}\text { No significant difference } \\
\text { between first-generation and } \\
\text { continuing-generation } \\
\text { students on adjusted NSSE } \\
\text { satisfaction items. }\end{array}$ \\
\hline $\begin{array}{l}\text { 4. Do Pike "scalelets" generate a } \\
\text { better predictive model of } \\
\text { senior satisfaction than the } \\
\text { engagement variables from high } \\
\text { impact practices/university- } \\
\text { specific activities? }\end{array}$ & $\begin{array}{l}\text { Multiple regression } \\
\text { using (a) } 4 \text { input variables; (b) } \\
12 \text { Pike "scalelets" or } 7 \text { high } \\
\text { impact practices/university- } \\
\text { specific activities; and (c) } \\
\text { student first-generation status } \\
\text { predicting combined senior } \\
\text { NSSE satisfaction score. }\end{array}$ & $\begin{array}{l}\text { Model 1. Pike "scalelets" were } \\
3 \text { significant positive } \\
\text { predictors: interpersonal } \\
\text { environment; higher order } \\
\text { thinking skills; and support for } \\
\text { student success. One negative } \\
\text { predictor: varied education } \\
\text { experience. } \\
\text { Model } 2 \text {. High impact } \\
\text { practices/ university-specific } \\
\text { activities were not significant. }\end{array}$ \\
\hline $\begin{array}{l}\text { 5. Is the quality of relationships } \\
\text { (with other students, faculty } \\
\text { members, and administrative } \\
\text { personnel and offices) a } \\
\text { significant predictor of senior } \\
\text { satisfaction for first-generation } \\
\text { and/or continuing-generation } \\
\text { students? }\end{array}$ & $\begin{array}{l}\text { Multiple regression } \\
\text { using (a) } 4 \text { input variables; (b) } \\
3 \text { NSSE quality of campus } \\
\text { relationships; and (c) student } \\
\text { first-generation status } \\
\text { predicting combined senior } \\
\text { NSSE satisfaction score. }\end{array}$ & $\begin{array}{l}\text { All } 3 \text { NSSE quality of campus } \\
\text { relationship items were } \\
\text { significant positive predictor } \\
\text { of combined senior NSSE } \\
\text { satisfaction score. }\end{array}$ \\
\hline $\begin{array}{l}\text { 6. Is the quality of relationships } \\
\text { (with other students, faculty } \\
\text { members, and administrative } \\
\text { personnel and offices) a } \\
\text { significant predictor of senior } \\
\text { measures of learning for first- } \\
\text { generation and/or continuing- } \\
\text { generation students? }\end{array}$ & $\begin{array}{l}\text { Multiple regression } \\
\text { using (a) } 4 \text { input variables; (b) } \\
5 \text { NSSE quality of campus } \\
\text { relationships and satisfaction } \\
\text { items; and (c) student first- } \\
\text { generation status predicting } \\
\text { ETS MAPP Total score. }\end{array}$ & $\begin{array}{l}\text { Model 1. Containing students } \\
\text { with EFC data: Significant } \\
\text { positive predictors were ACT } \\
\text { composite score and student } \\
\text { first-generation status. } \\
\text { Model } 2 \text {. Containing students } \\
\text { without EFC data: Significant } \\
\text { positive predictor was ACT } \\
\text { composite score. }\end{array}$ \\
\hline
\end{tabular}




\section{CHAPTER V}

\section{DISCUSSION AND CONCLUSION}

This chapter provides a summary of the dissertation study with conclusions drawn from the information presented in chapter IV. Implications for action and recommendations will be made for practitioners and policy makers. Ideas for future research will also be presented from the findings of this study.

\section{Overview of the Research Problem}

First-generation students experience college differently, reporting more work hours for pay while attending school, spending more time commuting to campus, dealing with family obligations requiring large amounts of time, earning lower grades, and choosing majors with immediate financial gain after graduating rather than preparing for graduate school (Chen, 2005; Pascarella, et al., 2004; Pascarella \& Terenzini, 1991). Evidence exists that first-generation students therefore learn less and do not have the same quality experience as continuing-generation students. Pike and Kuh (2005) concluded that first-generation students self-report less learning and intellectual development, as well as perceiving the college environment as less supportive. The critical factors which influence student learning are the reported frequency of diverse experiences and the perceptions of the college environment. Because first-generation students are generally less engaged in the overall college experience, the quality of the learning experience is influenced. 
While first-generation students report a different collegiate experience and less learning, studies investigating direct measures of student learning have shown contrasting results. Two primary studies concluded that the difference in collegiate experience failed to translate into substantial differences in direct measures of student learning (Arum \& Roksa, 2010; Terenzini, et al., 1996). Pascarella et al. (2004) found no significant differences existed in second-year writing skills or third-year reading comprehension or critical thinking scores, and only a small difference existed in second-year science reasoning (which reduced to nonsignificant when researchers accounted various college experiences). Terenzini (1996) reported similar findings in the freshman year using the same student sample. In a study with both similar and contrasting results, Arum and Roska (2010) found that first-generation students started with lower standardized test scores and gained less over the first two years of college than students with parents holding a graduate or professional degree (after controlling for aptitude with $\mathrm{ACT}$ or SAT scores). High school preparation and college experiences, however, accounted for $40 \%$ of the gap, and when removed, first-generation status no longer was statistically significant. Because there is limited research of direct measures of first-generation student learning, an additional study was needed in the senior year of college, focused on final learning outcomes at the end of the four-year experience (closer to the time of baccalaureate degree completion). Such a study could explore the college experiences and student engagement, both of which influence learning outcomes and satisfaction. Practitioners and faculty members must better understand how to foster an optimal fouryear learning environment for first-generation students. Small private institutions have a great opportunity to foster an environment which promotes first-generation student 
success because of smaller class sizes, a faculty focus on teaching and learning, and a community which strives to deliver a personal experience for each of its students. Curriculum, institutional programs, and faculty-student relationships often influence firstgeneration students more than continuing-generation students. Research shows that student success is less related to first-generation status than the experience these students have in college (Pike \& Kuh, 2005).

\section{Purpose Statement and Research Questions}

The purpose of the study was to better understand the four-year college experience of first-generation students by comparing their engagement, learning, and satisfaction to continuing-generation students at a small private institution. Using Astin's I-E-O model (1970), the following variables in the student experience were considered: precollege student characteristics (input); academic experiences, cocurricular involvement, campus relationships (environment); and satisfaction and learning measures (outcome). Results may be used to inform practitioners at a small private four-year college to better engage first-generation students on campus. Research questions included:

1. Does a statistically significant difference exist in senior measures of learning between first-generation and continuing-generation students?

2. Do senior NSSE benchmark scores (engagement variables) significantly predict senior measures of learning for first-generation and/or continuing-generation students?

3. Does a statistically significant difference exist in senior satisfaction measures between first-generation and continuing-generation students? 
4. Do Pike "scalelets" generate a better predictive model of senior satisfaction than the engagement variables from high impact practices/university-specific activities?

5. Is the quality of relationships (with other students, faculty members, and administrative personnel and offices) a significant predictor of senior satisfaction for first-generation and/or continuing-generation students?

6. Is the quality of relationships (with other students, faculty members, and administrative personnel and offices) a significant predictor of senior measures of learning for first-generation and/or continuing-generation students?

\section{Review of the Methods}

A quantitative, ex post facto research design was used to compare the four-year experience of first-generation students, to continuing-generation-students at a single institution in terms of engagement, learning, and satisfaction. The research was conducted using full-time undergraduate students participating in the National Survey of Student Engagement (NSSE) and/or a direct measure of general education student learning, Measure of Academic Proficiency and Progress (ETS MAPP). Using the NSSE instrument, researchers built several composite scores to help practitioners focus their efforts on the best practices associated with student success. NSSE grouped five factors as national benchmarks common to learning and student success: active and collaborative learning (ACL); student-faculty interaction (SFI); enriching educational experiences (EEE); supportive campus environment (SCE); and level of academic challenge (LAC). Pike (2006a) developed 12 "scalelets," each representing a specific content area with a set of survey questions. To make generalizations about an area, one survey item will not 
suffice, thus a group of survey questions increases the measure's "richness" of that element of the student experience. "Scalelets" include the following: course challenge; writing; active learning; higher order thinking skills; collaborative learning; course interaction; out-of-class interaction with faculty; use of information technology; emphasis on diversity; varied educational experiences; support for student success; and interpersonal environment.

The research setting was a small, private, Catholic university located in a large Midwestern city. In fall of 2009, the university enrollment included over 2000 full-time undergraduate students, over 950 undergraduate students living in the residence halls, and nearly 700 graduate students. Enrollment of first-generation students was substantial at the institution, which was somewhat unusual for a private Catholic Master's level institution. In fall 2009 , the freshman cohort included $40 \%$ first-generation students; the university defined a first-generation student as neither parent of the student completing a baccalaureate degree.

The conceptual framework used for the study was Astin input-environmentoutcome (I-E-O) model (1970), which serves as a tool to better understand student development while in college. Inputs represented the student characteristics at the time of entry into an institution. Environment addressed various educational and cocurricular experiences to which a student was exposed as well as the relationships student peers, faculty, and staff members. Outcomes focused on student characteristics after the student experienced the collegiate environment (spring of the senior year of college). Because of the complexity of the student experience during college, the model was a tool to assess student growth holistically. The premise of the model referred to understanding students 
at point of entry to determine whether the collegiate experience influenced student outcomes. Several statistical methods were used to assess measurements of the student's overall four-year experience. The models specifically were built using multiple regression techniques to identify predictor environmental variables which influence student learning and satisfaction. Other multivariate statistical techniques included multivariate analysis of covariance (MANCOVA). Engagement models may be presented in support of practitioner efforts to foster satisfaction and stronger learning environments for first-generation students.

Because private institutions have unique characteristics and missions, practitioners are often reluctant to apply findings from nationally representative datasets to their institutional settings. Consequently, for this research project, a single institution study was selected to account for the uniqueness of an individual institution. Many researchers found generalizing across institution type difficult because institutional categories were too broad and typically could not capture the uniqueness of individual institutional missions and their respective student experiences (Bensimon, et al., 2004). Therefore, a single institution study was needed to better understand the four-year experience of first-generation students and provide results to be used immediately by practitioners to improve learning and satisfaction. Specifically, an independent nonprofit institution may or may not prove to be a quality four-year experience for first-generation students as compared to continuing-generation students at the same institution. Students typically receive more individual attention at small private schools, but these institutions often lack the racial and cultural diversity of most first-generation groups. 
A limitation of single institution studies at small private schools is the number of student participants relative to the number of variables considered for analysis. Independence of sample was also a consideration because NSSE participation was not proctored. This self-reporting issue had been studied by the NSSE research team and poses no threat to validity on national scale. The ETS MAPP assessment has proven to be a reliable and valid direct measure of student learning in general education. However, sample size was an important consideration on the abbreviated form because the assessment was only 40 minutes in length. Additionally, the writing sub-score proved valid in measuring student's ability to determine sentence structure for example; however, actual writing skills could not be assessed with multiple choice questions.

\section{Summary of Findings}

No significant difference was found in direct measures of student learning (ETS MAPP total score and seven sub-scores) between first-generation and continuinggeneration college seniors at this small, private university in the Midwest $(n=342)$. This conclusion was made after controlling for aptitude (ACT composite score), which was significantly related to ETS MAPP scores $(p<.01)$. An additional analysis demonstrated that first-generation students work more hours for pay (47\% vs. 39\% reported working 16 or more hours per week); however, the variable was not significantly related to learning measures $(p=.644)$.

Senior engagement variables, NSSE benchmarks (LAC, ACL, EEE, SCE, SFI), were not significant $(p<.05)$ predictors of learning measures (ETS MAPP total score) for first-generation or continuing-generation students $(n=75)$. Senior engagement variables, student ratings of NSSE quality of campus relationships (other students, faculty 
members, and administrative offices and personnel), were also not significant $(p<.05)$ predictors of learning measures (ETS MAPP total score) for first-generation or continuing-generation students $(n=75)$. First-generation status was positively related ( $\beta$ $=.25$ with NSSE benchmark model and $\beta=.31$ with NSSE quality of relationship model) to senior learning measures (ETS MAPP total score) when the sample was limited to only students who completed a FAFSA (where EFC was available $(n=39)$. In this smaller sample, first-generation students had greater financial need, with $42.8 \%$ Pell eligible (EFC $<\$ 5273$ ) compared to $13.3 \%$ of continuing-generation students. The $M_{\mathrm{FG}}=$ $\$ 14,584$ EFC was substantially lower than $M_{\mathrm{CG}}=\$ 27,033$. Note that the relationship between learning measures and first-generation status was positive; first-generation students performed better on senior learning measures (ETS MAPP total score) when sample size was limited to the students with greater financial need. Other than an expected strong relationship between aptitude (ACT composite) and ETS MAPP total score $(\beta=.69)$, no other precollege characteristic or input was significantly related $(p<$ $.05)$ to learning measures.

In terms of NSSE senior satisfaction items $(n=175)$, there was no significant difference $(p<.05)$ between first-generation students $\left(M_{\mathrm{FG}}=113.05\right.$ evaluate your entire educational experience and $M_{\mathrm{FG}}=107.66$ would you go to the same institution) and continuing-generation students $\left(M_{\mathrm{CG}}=116.64, M_{\mathrm{CG}}=110.99\right.$, respectively). Aptitude (ACT composite) was used as a control variable; however, there was no significant relationship to NSSE satisfaction scores $(p=.696)$.

When considering the environmental variables which influence satisfaction, quality of campus relationships (students, faculty members, and administrative offices 
and personnel) was a strong predictor of NSSE composite satisfaction score (combined two items); with an adjusted $R^{2}=.405$, each NSSE relationship item had a significant partial regression coefficient $(p<.05)$. Because first-generation status was not significant $(p<.05)$ in the model, the quality of campus relationships was equally important to firstgeneration and continuing-generation students. In a separate model, four Pike "scalelets" were significant environmental variables, predicting NSSE composite satisfaction score with significant partial regression coefficients $(p<.05)$ : interpersonal environment $(\beta$ $=.59)$; varied education experience $(\beta=-.18)$; higher order thinking skills $(\beta=.14)$; and support for student success $(\beta=.17)$. The Pike "scalelet" interpersonal environment score is the same as NSSE quality of campus relationships and thus showed an expected very strong relationship with satisfaction. Varied education experience had a surprisingly negative relationship with satisfaction; students responded with lower ratings of foreign language coursework $(p<.05)$, and learning community experiences at a higher error threshold $(p<.1)$; a positive relationship existed with attending campus events and activities $(p<.05)$; however, the overall Pike "scalelet" was negatively related to satisfaction. Higher order thinking skills, a positive relationship with satisfaction $(p<$ $.05)$, is a student's rating of his/her ability to analyze, apply, and make judgments about concepts and information presented in coursework. The Pike "scalelet," support for student success, was a significant predictor of satisfaction because of students' perceived academic support from the university $(p<.05)$, rather than social or nonacademic support (also items in the composite score). The final satisfaction model considered high impact practices/university-specific activities, none of which were significant predictors of satisfaction $(p<.05)$. This model considered variables such as senior capstone 
experience, study abroad, and research with a faculty member. Because first-generation status was not significantly related to satisfaction $(p<.05)$, significant environment variables similarly influenced the first-generation and the continuing-generation student group. No precollege characteristics or inputs were significantly related to satisfaction ( $p$ $<.05)$.

The "frontier" (freshman peer-mentor first-generation) program was initiated for freshmen in 2008 , after the study participants completed their freshmen year; therefore no data were available to consider as a variable in the high impact practices/universityspecific activities model. A first-year regression model was built with the fall 2008 freshman cohort (231 students) predicting NSSE composite satisfaction score. NSSE quality of campus relationships (environment variables) were significant predictors $\left(\Delta R^{2}=.326\right)$, with two of the three relationship items loading as significant predictors at $p$ $<.05$ (campus relationships with students, campus relationships with faculty members). Finally, the "frontier" program was considered in the model, which was significant $(p<$ $.05)$, but with a limited effect ( $\Delta R^{2}$ from block two to block three was .011 or approximately $1 \%$ of the variance). Precollege characteristics or inputs, was not significant $(p<.05)$.

In summary of student satisfaction, campus relationships were found to be strong positive predictors of student satisfaction. Other significant yet less influential environment predictors included higher order thinking skills and academic support for student success. A negative relationship was found between varied education experiences such as rating of foreign language coursework. The statistically significant environmental predictors were significant regardless of first-generation status. 
In summary of student learning measures, senior ETS MAPP scores were strongly associated with precollege aptitude (ACT composite). This is reasonable because each assessment is a standardized direct measure of general education skills and content knowledge in a multiple choice question format. First-generation status was a positive predictor of learning only when non FAFSA submitters (presumably less financially needy students) were excluded. No other precollege characteristic or environment variable was associated with learning.

\section{Findings Related to the Literature}

\section{Astin (1970) inputs.}

The literature researching first-generation college students compared to continuing-generation college students concluded that first-generation students are highrisk for attrition (Ishitani, 2006; Pascarella \& Terenzini, 2005) because of many factors. First-generation students are overly represented by minority groups, especially Hispanic nonnative English speakers (Saenz, et al., 2007; Striplin, 1999; Warburton, et al., 2001). Furthermore, they tend to come from lower income families (Choy, 2001; Ishitani, 2006; Kuh, et al., 2006; Saenz, et al., 2007), are less prepared for postsecondary education (Chen, 2005; Choy, 2001; Thayer, 2000), live on-campus less frequently, attend local universities and colleges, and work for more hours per week for pay (Pascarella \& Terenzini, 2005; Pike \& Kuh, 2005; Somers, et al., 2004).

The demographics of this study were for the most part not similar to the literature. While nationally first-generation students are over-represented by Hispanic and African American students, the sample of first-generation students at this small private institution was similar to that of the continuing-generation students. The ETS MAPP senior sample 
consisted of 342 senior students with the following demographic composition: $26 \%$ firstgeneration students; $89 \%$ white; and $96 \%$ full-time students. The first-generation group was $88 \%$ white, compared to $90 \%$ of continuing-generation students. In terms of family income, the literature concluded that first-generation students frequently come from homes with lower income (Saenz, et al., 2007) and thus have a lower EFC. When the sample was limited to only students who completed a FAFSA (where EFC was available $(n=39)$, first-generation students had greater financial need, with $42.8 \%$ Pell eligible $(\mathrm{EFC}<\$ 5273)$ compared to $13.3 \%$ of continuing-generation students. The $M_{\mathrm{FG}}=$ $\$ 14,584$ EFC was substantially lower than $M_{\mathrm{CG}}=\$ 27,033$.

In terms of academic preparation, the literature concluded that first-generation students report lower grades in high school and test scores (Saenz, et al., 2007; Striplin, 1999). However, this study did not support these conclusions ( $n=342$ ); there was no difference in high school GPA or ACT scores $(p<.05)$. If a higher probability of error was used $(p<.1)$, first-generation students actually had stronger grades (GPA $=3.65$ vs. GPA $=3.56)$ but with lower ACT math scores (23.22 vs. 25.01). The ACT composite score and all subject scores appeared lower for first-generation students, but were not statistically different, even at $p<.1$.

The importance of living on-campus is widely recognized in the literature. Firstgeneration students who live on-campus are retained at higher percentages in the first year and self-report greater learning gains (Pike \& Kuh, 2005; Somers, et al., 2004). Similarly, students who work moderate amounts on-campus made greater learning gains in the first two years of college; working more than 15 hours a week, whether on or offcampus, is negatively associated with student learning (Arum \& Roksa, 2010). Pascarella 
and Terenzini (1991) concluded that first-generation students are negatively influenced by hours worked (either volunteer service or to earn money). This study found that firstgeneration students less frequently lived on-campus, typically lived locally with their families and worked more hours per week for pay; however, neither factor significantly influenced learning measures or satisfaction $(p<.05)$. In a sample where first-generation students represented $50 \%$ of the total students, $46 \%$ lived on-campus as freshmen compared to $58 \%$ continuing-generation students $(n=182)$. Regarding distance from home, $82 \%$ of first-generation students were local (less than 50 miles from home) compared to $72 \%$ of continuing-generation students $(n=182)$. Only $9 \%$ of firstgeneration students were from 200 miles or more from home compared to $17 \%$ of continuing-generation students $(n=182)$. In the ETS MAPP only sample $(n=342)$, firstgeneration students reported working more hours than continuing-generation students; $47 \%$ of first-generation reported working 16 or more hours per week, compared with $39 \%$ of continuing-generation students. More continuing-generation students worked a reasonable 1-15 hours (45\%) compared to first-generation students (40\%), or worked no hours at all (15\% vs. $14 \%)$. Overall, however, both groups worked a substantial amount of hours per week.

\section{Astin (1970) environment.}

In the literature, first-generation students reported similar levels of academic integration compared to continuing-generation students at four-year institutions. However, first-generation students reported lower levels of social integration such as participating in university clubs or organizations (Nunez \& Cuccaro-Alamin, 1998). Academic engagement has been reported as more important to first-generation students 
because they often needed the affirmation that they can do college level coursework (Kuh, et al., 2008) and also are busy with work hours and family responsibilities (Kuh, et al., 2006; Pascarella \& Terenzini, 2005; Pike \& Kuh, 2005). The key to overall student success in later undergraduate years may be the quality of relationships with faculty members, regardless of institution type or the attrition risk factors associated with each student. Much research associated the quality of student-faculty interactions with a broad range of positive student outcomes (Astin, 1993; Kuh, et al., 2006; Pascarella \& Terenzini, 2005). The findings of this study support the literature, but with similar importance to all students (no difference between first-generation and continuinggeneration students). The strongest positive influence on senior student satisfaction was the quality of campus relationships, with similar importance regarding relationships with other students, faculty members and administrative personnel and offices. This was demonstrated in multiple models and student samples (adjusted $R^{2}=.405$ ). Perceptions of academic support for student success also influenced senior satisfaction, but with less effect ( $\beta=$.17). Engagement in co-curricular and extra-curricular activities (measures with NSSE benchmark EEE or Pike "scalelet" varied education experience) had very limited influence; EEE was not significant predictor of satisfaction $(p<.05)$. The Pike "scalelet" varied education experience was a significant, but overall negative predictor with limited effect $(\beta=-.18)$; foreign language coursework $(p<.05)$ and experiences in learning community (at higher error threshold of $p<.01$ ) were negative, while campus events were found to be a positive influence $(p<.05)$. Practitioners often use these variables as measures of social integration, as well as students' perceptions of university 
support for social issues, but none of them were significantly associated with student satisfaction.

The university-specific activities model considered environment experiences high impact practices/university-specific activities as follows: capstone; study abroad; research with a faculty member; community service; honors program; Brown scholars (leadership and volunteer service program); mock trial team; athlete; work-study; and residence hall. None of these variables significantly influenced satisfaction or learning for either firstgeneration or continuing-generation students $(p<.05)$.

Literature suggests that frequency of diverse experiences and perception of support from the college environment correlates with first-generation student learning (Pike \& Kuh, 2005). The Pike "scalelet" diversity was an adequate measure; but it was not a predictor of learning or satisfaction measures $(p<.05)$. Students perceptions of academic support for student success influenced senior satisfaction, but with a small effect ( $\beta=.17)$, and it did not influence learning. Perceptions of university support for social and nonacademic experiences were not significant predictors of satisfaction or learning $(p<.05)$.

In terms of comparing environment variables without an outcome such as satisfaction or learning, no difference existed in first-generation and continuinggeneration students using two overall measures, NSSE benchmarks and Pike "scalelets." Subsequent analysis determined that individual NSSE benchmarks or Pike "scalelets" were not significantly different for the two student groups, with the two notable exceptions: Pike "scalelet" interpersonal environment (quality of campus relationships); and Pike "scalelet" support for student success. In each case, continuing-generation 
students reported stronger experiences than first-generation students $(p<.05)$. Interpersonal environment $M_{\mathrm{FG}}=89.17$ was lower than $M_{\mathrm{CG}}=92.38$, while support for student success $M_{\mathrm{FG}}=83.40$ was lower than $M_{\mathrm{CG}}=90.26$. While this was not considered directly by the research questions in this study, the finding is significant because of the unique needs of first-generation students. As previously discussed in the literature, these high-risk students report academic support and interventions as more important than for continuing-generation students (Kuh, et al., 2008). In the satisfaction and learning models, this was not the case; however, when compared individually with a simple t-test, the finding is an important consideration.

The literature supported the findings that environment variables affect student satisfaction more than precollege characteristics (Astin, 1993) and that satisfaction with students' college experience improves as the number of quality peer and faculty member interactions increase (NSSE, 2005). However, Pascarella and Terenzini (2005) found that the effects of college experiences on outcomes are conditional; thus engagement trends vary across student groups. In this study that was not the case; the effects of the college experience did not vary between first-generation or continuing-generation students in terms of satisfaction scores.

Chen (2005) demonstrated a relationship between first-year success and overall success in college for first-generations students. Researchers concluded that when students participate in educationally purposeful activities in the first year, the effects of demographics, precollege experiences, and prior academic achievement are greatly diminished. The influence of parents' education level essentially "disappears." Practitioners therefore considered the influence of educationally purposeful activities to 
be "compensatory" for high-risk students i.e. more influential for first-generation students than continuing-generation students (Kuh, et al., 2008, p. 555), because high-risk students need more affirmation that they are capable of doing college level work. In this study, the "frontier" (first-generation freshman peer-mentor) program was evaluated. The variable did influence freshman student satisfaction, but with limited effect. The quality of campus relationships was far more influential on student satisfaction (adjust $R^{2}=.326$ with two of the three items loading as significant predictors at $p<.05$, campus relationships with students, campus relationships with faculty members). The "frontier" program was a significant predictor of freshman satisfaction $(p<.05)$, but with a limited effect $\left(\Delta R^{2}=.011\right.$ or approximately $1 \%$ of the variance $)$.

\section{Astin (1970) outcomes.}

In terms of student learning outcomes, Pike and Kuh (2005) concluded that firstgeneration students self-report less learning and intellectual development; however, the literature using direct measures of student learning had mixed conclusions. Pascarella et al. (2004) found no significant differences existing in second-year writing skills or thirdyear reading comprehension or critical thinking scores, and only a small difference in second-year science reasoning (which reduced to nonsignificant when researchers accounted various college experiences). Terenzini (1996) reported similar findings in the freshman year using the same student sample. Arum and Roska (2010) found that firstgeneration students started with lower standardized test scores and gained less over the first two years of college than students with parents holding a graduate or professional degree (after controlling for aptitude with ACT or SAT scores). However, high school 
preparation and college experiences accounted for $40 \%$ of the gap and, when removed, first-generation status no longer was statistically significant.

The results of this study confirmed the Terenzini (1996) and Pascarella (2004) studies. No difference was found in direct measures of college student learning (senior year ETS MAPP total score and sub-scores) between first-generation and continuinggeneration students after controlling for aptitude (ACT composite score). The overall MANCOVA was insignificant $(p<.05)$. There was also no significant difference in ACT scores or high school grade point average between the two groups $(p<.05)$.

In terms of predicting senior measures of learning, aptitude (ACT composite) was, as expected, a strong predictor of ETS MAPP with a $\beta=.64, p<.01$. Other precollege characteristics or inputs were not significant predictors of senior learning measures. Furthermore, no environmental experiences were significant $(p<.05)$ after considering NSSE benchmarks, quality of campus relationships, and additional procedures to explore Pike "scalelets." This was surprising because the literature overwhelmingly concludes that students more engaged in the overall college experience self-report more learning (Pike \& Kuh, 2005) and perform better on direct measures of learning (Arum \& Roksa, 2010; Pascarella, et al., 2004; Terenzini, et al., 1996).

First-first-generation status was a significant positive predictor of student learning (ETS MAPP) if the sample was limited to students who submitted a FAFSA ( $\mathrm{n}=39$ ). These students were assumed to have a greater need than those students without a FAFSA, because this is an application for additional student financial aid. Literature has begun to focus on first-generation students who are low-income (Engle \& Tinto, 2008), which seems appropriate, considering these findings. However, rather than being 
disadvantaged, first-generation students in this model scored better on the ETS MAPP than continuing-generation students.

In terms of satisfaction scores, there was no difference in first-generation and continuing-generation student NSSE scores after controlling for aptitude (ACT composite score). Controlling for aptitude did not influence results because it was not related to student satisfaction $(p<.05)$. There was limited research literature regarding whether satisfaction varies with parents' education level however, first-generation students report academic integration and academic support as more important than social aspects of college (Kuh, et al., 2008; Nunez \& Cuccaro-Alamin, 1998). The finding of this study did not support the literature because significant environmental factors which influenced satisfaction did so equally regardless of first-first-generation status. As stated in the environment discussion of this chapter, the quality of campus relationships (other students, faculty members, administrative personnel and offices) was a strong predictor of satisfaction, as well as varied educational experiences, academic support, and higher order thinking skills. Higher order thinking skills $(\beta=.14)$ had a positive relationship with satisfaction from three of the four items used to create the score: perceived coursework; emphasize on analyzing; applying; and making judgments about information, concepts and ideas). None of these variables influenced learning measures, which was surprising, considering that higher order thinking skills and academic support are often used by practitioners as an indirect measure of student learning. NSSE benchmarks (see Table 3.4) and Pike "scalelets" such as diversity of experiences, academic support, and overall perception of the university, typically are strongly related to student self-reported learning outcomes (Pike, 2006a). Furthermore, Pike and Kuh 
(2005) found that learning is less related to precollege characteristics and more influenced by what the students do during college, with critical factors being the reported frequency of diverse experiences and the perceptions of the college environment.

Because this study was a direct measure of student learning, differences in precollege and environmental factors were anticipated. However, only first-firstgeneration status and aptitude ACT composite (both precollege characteristics) were significantly related to learning, with no environmental variables, which was unanticipated. In other studies of direct measures of learning, variables such as hours worked, faculty expectations and relationships, and academic preparation, were demonstrated to be significant predictors (Arum \& Roksa, 2010). Aptitude (ACT composite) in this study can be considered a measure of academic preparation, which appropriately influenced direct measures of senior learning. Regarding first-firstgeneration status, Arum \& Roksa (2010) found first-generation negatively associated with learning (CLA writing assessment), in direct contrast to the finding of this study.

Cumulative grade point average (GPA) was the same for both first-generation and continuing-generation students (GPA $=3.36$ on a 4.0 scale). This is consistent with results of this study's considered learning measures (ETS MAPP total score and sub-scores). However, this is in contrast to the literature, which indicates that first-generation who earn baccalaureate degrees typically earn lower grades during the undergraduate experience and are less likely than continuing-generation students to enroll in graduate school (Chen, 2005; Nunez \& Cuccaro-Alamin, 1998; Pascarella, et al., 2004).

Determining outcomes with regard to employment and graduate school placement was outside the scope of this study. However, a brief look at the frequency of majors in 
the senior year at this small liberal arts institution in the Midwest illustrated that firstgeneration students were more likely to choose professional majors leading to immediate employment, rather than arts and science majors which often serve as a preparation for graduate school. This is consistent with the literature, with studies concluding that firstgeneration students completing a four-year degree attend graduate school at significantly lower rates (Nunez \& Cuccaro-Alamin, 1998; Pascarella, et al., 2004; Terenzini, et al., 1996). In this study, first-generation students at a small private school reported a slightly greater frequency than continuing-generation students in professional majors (business administration, accounting, health and medical sciences) rather than traditional arts and sciences disciplines; $36 \%$ of first-generation students chose professional majors compared to $33 \%$ of continuing-generation students.

\section{Recommendations for Practitioners and Policymakers}

The strongest conclusion of the study was the positive influence of campus relationships on senior student satisfaction, regardless of parents' education level. Table 5.1 illustrates the relationship. For most administrators and faculty members, this finding would certainly be expected. The strength of the influence on reported student satisfaction (adjusted $R^{2}=.405$ ), a critical component to the student experience at a small private institution where faculty members typically have better opportunities to build personal relationships with their students, is important to consider. The pressures on faculty members remain high to produce quality and substantial research publications. These publications are considered in promotion and tenure evaluation, widely recognized as the key for advancement at large research universities, but also an important part of the evaluative process at this small private institution. This particular finding from the study 
may help faculty members better justify time spent getting to know their students personally, given the importance of student satisfaction as an outcome. This particular finding was true in both the freshman satisfaction model and the four-year model. Certainly smaller classes at private liberal arts institutions facilitate building campus relationships. Faculty members who focus on teaching and relationships with their students can better justify this time allocation, knowing their efforts influence student satisfaction. A satisfied student is more likely to be retained and graduate from the institution, and later become an engaged and generous alumna/alumnus. Administrators, practitioners, and policymakers need to continue to allocate funding at small private institutions to ensure sufficient numbers of full-time faculty members, where class sizes can remain small enough to foster an environment where each student has a personalized experience.

Other factors which influenced senior satisfaction (again regardless of firstgeneration or continuing-first-generation status) were higher order thinking skills ( $\beta$ $=.14$ ), support for student success $(\beta=.17)$, and varied education experience (a negative predictor with $\beta=-.18$ ). While the strength of these predictor variables on student satisfaction was much smaller than campus relationships, there are considerations for practitioners and policymakers. Higher order thinking skills reflects the perceived coursework emphasis the university places on analyzing, applying and making judgments of information, concepts and ideas. Faculty members must clearly articulate these goals for each course, instilling confidence in the students that they will develop these skills. This is common practice at most institutions; however the practice is often assumed effective. For practitioners and policymakers at small private institutions, this conclusion 
from the study suggests the importance of effective communication of the institution's student learning outcomes, both at the course and program level. For example, these skills are often included in the institution's general education program learning goals; however, students may need continuous reminders of the skills they are developing. In terms of support for student success, administrators should look more closely at academic support such as advising and tutoring, given that items representing social and nonacademic support for students did not influence student satisfaction. In fact, the literature suggests that first-generation students value academic integration and academic support more than social issues. This is consistent with the study's findings, in this case for both continuing-generation and first-generation students. Because over one third of students work 16 hours or more per week and over one half of the students live offcampus, the findings suggest that academic support is critical for students' satisfaction, given their busy schedules. Students establishing strong relationships with advisors (typically faculty members within the degree program), falls under this umbrella of the importance of campus relationships.

Finally, varied educational experiences was a negative predictor of student satisfaction, but this stemmed from the institution not having a foreign language requirement and the consequent of low student enrollment in these courses. Recently, the institution adopted a foreign language proficiency requirement in its college of arts and sciences, which will improve participation. Student involvement in learning communities was also very limited to only a few honors students; this opportunity may need to be expanded in the future. In fact, a house system is currently under consideration at the institution. Items such as attending campus events were positively related to student 
satisfaction. This Pike "scalelet" is best analyzed with a separate model looking at the individual survey items which influence student satisfaction.

In terms of environment variables, for the most part no differences existed in firstgeneration and continuing-generation students, with two exceptions, Pike "scalelet" interpersonal environment (quality of campus relationships) and Pike "scalelet" support for student success. In each case, continuing-generation students reported stronger experiences than first-generation students. Because these variables were not significantly different between the two student groups when in context with outcome models (satisfaction and learning), the findings were mitigated. Nevertheless, practitioners and policymakers should look at these scores at the institution level to determine if there is cause for concern. The students in this dataset did not participate in the "frontier" (freshman peer-mentor first-generation) program, which focuses almost entirely on relationships, academic support, and retention. A look at these students as seniors will determine if first-generation students not feeling as supported academically is a trend or if the issue has been resolved with targeted programming such as the "frontier" program. The answer may be the latter, because the "frontier" program was a significant predictor of freshman satisfaction, along with quality of relationships with students and faculty members. 


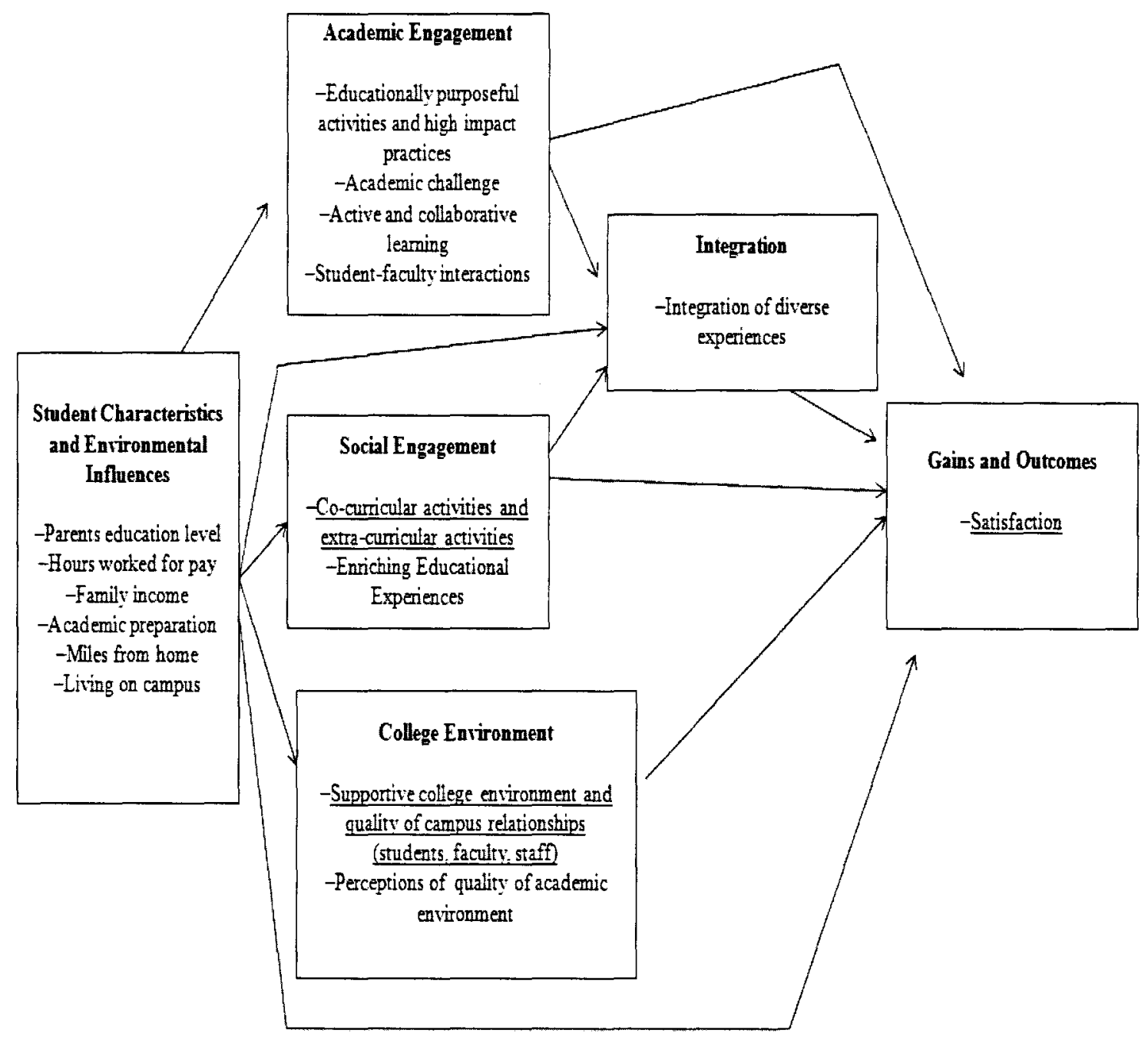

Figure 5.1. Model representing factors which influence senior student NSSE composite satisfaction score. Underlined are those factors found to significant predictors of satisfaction (as measured by NSSE). The Astin (1993) I-E-O, Pascarella (1985) and Pike and Kuh (2005) models were integrated for practitioners use in evaluating the characteristics and experiences which influence first-generation student learning and satisfaction. 
In terms of student learning, no environment or precollege variables were significant predictors, with the exception of aptitude (ACT composite), which was not significantly different for first-generation and continuing-generation students. Aptitude was a very strong predictor, which was expected. Because the learning measure was similar (the ACT compared to the ETS MAPP), the idea of academic preparation is certainly larger than only one measure, the ACT composite. However, practitioners and policymakers need to make note of the finding because it is reasonable to assume that if the ACT composite score greatly influences the ETS MAPP, it will also be a stronger predictor of assessments used for admission to graduate school such as the standardized Graduate Record Examination (GRE). If analyzed at 10\% confidence level (rather than 5\% used in this study), first-generation students scored lower in ACT Math, yet earned a higher GPA in high school. Regardless, there was no significant difference in ETS MAPP scores in the senior year college, nor was there a difference in cumulative college GPA, when the entire sample $(n=342)$ was considered.

In subsequent modeling, first-first-generation status was a significant yet weak positive predictor of ETS MAPP. Figure 5.2 illustrates the relationship. This sample was much smaller $(n=39)$, considering only those students who submitted a FAFSA (the presumably higher financial need students). However, it is important to note that while EFC did not significantly influence learning in any of the models, first-first-generation status became significant when the sample was limited to only the higher need group. First-generation in this group did have a substantially lower EFC than continuinggeneration students, yet performed better on ETS MAPP. Practitioners can consider this a confirmation of the literature that first-generation do not make fewer gains or perform 
worse on standardized measures when they have a similar college experience as continuing-generation students. The literature is consistent in indicating that success in college is more related to the student experience rather than a precollege characteristic such as first-first-generation status. Targeted programs such as "frontier" efforts should help ensure that these students receive additional support if they need it, as well as fostering quality relationships, even if the students' work hours off-campus and family obligations are more substantial.

The future of effective engagement practices may lie in developing programs targeted at specific student groups campus-wide in the first year and encouraging faculty members to customize the experience within each academic department in the students' remaining undergraduate years. Literature suggests that the types of engagement and their effectiveness vary by department in the overall undergraduate experience (Brint, et al., 2008). Based on the finding of this study, empowering department chairs to foster an environment where strong relationships are built, will influence student satisfaction. What works for each academic department can best be determined by the faculty members within each department. Additional studies are needed by discipline, where faculty members investigate the precollege and environment variables which influence student learning and student satisfaction within the major during the entire undergraduate experience. 


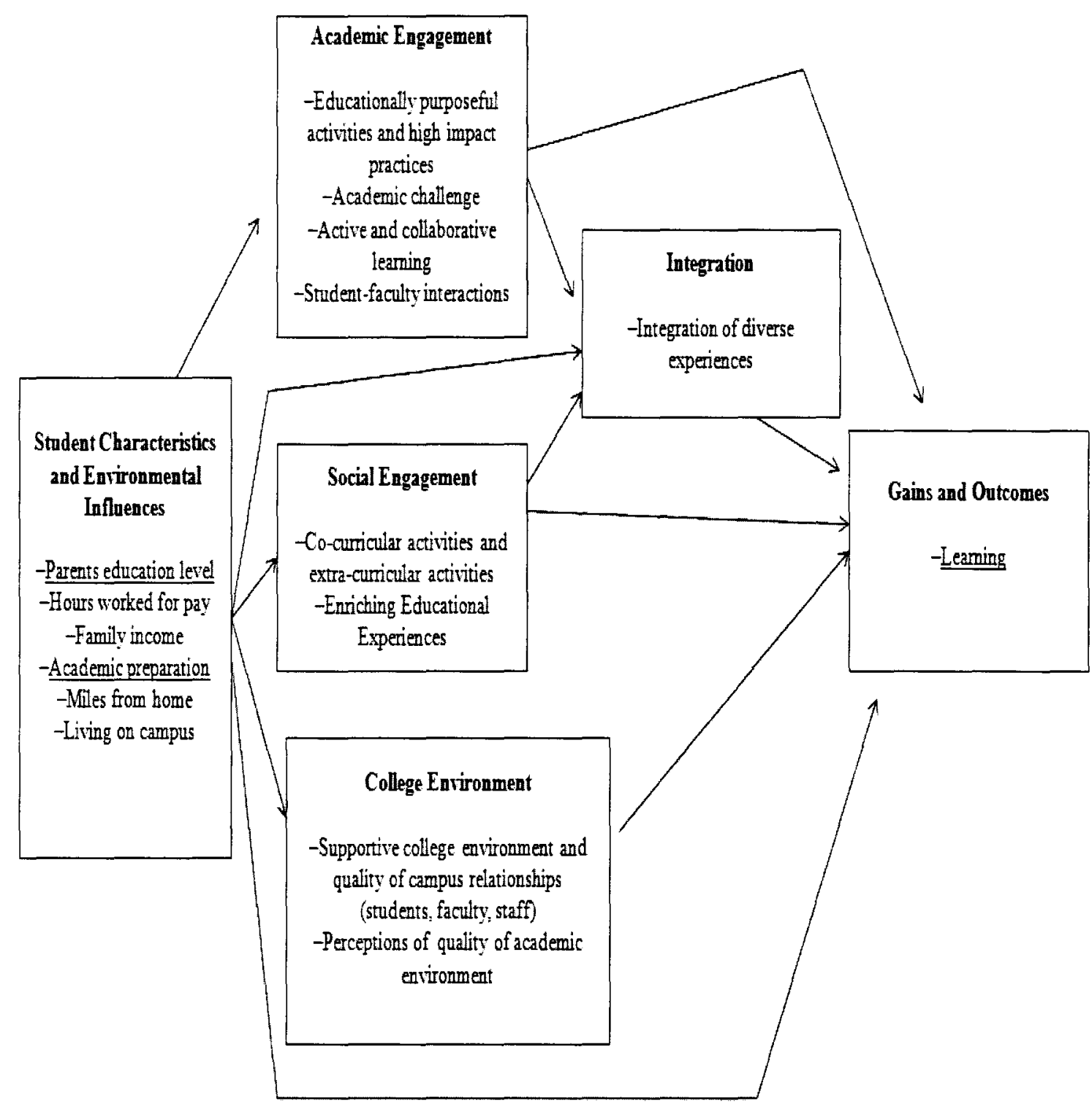

Figure 5.2. Model representing factors which influence senior student learning (ETS MAPP). Underlined are those factors found to significant predictors of learning. The Astin (1993) I-E-O, Pascarella (1985) and Pike and Kuh (2005) models were integrated for practitioners use in evaluating the characteristics and experiences which influence first-generation student learning and satisfaction. 


\section{Future Research}

The environment variables (measured by NSSE items) used to assess academic quality were not significant predictors of ETS MAPP. Items such as Pike "scalelet" higher order thinking skills and Pike "scalelet" support for student success were significant positive predictors of satisfaction, but not significant predictors of learning. The institution is beginning a new assessment, College Learning Assessment (CLA), which is a 90 -minute writing exam measuring written communication critical thinking, problem solving, and analytical reasoning. Future research needs to be expanded beyond only a multiple choice assessment, especially at a private liberal arts institution, where skills such as writing and critical thinking are core to the mission. Additionally, internal assessments such as individual course grades, quantitative rubrics, and portfolios may be important learning outcomes in addition to a standardized measure such as the ETS MAPP. A better understanding of what precollege and environment variables influence learning may begin by considering more measures of student learning.

The findings of this study confirm previous research suggesting that more firstgeneration live locally off-campus, are from lower income families, and choose professional majors leading to immediate employment after graduation. Additional analysis of employment and graduate school outcomes is needed to better understand if social and cultural capital influences these students' placement after college. In fields such as nursing and other health sciences, networking skills may be less important than the majors chosen in arts and sciences; however, the literature suggests that there is no difference in employment placement and a lower percentage of first-generation students attending graduate school. A study of placement after undergraduate completion, 
followed by a longitudinal study one year, five years and 10 years later, would help practitioners understand employment and graduate school aspirations.

Do first-generation students continue to be high-risk? This question is based on previous research findings that first-generation students are high-risk for the following reasons: lower retention and graduation rates; less engagement in the overall college experience; lower grades; and lower percentages of attending graduate school. While these measures remain appropriate, future research may need to focus on first-firstgeneration status combined with another demographic or precollege risk-factors. For example, future research should consider low-income first-generation students, male first-generation students, and Hispanic first-generation students where English is the native language of the student. As found in this study, first-first-generation status alone may no longer be a significant risk factor. This change may stem from the difference in parental support. The literature suggests that current parents of college first-generation students, regardless of education attainment level, support their children attending college. The downturn in the U.S. economy with fewer agriculture and manufacturing jobs (requiring less education) may be the reason for the change in attitude in parents of first-generation students. Researchers in the 1990s (Hsiao, 1992; Striplin, 1999) found that parents of first-generation students often discouraged their children from attending college because they did not understand the rewards of a college degree. Over the past decade, parental encouragement increased dramatically. First-generation students reported more often than continuing-generation students that the reason for attending college related to parental encouragement (Saenz, et al., 2007). Surveys conducted by the U.S. Department of Education concluded that nine of ten parents, regardless of race 
(white, black, or Hispanic) or education level, now expect their children to attend college. Additionally, high school guidance counselors and university admission/financial aid offices now widely recognize the unique challenges of first-generation students and customize services to fit their needs. A wealth of literature exists to inform the reallocation of resources and personnel. Focusing research on students with multiple risk factors will better identify the first-generation students with greatest need of additional services, rather than the simple definition which worked in the past.

For first-generation high school graduates who aspire to attend a four-year institution, additional research is needed to better understand how to recruit and enroll a greater percentage directly to four-year private institutions because many of these students did not successfully transfer from the two-year to the four-year institution. The first-generation students studied at this small, private, university had already overcome many obstacles by matriculating and persisting for four years. Because no significant difference was found in the satisfaction or learning of first-generation students at this institution, understanding how to continue to grow this population will be important to overall enrollment as well as the diversity of the student body. The first-generation students in this study represented a greater percentage of high financial need students than continuing-generation students, who in the past had not typically considered a private institution. Small private institutions have a unique environment to facilitate success of first-generation students; however, continuing to grow their enrollment numbers through successful recruitment of both traditional and adult students remains an important research endeavor. 


\section{REFERENCES}

Adelman, C. (2006). The toolbox revisited: Paths to degree completion from high school through college. Washington, DC: U.S. Department of Education.

Arum, R., \& Roksa, J. (2010). Academically adrift: Limited learning on college campuses. Paper presented at the Council of Indepent Colleges/Council for Aid to Education, Jersey City, NJ.

Association of American Colleges and Universities. (2007). College learning for a new global century: A report from the National Leadership Council for Liberal Education and America's Promise. Washington, DC: Association of American Colleges and Universities.

Astin, A. W. (1970). The methodology of research on college impact, part one. Sociology of Education, 43(3), 223-254.

Astin, A. W. (1984). Student involvement: A developmental theory for higher education. Journal of College Student Personnel, 25(4), 297-308.

Astin, A. W. (1993). What matters in college? Four critical years revisited (1st ed.). San Francisco, CA: Jossey-Bass.

Bailey, T., Jenkins, D., \& Leinbach, T. (2005). Graduation rates, student goals, and measuring community college effectiveness. Community College Research Center, 28, 1-4. 
Beil, C., Reisen, C. A., Zea, M. C., \& Caplan, R. C. (1999). A longitudinal study of the effects of academic and social integration and commitment on retention. NASPA Journal, 37(1), 376-385.

Bensimon, E. M., Polkinghorne, D. E., Bauman, G. L., \& Vallejo, E. (2004). Doing research that makes a difference. The Journal of Higher Education, 75(1), 104126.

Berkner, L., \& Chavez, L. (1997). Access to postsecondary education for the 1992 high school graduates. (NCES Publication No. 0-16-049287-4). Washington, DC: U.S. Department of Education.

Billson, J. M., \& Terry, M. B. (1982). In search of the silken purse: Factors in attrition among first-generation students. College and University, 58(1), 57-75.

Brint, S., Cantwell, A. M., \& Hanneman, R. A. (2008). The two cultures of undergraduate academic engagement. Research in Higher Education, 49(5), 383402.

Bui, V. T. (2002). First-generation college students at a four-year university: Background characteristics, reasons for pursuing higher education, and first-year experiences. College Student Journal, 36(1), 3-11.

Cejda, B. D., \& Kaylor, A. J. (2001). Early transfer: A case study of traditional-aged community college students. Community College Journal of Research and Practice, 25(8), 621-638.

Chen, X. (2005). First generation students in postsecondary education: A look at their college transcripts. (NCES 2005-171). U.S. Department of Education. Washington, DC: U.S. Government Printing Office. 
Chickering, A. W., \& Gamson, Z. F. (1987). Seven principles for good practice in undergraduate education. AAHE Bulletin, 39(7), 3-7.

Choy, S. P. (2001). Students whose parents did not go to college: Postsecondary access, persistence, and attainment. (NCES 2001-126). U.S. Department of Education. Washington, DC: National Center for Education Statistics.

Elkins, S. A., Braxton, J. M., \& James, G. W. (2000). Tinto's separation stage and its influence on first-semester college student persistence. Research in Higher Education, 41(2), 251-268.

Engle, J., \& Tinto, V. (2008). Moving beyond access: College success for low-income, first-generation students. Washington D.C.: The Pell Institute.

Gordon, J., Ludlum, J., \& Hoey, J. J. (2008). Validating NSSE against student outcomes: Are they related? Research in Higher Education, 49(1), 19-39.

Hamrick, F. A., \& Stage, F. K. (2004). College predisposition at high-minority enrollment, low-income schools. The Review of Higher Education, 27(2), 151168.

Horn, L., \& Kojaku, L. K. (2001). High school academic curriculum and the persistence path through college: Persistence and transfer behavior of undergraduates 3 years after entering 4-year institutions. Education Statistics Quarterly, 3(3), 65-72.

Horn, L., \& Nunez, A. M. (2000). Mapping the road to college: First-generation students' math track, planning strategies, and context of support. Education Statistics Quarterly, 2(1), 81-86. 
Hossler, D. (1999). Going to college: How social, economic, and educational factors influence the decisions students make. Baltimore, MD: Johns Hopkins University Press.

Hsiao, K. P. (1992). First-generation college students (ED351079). Retrieved from ERIC database.

Isaac, S., \& Michael, W. B. (1981). Handbook in research and evaluation (2nd ed.). San Diego, CA: Edits Publishers.

Ishitani, T. T. (2006). Studying attrition and degree completion behavior among firstgeneration college students in the united states. Journal of Higher Education, $77(5), 861-885$.

Kahn, J. H., \& Nauta, M. M. (2001). Social-cognitive predictors of first-year college persistence: The importance of proximal assessment. Research in Higher Education, 42(6), 633-652.

Kim, Y. K., \& Sax, L. J. (2009). Student-faculty interaction in research universities: Differences by student gender, race, social class, and first-generation status. Research in Higher Education, 50(5), 437-459.

Kinzie, J., Gonyea, R., Shoup, R., \& Kuh, G. D. (2008). Promoting persistence and success of underrepresented students: Lessons for teaching and learning. New Directions for Teaching and Learning, 2008(115), 21-38.

Klein, S., Liu, O. L., \& Sconing, J. (2009). Test validity study report. New York, NY: Fund for the Improvement of Postsecondary Education.

Kuh, G. D. (2001). Assessing what really matters to student learning: Inside the National Survey of Student Engagement. Change, 33(3), 10-17. 
Kuh, G. D. (2003a). The National Survey of Student Engagement: Conceptual framework and overview of psychometric properties. Indiana University Center for Postsecondary Research and Planning. Retrieved April 7, 2010, from http://nsse.iub.edu/pdf/conceptual_framework_2003.pdf

Kuh, G. D. (2003b). What we're learning about student engagement from NSSE: Benchmarks for effective educational practices. Change, 35(2), 24-32.

Kuh, G. D., Cruce, T. M., Shoup, R., Kinzie, J., \& Gonyea, R. M. (2008). Unmasking the effects of student engagement on first-year college grades and persistence. Journal of Higher Education, 79(5), 540-563.

Kuh, G. D., Kinzie, J., Buckley, J. A., Bridges, B. K., \& Hayek, J. C. (2006). What matters to student success: A review of the literature. Washington, DC: National Postsecondary Education Cooperative.

Kuh, G. D., Kinzie, J., Cruce, T. M., Shoup, R., \& Gonyea, R. (2007). Connecting the dots: Multi-faceted analyses of the relationships between student engagement results from the NSSE, and the institutional practices and conditions that foster student success. Bloomington, IN: Lumina Foundation for Education.

Kuh, G. D., Kinzie, J., Schuh, J. H., \& Whitt, E. J. (2005a). Assessing conditions to enhance educational effectiveness: The inventory for student engagement and success. San Francisco: Jossey-Bass.

Kuh, G. D., Kinzie, J., Schuh, J. H., \& Whitt, E. J. (2005b). Student success in college: Creating conditions that matter (1st ed.). San Francisco, CA: Jossey-Bass. Lipka, S. (2010, February 19). Wal-mart's \$10-million diplomas. The Chronicle of Higher Education, p. A1. 
Lohfink, M. M., \& Paulsen, M. B. (2005). Comparing the determinants of persistence for first-generation and continuing-generation students. Journal of College Student Development, 46(4), 409-428.

Longwell-Grice, R., \& Longwell-Grice, H. (2008). Testing tinto: How do retention theories work for first-generation, working-class students? Journal of College Student Retention: Research, Theory \& Practice, 9(4), 407-420.

Marr, D. (1995). Validity of academic profile. Educational Testing Service. Retrieved April 10, 2010, from http://www.ets.org/s/proficiencyprofile/pdf/Validity_Academic_Profile.pdf McCarthy, M., \& Kuh, G. D. (2006). Are students ready for college? What student engagement data say. Phi Delta Kappan, 87(9), 664-669.

Menard, S. (1995). Appied logistic regression analysis. Thousand Oaks, CA: Sage.

Mertens, D. M. (1998). Research methods in education and psychology. Thousands Oaks, CA: Sage.

Muraskin, L. D. (1998). A structured freshman year for at-risk students. (ED420265). U.S. Department of Education. Washington DC: The National Trio Clearinghouse.

National Center for Education Statistics. (1999). The condition of education 1998: Supplemental and standard error tables. (ED432068). U.S. Department of Education. Washington, DC: Author.

National Survey of Student Engagement. (2005). Student engagement: Exploring different dimensions of student engagement. Bloomington, IN: Indiana University Center for Postsecondary Research. 
National Survey of Student Engagement. (2009). Institutional report 2009. Bloomington, IN: Indiana University Center for Postsecondary Research.

Nunez, A. M., \& Cuccaro-Alamin, S. (1998). First-generation students: Undergraduates whose parents never enrolled in postsecondary education. (NCES 1998-082). U.S. Department of Education. Washington, DC: National Center for Educational Statistics.

Pace, C. R. (1980). Measuring the quality of student effort. Improving teaching and institutional quality, current issues in higher education (no. 1). Washington, DC: American Association for Higher Education.

Pascarella, E. T. (1985). College environment influences on learning and cognitive development: A critical review and synthesis. In J. C. Smart (Ed.), Higher Education: Handbook of Theory and Research (Vol. 1, pp. 1-62). New York, NY: Agathon.

Pascarella, E. T. (2006). How college affects students: Ten directions for future research. Journal of College Student Development, 47(5), 508-520.

Pascarella, E. T., Pierson, C. T., Wolniak, G. C., \& Terenzini, P. T. (2004). Firstgeneration college students: Additional evidence on college experiences and outcomes. Journal of Higher Education, 75(3), 249-284.

Pascarella, E. T., \& Terenzini, P. T. (1991). How college affects students: Findings and insights from twenty years of research. San Francisco, CA: Jossey-Bass Inc.

Pascarella, E. T., \& Terenzini, P. T. (2005). How college affects students: $A$ third decade of research (2nd ed.). San Francisco, CA: Jossey-Bass 
Pike, G. R. (2006a). The convergent and discriminant validity of NSSE scalelet scores. Journal of College Student Development, 47(5), 551-564.

Pike, G. R. (2006b). The dependability of NSSE scalelets for college- and departmentlevel assessment. Research in Higher Education, 47(2), 177-195.

Pike, G. R., \& Kuh, G. D. (2005). First- and second-generation college students: A comparison of their engagement and intellectual development. Journal of Higher Education, 76(3), 276-300.

Saenz, V. B., Hurtado, S., Barrera, D., Wolf, D., \& Yeung, F. (2007). First in my family: A profile of first-generation college students at four-year institutions since 1971. Los Angeles, CA: Higher Education Research Institute, UCLA.

Schilling, K. M., \& Schilling, K. L. (1999). Increasing expectations for student effort. About Campus, 4(2), 4-10.

Schmidt, P. (2003, November, 28). Academe's hispanic future: The nation's largest minority group faces big obstacles in higher education, and colleges struggle to find the right ways to help. The Chronicle of Higher Education, p. A1.

Somers, P., Woodhouse, S., \& Cofer, J. (2004). Pushing the boulder uphill: The persistence of first-generation college students. NASPA Journal, 4l(3), 418-435.

Stevens, J. (2002). Applied multivariate statistics for the social sciences (4th ed.). Mahwah, NJ: L. Erlbaum.

Striplin, J. J. (1999). Facilitating transfer for first-generation community college students. (ED430627). Retrieved from ERIC database. 
Swail, W. S., Cabrera, A. F., Lee, C., \& Williams, A. (2005). Latino students \& the educational pipeline: A three-part series. Part three: Pathways to the bachelor's degree for latino students. Stafford, VA: Education Policy Institute.

Swing, R. L. (2008, November). An institutional research imperative: Proving \& improving the first year of college. Paper presented at the Kentucky Association of Institutional Research, Lexington, KY.

Terenzini, P. T., Springer, L., Yaeger, P. M., Pascarella, E. T., \& Nora, A. (1996). Firstgeneration college students: Characteristics, experiences, and cognitive development. Research in Higher Education, 37(1), 1-22.

Thayer, P. B. (2000). Retention of students from first generation and low income backgrounds. (ED446633). Retrieved from ERIC database.

Tinto, V. (1993). Leaving college: Rethinking the causes and cures of student attrition (2nd ed.). Chicago, IL: University of Chicago Press.

Tinto, V. (1998). Colleges as communities: Taking research on student persistence seriously. Review of Higher Education, 21(2), 167-177.

Tym, C., McMillion, R., Barone, S., \& Webster, J. (2004). First-generation college students: A literature review. Texas Round Rock, TX: Texas Guaranteed Student Loan Corporation.

Vargas, J. H. (2004). College knowledge: Addressing information barriers to college. Boston, MA: College Access Services: The Education Resource Institute (TERI). Warburton, E. C., Bugarin, R., \& Nunez, A. M. (2001). Bridging the gap: Academic preparation and postsecondary success of first-generation students. Statistical 
analysis report. Postsecondary education descriptive analysis reports. (NCES 2001-153). Washington DC: National Center for Education Statistics.

Wilcox, L. (2008). Wal-mart foundation grant to cic of \$2.266 million will support college success awards. The Council of Independent Colleges. Retrieved June 5, 2010, from http://www.cic.edu/publications/pressroom/pressreleases/walmart_grant.asp

Winston, G. C., \& Zimmerman, D. J. (2003). Peer effects in higher education. (ED474478). Retrieved from ERIC database.

Wolf-Wendel, L., Ward, K., \& Kinzie, J. (2009). A tangled web of terms: The overlap and unique contribution of involvement, engagement, and integration to understanding college student success. Journal of College Student Development, $50(4), 407-428$.

Young, J. W. (2007). Validity of the measure of academic proficiency and progress. Educational Testing Service. Retrieved April 10, 2010, from http://www.ets.org/s/mapp/pdf/5018.pdf

Zwerling, L. S., \& London, H. B. (1992). First-generation students: Confronting the cultural issues. San Francisco, CA: Jossey-Bass. 


\section{APPENDIX A}

National Survey of Student Engagement (NSSE): 2009 U.S. Web Version

Retrieved from http://www.nsse.iub.edu/pdf/US_web_09.pdf 


\section{APPENDIX B}

National Survey of Student Engagement Measurement Scales, Component Scales, and Intercorrelation Tables (NSSE 2009 Data)

Retrieved from

http://nsse.iub.edu/2009 Institutional_Report/pdf/2009\%20Intercorrelation.pdf 


\section{APPENDIX C}

National Survey of Student Engagement (NSSE) Syntax Library: Satisfaction Score, Satisfaction plus Quality of Campus Relationship Score, Quality of Campus Relationships Score, Pike scalelets, Gain in General Education Score SPSS Code for calculating 2 item satisfaction score, and the combination of satisfaction score and quality of campus relationships, and 3 item quality of campus relationship composite score.

$* * * * * *$ Overall Satisfaction $(2$ items) $* * *$

How would you evaluate your entire educational experience at this institution? ( $1=$ poor, 2=fair, 3=good, 4=excellent)

compute entirexph $=(($ entirexp $) / 3) * 100$.

If you could start over again, would you go to the same institution you are now attending? ( $1=$ definitely no, $2=$ probably no, $3=$ probably yes, $4=$ definitely yes $)$ compute samecollh $=((\text { samecoll }) / 3)^{*} 100$.

Take the mean of the 2 items when a respondent has at least 1 of the 2 items. Compute STovl = mean(entirexph,samecollh). Variable Labels STovl "Overall Satisfaction".

$* * * * * * *$ Satisfaction plus Quality of Campus Relationship (6 items)***********.

Overall, how would you evaluate the quality of academic advising you have received at your institution? (1=poor, $2=$ fair, $3=$ good, $4=$ excellent) 
compute adviseh $=((\text { advise }) / 3)^{*} 100$.

Select the circle that best represents the quality of your relationships with people at your institution. Relationships with other students. (1=unfriendly, unsupportive, sense of alienation, $7=$ friendly, supportive, sense of belonging) compute envstuh $=(($ envstu $) / 6) * 100$.

Relationships with faculty members. (1=unfriendly, unsupportive, sense of alienation, $7=$ friendly, supportive, sense of belonging) compute envfach $=(($ envfac $) / 6) * 100$. Relationships with administrative personnel and offices. (1=unfriendly, unsupportive, sense of alienation, $7=$ friendly, supportive, sense of belonging) compute envadmh $=(($ envadm $) / 6) * 100$.

Take the mean of the 6 items when a respondent has at least 4 of the 6 items. Compute STqcr = mean.4(entirexph,samecollh,adviseh, envstuh, envfach, envadmh). Variable Labels STqcr "Satisfaction plus Quality of Campus Relationships".exe. $* * * * * *$ Quality of Campus Relationship (3 items) ${ }^{* * *}$ compute SR-envstuh $=(($ SR-envstu $) / 3) * 100$. compute SR-envfach $=((\mathrm{SR}-\mathrm{envfac}) / 3) * 100$. compute SR-envadmh $=(($ SR-envadm $) / 3) * 100$.

Take the mean of the 3 items when a respondent has at least 2 of the 3 items. Compute QCcrs = mean.3(SR-envstuh,SR-envfach,SR-envadmh). Variable Labels QCcrs "Quality of Combined Campus Relationships".exe. ******Pike Scalelets******

\#1 Course Challenge. 
Worked harder than you thought you could to meet an instructor's standards or expectations ( $1=$ never, $2=$ sometimes, $3=$ often, $4=$ very often)

compute workhardh $=((\text { workhard }) / 3)^{*} 100$.

In your experience at your institution during the current school year, about how often have you done each of the following? Come to class without completing readings or assignments ( $1=$ never, $2=$ sometimes, $3=$ often, $4=$ very often)

compute clunpreph $=((4 *$ clunprep $) / 3) * 100$.

***clunprep is reverse coded.

Select the circle that best represents the extent to which your examinations during the current school year have challenged you to do your best work. (1=very little, $7=$ very much)

compute examsh $=((\mathrm{exams}) / 6) * 100$.

About how many hours do you spend in a typical 7-day week doing each of the following? Preparing for class (studying, reading, writing, doing homework or lab work, analyzing data, rehearsing, and other academic activities) $(1=0$ hours per week, $2=1-5$, $3=6-10,4=11-15,5=16-20,6=21-25,7=26-30,8=$ More than 30 hours)

compute acadpr01h $=((\operatorname{acadpr} 01) / 7)^{*} 100$.

To what extent does your institution emphasize each of the following? Spending significant amounts of time studying and on academic work ( $1=$ very little, $2=$ some, $3=$ quite a bit, $4=$ very much)

compute envscholh $=(($ envschol $) / 3) * 100$.

compute CourseChallenge $=$

mean.4(workhardh,clunpreph,examsh,acadpr01h,envscholh).

\#2 Writing.

In your experience at your institution during the current school year, about how often have you done each of the following? Prepared two or more drafts of a paper or assignment before turning it in ( $1=$ never, $2=$ sometimes, $3=$ often, $4=$ very often)

compute rewropaph $=((\text { rewropap }) / 3)^{*} 100$.

In your experience at your institution during the current school year, about how often have you done each of the following? Worked on a paper or project that required 
integrating ideas or information from various sources $(1=$ never, $2=$ sometimes, $3=0$ often, $4=$ very often)

compute integrath $=((\text { integrat }) / 3)^{*} 100$.

During the current school year, about how much reading and writing have you done? Number of written papers or reports of 20 pages or more ( $1=$ none, $2=1-4,3=5-10,4=11$ $20,5=$ more than 20 )

compute writemorh $=(($ writemor $) / 4) * 100$.

During the current school year, about how much reading and writing have you done? Number of written papers or reports between 5 and 19 pages ( $1=$ none, $2=1-4,3=5-10$, $4=11-20,5=$ more than 20 )

compute writemidh $=(($ writemid $) / 4) * 100$.

During the current school year, about how much reading and writing have you done? Number of written papers or reports of fewer than 5 pages (1=none, $2=1-4,3=5-10,4=1$ $20,5=$ more than 20 )

compute writesmlh $=((\text { writesml }) / 4)^{*} 100$.

compute Writing = mean.4(rewropaph,integrath,writemorh, writemidh,writesmlh).

\#3 Active-Learning.

In your experience at your institution during the current school year, about how often have you done each of the following? Asked questions in class or contributed to class discussions ( $1=$ =never, $2=$ sometimes, $3=$ often, $4=$ very often)

compute clquesth $=((\text { clquest }) / 3)^{*} 100$.

In your experience at your institution during the current school year, about how often have you done each of the following? Made a class presentation (1=never, $2=$ sometimes, $3=$ often, $4=$ very often)

compute clpresenh $=((\text { clpresen }) / 3)^{*} 100$.

In your experience at your institution during the current school year, about how often have you done each of the following? Participated in a community-based project (e.g., service learning) as part of a regular course ( $1=$ never, $2=$ sometimes, $3=$ often, $4=$ very often)

compute commprojh $=((\text { commproj }) / 3)^{*} 100$. 
compute ActiveLearning = mean.3(clquesth, clpresenh, commprojh).

\#4 Higher-order Thinking (4 items).

During the current school year, how much has your coursework emphasized the following mental activities? Analyzing the basic elements of an idea, experience, or theory, such as examining particular case or situation in depth and considering its components ( $1=$ very little, $2=$ some, $3=$ quite a bit, $4=$ very much)

compute analyzeh $=(($ analyze $) / 3) * 100$.

During the current school year, how much has your coursework emphasized the following mental activities? Synthesizing and organizing ideas, information, or experiences into new, more complex interpretations and relationships (1=very little, $2=$ some, $3=$ quite a bit, $4=$ very much)

compute syntheszh $=(($ synthesz $) / 3) * 100$.

During the current school year, how much has your coursework emphasized the following mental activities? Making judgments about the value of information, arguments, or methods, such as examining how others gathered and interpreted data and assessing the soundness of their conclusions ( $1=$ verylittle, $2=$ some, $3=$ quiteabit, $4=$ very much)

compute evaluateh $=((\text { evaluate }) / 3)^{*} 100$.

During the current school year, how much has your coursework emphasized the following mental activities? Applying theories or concepts to practical problems or in new situations ( $1=$ very little, $2=$ some, $3=$ quite a bit, $4=$ =very much)

compute applyingh $=(($ applying $) / 3) * 100$.

Take the mean of the 4 items when a respondent has at least 3 of the 4 items.

Compute DPhio = mean.3(analyzeh,syntheszh, evaluateh, applyingh).

Variable Labels DPhio "Deep Learning - Higher Order Thinking Subscale".

\#5 Collaborative Learning Experiences.

In your experience at your institution during the current school year, about how often have you done each of the following? Worked with other students on projects during class ( $1=$ never, $2=$ sometimes, $3=$ often, $4=$ very often)

compute classgrph $=((\text { classgrp }) / 3)^{*} 100$. 
In your experience at your institution during the current school year, about how often have you done each of the following? Worked with classmates outside of class to prepare class assignments $(1=$ never, $2=$ sometimes, $3=$ often, $4=$ very often)

compute occgrph $=((\text { occgrp }) / 3)^{*} 100$.

In your experience at your institution during the current school year, about how often have you done each of the following? Tutored or taught other students (paid or voluntary) ( $1=$ never, $2=$ sometimes, $3=$ often, $4=$ very often)

compute tutorh $=((\text { tutor }) / 3)^{*} 100$.

Discussed ideas from your readings or classes with others outside of class (students, family members, coworkers, etc.) (1=never, $2=$ sometimes, $3=$ often, $4=$ very often)

compute oocideash $=(($ oocideas $) / 3) * 100$.

compute Collaborative $=$ mean.3 (classgrph, occgrph, tutorh, oocideash).

\#6 Course Interactions.

In your experience at your institution during the current school year, about how often have you done each of the following? Discussed grades or assignments with an instructor ( $1=$ never, $2=$ sometimes, $3=$ often, $4=$ very often)

compute facgradeh $=((\text { facgrade }) / 3)^{*} 100$.

In your experience at your institution during the current school year, about how often have you done each of the following? Discussed ideas from your readings or classes with faculty members outside of class ( $1=$ never, $2=$ sometimes, $3=$ often, $4=$ very often)

compute facideash $=(($ facideas $) / 3) * 100$.

In your experience at your institution during the current school year, about how often have you done each of the following? Received prompt written or oral feedback from faculty on your academic performance ( $1=$ never, $2=$ sometimes, $3=$ often, $4=$ very often)

compute facfeedh $=((\text { facfeed }) / 3)^{*} 100$.

compute FacCourse $=$ mean. $3($ facgradeh,facideash,facfeedh $)$.

\#7 Out-of-Class Interaction with Faculty.

In your experience at your institution during the current school year, about how often have you done each of the following? Talked about career plans with a faculty member or advisor $(1=$ never, $2=$ sometimes, $3=$ often, $4=$ very often $)$ 
compute facplansh $=((\text { facplans }) / 3)^{*} 100$.

In your experience at your institution during the current school year, about how often have you done each of the following? Worked with faculty members on activities other than coursework (committees, orientation, student life activities, etc.) (1=never, $2=$ sometimes, $3=$ often, $4=$ very often)

compute facotherh $=((\text { facother }) / 3)^{*} 100$.

recode resrch04 $(4=100)(1,2,3=0)$ into resrch04h.

compute FacOut $=$ mean.3(facplansh, facotherh, resrch04h).

\#8 Info Technology.

In your experience at your institution during the current school year, about how often have you done each of the following? Used an electronic medium (listserv, chat group, Internet, instant messaging, etc.) to discuss or complete an assignment (1=never, $2=$ sometimes, $3=$ often, $4=$ very often)

compute itacademh $=((\text { itacadem }) / 3)^{*} 100$.

In your experience at your institution during the current school year, about how often have you done each of the following? Used e-mail to communicate with an instructor ( $1=$ never, $2=$ sometimes, $3=$ often, $4=$ very often)

compute emailh $=((\text { email }) / 3)^{*} 100$.

To what extent does your institution emphasize each of the following? Using computers in academic work ( $1=$ very little, $2=$ some, $3=$ quite a bit, $4=$ very much)

compute envcomph $=((\text { envcompt }) / 3)^{*} 100$.

compute Tech $=$ mean.3(itacademh,emailh,envcomph).

\#9 Emphasis on Diversity.

Had serious conversations with students of a different race or ethnicity than your own (1=never, 2 =sometimes, $3=$ often, $4=$ very often)

compute divrstudh $=((\text { divrstud }) / 3)^{*} 100$.

Had serious conversations with students who are very different from you in terms of their religious beliefs, political opinions, or personal values (1=never, $2=$ sometimes, $3=$ often, $4=$ very often) 
compute diffstu2h $=(($ diffstu2 $) / 3) * 100$.

To what extent does your institution emphasize each of the following? Encouraging contact among students from different economic, social, and racial or ethnic backgrounds (1=very little, $2=$ some, $3=$ quite a bit, $4=$ very much)

compute envdivrsh $=((\text { envdivrs }) / 3)^{*} 100$.

compute Diversity $=$ mean.3(divrstudh, diffstu2h,envdivrsh).

\#10 Varied Educational Experiences.

Which of the following have you done or do you plan to do before you graduate from your institution? Practicum, internship, field experience, co-op experience, or clinical assignment $(1=$ Have not decided, $2=$ Do not plan to do, $3=$ Plan to do, $4=$ Done $)$

recode intern04 $(4=100)(1,2,3=0)$ into intern04h.

Which of the following have you done or do you plan to do before you graduate from your institution? Community service or volunteer work $(1=$ Have not decided, $2=$ Do not plan to do, 3=Plan to do, 4=Done)

recode volntr04 $(4=100)(1,2,3=0)$ into volntr04h.

Which of the following have you done or do you plan to do before you graduate from your institution? Foreign language coursework ( $1=$ Have not decided, $2=$ Do not plan to do, $3=$ Plan to do, 4=Done)

recode forlng04 $(4=100)(1,2,3=0)$ into forlng04h.

Which of the following have you done or do you plan to do before you graduate from your institution? Study abroad ( $1=$ Have not decided, 2=Do not plan to do, 3=Plan to do, 4=Done)

recode stdabr04 $(4=100)(1,2,3=0)$ into stdabr04h.

Which of the following have you done or do you plan to do before you graduate from your institution? Practicum Independent study or self-designed major (1= Have not decided, $2=$ Do not plan to do, 3=Plan to do, 4=Done)

recode indstd04 $(4=100)(1,2,3=0)$ into indstd04h.

Which of the following have you done or do you plan to do before you graduate from your institution? Culminating senior experience (capstone course, senior project or thesis, 
comprehensive exam, etc.) $(1=$ Have not decided, $2=$ Do not plan to do, $3=$ =Plan to do, $4=$ Done)

recode snrx04 $(4=100)(1,2,3=0)$ into snrx04h.

Which of the following have you done or do you plan to do before you graduate from your institution? Participate in a learning community or some other formal program where groups of students take two or more classes together $(1=$ Have not decided, $2=$ Do not plan to do, $3=$ Plan to do, 4=Done)

recode lrncom04 $(4=100)(1,2,3=0)$ into lrncom04h.

About how many hours do you spend in a typical 7-day week doing each of the following? Participating in co-curricular activities (organizations, campus publications, student government, fraternity or sorority, intercollegiate or intramural sports, etc.) (1=none, $2=1-5,3=6-10$, $4=11-15,5=16-20,6=21-25,7=26-30,8=$ more than 30 hours)

compute cocurr $01 \mathrm{~h}=((\text { cocurr } 01) / 7)^{*} 100$.

To what extent does your institution emphasize each of the following? Attending campus events and activities (special speakers, cultural performances, athletic events, etc.)

(1=very little, $2=$ some, $3=$ quite a bit, $4=$ very much)

compute enveventh $=((\text { envevent }) / 3)^{*} 100$.

compute VariedExper $=$ mean.6(intern04h,volntr04h,forlng04h,stdabr04h,indstd04h,snrx04h,Irncom04h,cocurr01 $h$, enveventh).

\section{\#11 Support for Student Success.}

To what extent does your institution emphasize each of the following? Providing the support you need to help you succeed academically ( $1=$ very little, $2=$ some, $3=$ quite a bit, $4=$ very much)

compute envsuprth $=(($ envsuprt $) / 3) * 100$.

To what extent does your institution emphasize each of the following? Helping you cope with your nonacademic responsibilities (work, family, etc.) (1=very little, $2=$ some, $3=$ quite a bit,4=very much)

compute envnacadh $=(($ envnacad $) / 3) * 100$.

To what extent does your institution emphasize each of the following? Providing the support you need to thrive socially ( $1=$ very little, $2=$ some, $3=$ quite a bit, $4=$ very much) 
compute envsocalh $=((\text { envsocal }) / 3)^{*} 100$.

compute SuppStuSucc=mean.3(envsuprth,envnacadh,envsocalh).

\#12 Interpersonal Environment.

Select the circle that best represents the quality of your relationships with people at your institution. Relationships with other students (1=unfriendly, unsupportive, sense of alienation, $7=$ friendly, supportive, sense of belonging)

compute envstuh $=((\text { envstu }) / 6)^{*} 100$.

Select the circle that best represents the quality of your relationships with people at your institution. Relationships with faculty members ( $1=$ unfriendly, unsupportive, sense of alienation, $7=$ friendly, supportive, sense of belonging)

compute envfach $=((\mathrm{envfac}) / 6) * 100$.

Select the circle that best represents the quality of your relationships with people at your institution. Relationships with administrative personnel and offices ( $1=$ unfriendly, unsupportive, sense of alienation, $7=$ friendly, supportive, sense of belonging)

compute envadmh $=(($ envadm $) / 6) * 100$.

compute IntpEnv=mean.3(envstuh,envfach,envadmh).

Revised on September 26, 2008.

******Gain in General Education (4 items) ${ }^{*}$

compute gnwriteh $=(($ gnwrite $) / 3) * 100$.

compute gnspeakh $=(($ gnspeak $) / 3) * 100$.

compute gngenledh $=((\text { gngenled }) / 3)^{*} 100$.

compute gnanalyh $=((\text { gnanaly }) / 3)^{*} 100$.

***Take the mean of the 4 items when a respondent has at least 2 of the 4 items.

Compute GNGED = mean.2(gnwriteh,gnspeakh,gngenledh,gnanalyh).

Variable Labels GNGED "Gains in General Education".exe. 


\section{APPENDIX D}

Creating NSSE Benchmarks: Retrieved from

http://nsse.iub.edu/ $/$ ?cid $=367$

NSSE 2009 Codebook: Retrieved from

http://nsse.iub.edu/2009_Institutional_Report/pdf/NSSE $\% 202009 \% 20$ Codebook.pdf ******ACADEMIC CHALLENGE - UNADJUSTED (LAC) ( $^{* * * * * *}$.

PUT ALL CHALLENGE ITEMS ON A 0-100 POINT SCALE.

compute reasgnh $=((\text { readasgn }) / 4)^{*} 100$.

compute writmorh $=((\text { writemor }) / 4)^{*} 100$.

compute writmidh $=(($ writemid $) / 4) * 100$.

compute writsmlh $=(($ writesml $) / 4) * 100$.

compute analh $=((\text { analyze }) / 3)^{*} 100$.

compute synthh $=(($ synthesz $) / 3) * 100$.

compute evalh $=(($ evaluate $) / 3) * 100$.

compute applyh=((applying $) / 3) * 100$.

compute workhrdh $=(($ workhard $) / 3) * 100$.

compute acadprh $=(($ acadpr01 $) / 7) * 100$.

compute envschh $=(($ envschol $) / 3) * 100$. exe.

Takes the mean of the 11 items when a respondent has at least 7 of the 11 items. 
compute $\mathrm{AC}=$ mean.7(reasgnh,writmorh,writmidh,writsmlh,analh,synthh,evalh,applyh, workhrdh,acadprh,envschh).exe.

******ACTIVE AND COLLABORATIVE (ACL) $)^{* * * * * *}$.

Put everything on a $0-100$ point scale and average.

compute clquesth $=(($ clquest $) / 3) * 100$.

compute clpreseh $=(($ clpresen $) / 3) * 100$.

compute classgrh $=(($ classgrp $) / 3) * 100$.

compute occgrph $=((\text { occgrp }) / 3)^{*} 100$.

compute tutorh $=((\text { tutor }) / 3)^{*} 100$.

compute commproh $=((\text { commproj }) / 3)^{*} 100$.

compute oocideah $=((\text { oocideas }) / 3)^{*} 100$.exe.

Takes the mean of the items when a respondent has at least 4 of the 7 items.

compute $\mathrm{ACL}=$ mean.4(clquesth,clpreseh,classgrh,occgrph,tutorh,commproh,oocideah).

******STUDENT-FACULTY INTERACTION (SFI)******.

MEAN OF ITEMS PUT ON 0-100 POINT SCALE.

compute facgradh $=(($ facgrade $) / 3) * 100$.

compute facideah $=(($ facideas $) / 3) * 100$.

compute facplanh $=(($ facplans $) / 3) * 100$.

compute facfeedh $=((\text { facfeed }) / 3)^{*} 100$.

compute facothrh $=((\text { facother }) / 3)^{*} 100$.

RECODE resrch04 $(4=100)(1,2,3=0)$ INTO researh.exe.

***Takes the mean of those students who answered at least four of the items.

compute SFI= mean.4(facgradh,facideah,facplanh,facfeedh,facothrh,researh). 


\section{$* * * * * *$ ENRICHING EDUCATIONAL EXPERIENCES (EEE) $)^{* * * * * *}$.}

Put all items on a $0-100$ point scale.

compute diffstuh $=(($ diffstu2 $) / 3) * 100$.

compute divrstuh $=(($ divrstud $) / 3) * 100$.

compute envdivrh $=(($ envdivrs $) / 3) * 100$.

compute cocurrh $=((\text { cocurr } 01) / 7)^{*} 100$.

compute itacadeh $=(($ itacadem $) / 3) * 100$.

****for 2003 and before, recode no and undecided to no (0).

RECODE intern04 volntr04 lrncom04 forlng04 stdabr04 indstd04 snrx04

$(4=100)(1,2,3=0)$ INTO internh volunteh learncoh forlangh studyabh indstudh

seniorxh.exe.

Takes the mean of those students who answered at least 8 of the 12 items.

compute $\mathrm{EEE}=$ mean.8(internh,volunteh,learncoh,forlangh,studyabh,indstudh,seniorxh, diffstuh,divrstuh,envdivrh,cocurrh,itacadeh).

******SUPPORTIVE CAMPUS ENVIRONMENT (SCE)******.

MEAN OF ITEMS SET ALL RESPONSES ON 0-100 POINT.

compute envsoclh $=(($ envsocal $) / 3) * 100$.

compute envsuprh $=(($ envsuprt $) / 3) * 100$.

compute envnacah $=(($ envnacad $) / 3) * 100$.

compute envstuh $=((\text { envstu }) / 6)^{*} 100$.

compute envfach $=(($ envfac $) / 6) * 100$.

compute envadmh $=((\text { envadm }) / 6)^{*} 100$.

Takes the mean of those students who answered at least four of the six items. 
compute $\mathrm{SCE}=$ mean.4(envsoclh,envsuprh,envnacah,envstuh,envfach,envadmh). variable labels AC 'Academic Challenge (unadjusted) - raw, student-level score' ACL 'Active and Collaborative Learning - raw, student-level score' SFI 'Student-Faculty Interaction - raw, student-level score' EEE 'Enriching Educational Experiences - raw, student-level score' SCE 'Supportive Campus Environment - raw, student-level score'. 


\section{APPENDIX E}

\begin{tabular}{|c|c|c|c|}
\hline $\begin{array}{c}\text { Expected Family Contribution } \\
\text { (EFC Categories) }\end{array}$ & Level & $\begin{array}{c}\text { Number of } \\
\text { Students RQ 3, } \\
\text { RQ4, RQ5 }\end{array}$ & $\begin{array}{c}\text { Number of } \\
\text { Students RQ 1, } \\
\text { RQ2, RQ6 }\end{array}$ \\
\hline$\$ 0-\$ 999$ & 1 & 11 & 1 \\
\hline$\$ 1,000-\$ 5,273$ & 2 & 23 & 9 \\
\hline$\$ 5,274-9,999$ & 3 & 27 & 7 \\
\hline$\$ 10,000-\$ 14,999$ & 4 & 21 & 9 \\
\hline$\$ 15,000-\$ 24,999$ & 6 & 21 & 31 \\
\hline$\$ 25,000-\$ 99,000$ & 7 & 56 & 75 \\
\hline No EFC (FAFSA not submitted) & & 182 & 71 \\
\hline TOTAL & & 23 & 7 \\
\hline
\end{tabular}

Note: No EFC category was combined with level six for regression methods. Families not submitting a FAFSA typically are in the highest family income category.

\begin{tabular}{|c|c|c|c|}
\hline Miles from Home (Distance) & Level & $\begin{array}{c}\text { Number of } \\
\text { Students RQ 3, } \\
\text { RQ4, RQ5 }\end{array}$ & $\begin{array}{c}\text { Number of } \\
\text { Students RQ 1, } \\
\text { RQ2, RQ6 }\end{array}$ \\
\hline $0-50$ & 1 & 140 & 55 \\
\hline $51-100$ & 2 & 5 & 4 \\
\hline $101-150$ & 3 & 12 & 3 \\
\hline $151-200$ & 4 & 2 & 9 \\
\hline 201 or greater & 5 & 23 & 75 \\
\hline TOTAL & & 182 & \\
\hline
\end{tabular}




\section{APPENDIX F}

\section{Comparison of Learning Measures for Incoming Freshmen}

\begin{tabular}{lcc}
\cline { 2 - 3 } & $\begin{array}{c}\text { First- } \\
\text { generation }\end{array}$ & $\begin{array}{c}\text { Continuing- } \\
\text { generation }\end{array}$ \\
\hline ACT Composite Score (0-36 point scale) & 24.29 & 25.07 \\
ACT English Score (0-36 point scale) & 24.70 & 25.17 \\
ACT Reading Score $(0-36$ point scale) & 26.05 & 26.69 \\
ACT Science Score $(0-36$ point scale) & 23.99 & 24.71 \\
ACT Math Score $(0-36$ point scale) & 23.22 & 25.01 \\
High School GPA $\left(0-4\right.$ point scale) $^{*}$ & 3.65 & 3.56 \\
\hline
\end{tabular}

Note: ETS MAPP mean scores were adjusted from MANCOVA.

${ }^{*} p<.1{ }^{* *} p<.05 .{ }^{* * *} p<.01$. 


\begin{abstract}
APPENDIX G
The following Pike "scalelets" were significant predictors of student satisfaction in the senior year $(p<.05)$. The NSSE items used for calculation of each significant "scalelet" are listed below.

Higher order thinking skills $(\beta=.14$ ) includes the following items. When considered individually, all of which had positive relationships with NSSE satisfaction composite score except synthesizing ideas:
\end{abstract}

- During the current school year, how much has your coursework emphasized the following mental activities? Analyzing the basic elements of an idea, experience, or theory, such as examining particular case or situation in depth and considering its components ( $1=$ very little, $2=$ some, $3=$ quite a bit, $4=$ very much).

- During the current school year, how much has your coursework emphasized the following mental activities? Applying theories or concepts to practical problems or in new situations ( $1=$ very little, $2=$ some, $3=$ quite a bit, $4=$ very much).

- During the current school year, how much has your coursework emphasized the following mental activities? Making judgments about the value of information, arguments, or methods, such as examining how others gathered and interpreted data and assessing the soundness of their conclusions $(1=$ very little, $2=$ some, $3=$ quite a bit, $4=$ very much).

- During the current school year, how much has your coursework emphasized the following mental activities? Synthesizing and organizing ideas, information, or 
experiences into new, more complex interpretations and relationships (1=very little, $2=$ some, $3=$ quite a bit, $4=$ very much).

Varied education experience (a negative predictor $B e t a=-.18$ ) includes the NSSE individual items below. An explanation regarding the influence of individual items follows in this chapter.

- Which of the following have you done or do you plan to do before you graduate from your institution? Practicum, internship, field experience, co-op experience, or clinical assignment ( $1=$ Have not decided, $2=$ Do not plan to do, $3=$ Plan to do, 4=Done).

- Which of the following have you done or do you plan to do before you graduate from your institution? Community service or volunteer work $(1=$ Have not decided, 2=Do not plan to do, $3=$ =Plan to do, 4=Done).

- Which of the following have you done or do you plan to do before you graduate from your institution? Foreign language coursework ( 1 = Have not decided, $2=$ Do not plan to do, 3=Plan to do, 4=Done).

- Which of the following have you done or do you plan to do before you graduate from your institution? Study abroad ( $1=$ Have not decided, $2=$ Do not plan to do, $3=$ Plan to do, $4=$ Done) .

- Which of the following have you done or do you plan to do before you graduate from your institution? Practicum Independent study or self-designed major $(1=$ Have not decided, 2=Do not plan to do, 3=Plan to do, 4=Done).

- Which of the following have you done or do you plan to do before you graduate from your institution? Culminating senior experience (capstone course, senior 
project or thesis, comprehensive exam, etc. $)(1=$ Have not decided, $2=$ Do not plan to do, $3=$ Plan to do, 4=Done).

- Which of the following have you done or do you plan to do before you graduate from your institution? Participate in a learning community or some other formal program where groups of students take two or more classes together $(1=$ Have not decided, 2=Do not plan to do, 3=Plan to do, 4=Done).

- About how many hours do you spend in a typical 7-day week doing each of the following? Participating in co-curricular activities (organizations, campus publications, student government, fraternity or sorority, intercollegiate or intramural sports, etc. $)(1=$ none, $2=1-5,3=6-10,4=11-15,5=16-20,6=21-25$, $7=26-30,8=$ more than 30 hours).

- To what extent does your institution emphasize each of the following? Attending campus events and activities (special speakers, cultural performances, athletic events, etc.) (1=very little, $2=$ some, $3=$ =quite a bit, $4=$ very much).

Support for student success (Beta $=.17)$ was a positive predictor because of individual NSSE item, support for student academically, which had a significant partial regression coefficient $(p<.05)$. The other items (support for social and nonacademic responsibilities) were not significant when considered individually.

- To what extent does your institution emphasize each of the following? Providing the support you need to help you succeed academically (1=very little, $2=$ some, $3=$ quite a bit, $4=$ very much). 
- To what extent does your institution emphasize each of the following? Helping you cope with your nonacademic responsibilities (work, family, etc.) (1=very little, $2=$ some, $3=$ quite a bit, $4=$ very much).

- To what extent does your institution emphasize each of the following? Providing the support you need to thrive socially ( $1=$ very little, $2=$ some, $3=$ quite a bit, $4=$ very much).

Interpersonal environment (Beta $=.59)$ includes the following items, each of which had a significant partial regression coefficient $(p<.05)$. This Pike "scalelet" is the same as the NSSE quality of campus relationships composite score (other students, faculty members, administrative offices and personnel).

- Select the circle that best represents the quality of your relationships with people at your institution. Relationships with other students (1=unfriendly, unsupportive, sense of alienation, $7=$ friendly, supportive, sense of belonging).

- Select the circle that best represents the quality of your relationships with people at your institution. Relationships with faculty members (1=unfriendly, unsupportive, sense of alienation, $7=$ friendly, supportive, sense of belonging).

- Select the circle that best represents the quality of your relationships with people at your institution. Relationships with administrative personnel and offices ( $1=$ unfriendly, unsupportive, sense of alienation, $7=$ friendly, supportive, sense of belonging). 


\section{CURRICULUM VITAE}

NAME:

ADDRESS:

EDUCATION

\& TRAINING:
David M. Mahan

224 South Hampton Road

Louisville, KY 40223

B.A., Chemistry

Bellarmine University 1990-1993

M.A., Administration and Higher Education University of Louisville 1997-1999

Director, Institutional Research and Effectiveness Bellarmine University 2006-Present

Admission Officer

Bellarmine University 2003-2006

Intern in Department of Student Affairs (210 hours) Bellarmine University 1998-1999

Sales and Marketing Positions

LexisNexis

1996-2003

Teaching Assistant, Department of Chemistry University of Louisville 1996

Sales Representative Arch Communications 1993-1995 
AWARDS:

Association of Institutional Research (AIR) Fellowship for Graduate Studies 2007-2010

LexisNexis Sales Performance Award 2000

Great Lakes Valley Conference (GLVC) Academic All-American 1992 (Bellarmine University Athletic Conference)

Honor Society, St. Xavier High School 1987

PROFESSIONAL SOCIEITIES:

Association of Institutional Research (AIR)

Kentucky Association of Institutional Research (KAIR)

National Association for College Admission Counseling (NACAC)

American Association of Collegiate Registrars and Admission Officers (AACRAO)

College Personnel Association of Kentucky (CPAK a state division of the American College Personnel Association ACPA)

National Association of International Student Advisors (NAFSA)

NATIONAL

MEETING

PRESENTATIONS: Completion of the 2009 National Summer Data Policy Institute (AIR, NCES, NSF)

Presentation at the 2010 College Personnel Association of Kentucky (CPAK), Pioneering Practices, Enhancing Education Presentation Title: Collaboration between Offices of Institutional Research and Student Affairs

2008 Annual KAIR Conference, Presented to the Association of Independent Kentucky Colleges and Universities (AIKCU), Presentation: Building an Institutional Research Office 